Illinois State University

ISU ReD: Research and eData

Theses and Dissertations

6-18-2019

\title{
Let's Be Perfectly Clear About Ambiguity: Exploring Instructor Use Of Strategic Ambiguity To Enhance Student Work And Learning Outcomes
}

Anna M. Wright

Illinois State University, anna.wright13@gmail.com

Follow this and additional works at: https://ir.library.illinoisstate.edu/etd

Part of the Communication Commons, and the Education Commons

\section{Recommended Citation}

Wright, Anna M., "Let's Be Perfectly Clear About Ambiguity: Exploring Instructor Use Of Strategic Ambiguity To Enhance Student Work And Learning Outcomes" (2019). Theses and Dissertations. 1148. https://ir.library.illinoisstate.edu/etd/1148

This Dissertation is brought to you for free and open access by ISU ReD: Research and eData. It has been accepted for inclusion in Theses and Dissertations by an authorized administrator of ISU ReD: Research and eData. For more information, please contact ISUReD@ilstu.edu. 


\title{
LET’S BE PERFECTLY CLEAR ABOUT AMBIGUITY: EXPLORING INSTRUCTOR USE OF STRATEGIC AMBIGUITY TO ENHANCE STUDENT WORK AND LEARNING OUTCOMES
}

\begin{abstract}
ANNA M. WRIGHT
149 Pages

Instructors often desire to be clear in their teaching. However, a new area of research raises the possibility that instructors can use ambiguity strategically in courses and assignments to foster improved learning outcomes for students. This study uses quantitative research methods to explore how student characteristics affect learning outcomes when presented with varying levels of clarity or ambiguity in instructor messaging regarding assignments. Specifically, the study measured student's tolerance for ambiguity, mindset, as well as learning orientation and grade orientation as well as the impact instructor messaging regarding assignments has on student's learner empowerment and affective learning. Findings suggest that instructor messaging does impact student learning. Specifically, ambiguous assignments were more impactful than clear or strategically ambiguous assignments in most cases. Additionally, tolerance for ambiguity and learning orientation did relate to student learning, but mindset and grade orientation did not. Results of this study have implications for how and when instructors provide information regarding classroom assessments.

KEYWORDS: Clarity, Strategic Ambiguity, Tolerance for Ambiguity, Mindset, Implicit Theory, Learning and Grade Orientation, Affective Learning, Assessment, Learner Empowerment
\end{abstract}




\section{LET'S BE PERFECTLY CLEAR ABOUT AMBIGUITY: EXPLORING INSTRUCTOR USE OF STRATEGIC AMBIGUITY TO ENHANCE STUDENT WORK AND LEARNING OUTCOMES}

ANNA M. WRIGHT

A Dissertation Submitted in Partial Fulfillment of the Requirements for the Degree of DOCTOR OF EDUCATION

School of Teaching and Learning ILLINOIS STATE UNIVERSITY 
Copyright 2019 Anna M. Wright 


\section{LET'S BE PERFECTLY CLEAR ABOUT AMBIGUITY: EXPLORING INSTRUCTOR USE OF STRATEGIC AMBIGUITY TO ENHANCE STUDENT WORK AND LEARNING OUTCOMES}

ANNA M. WRIGHT

COMMITTEE MEMBERS:

Kevin R. Meyer, Co-Chair

Jay C. Percell, Co-Chair

Stephen K. Hunt

Robyn Seglem 


\section{ACKNOWLEDGMENTS}

There are many people who deserve thanks for their support on my dissertation. First, I would like to thank my co-chairs, Dr. Kevin R. Meyer and Dr. Jay C. Percell. Kevin's guidance and support has pushed me to become the best scholar I can be. I appreciate his willingness to work with me, even when I did not want to work, and I have always loved his bad humor, including his suggestion that I may not get it to the circus because, "They have a rich history here. I heard they're tough to get into.” Like many other times, he was right. I was not cut out for the circus - finishing my dissertation was more aligned with my expertise. Kevin has mentored me for many years, and I owe him a great amount of gratitude for who I am as an academic today. Thank you, Kevin, for believing in me even when I did not believe in myself and for ensuring I did not give up on myself, too.

Dr. Percell also provided a great amount of guidance and support. He gave thorough and thoughtful line edits, had excellent content knowledge, and was always offering words of encouragement throughout the process. I am grateful for Dr. Percell's grading system, which does not use points, as it served as inspiration for the line of research I chose to pursue. I appreciate his willingness to help me collect data. Dr. Precell was very patient as the first TCH faculty member to work directly with a Communication faculty member and for that I am very grateful.

I also owe a special thanks to my committee members, Dr. Robyn Seglam and Dr. Stephen K. Hunt. Robyn was instrumental in my data collection and graciously allowed me to use her class time to collect data. She provided critical insight into the proposal process, which helped make this a strong project in the end. Steve helped multiple times throughout the process, particularly with data analysis and research design. I am most grateful to Steve as he also served 
as a support system when I was overwhelmed. I am honored to have both of these accomplished scholars serve on my committee.

I want to thank Brian Rohman for serving as an actor in my video, and Dr. Nathan Carpenter for helping me record and edit the videos. I appreciate both of your work. I also want to thank each faculty member and graduate student in the School of Communication and the College of Education for their help in data collection.

I owe a great deal of gratitude to my family for always supporting me, encouraging me, believing in me when I did not believe in myself, and for just loving me, always. To my parents, Judy and Reuel and my siblings, Liz, Chris, and Kayla, I am truly humbled by your unwavering support through this process and I can never fully repay you. I know your pride in me will help me strive to be the best, always. To my nephew, Reuel, and my niece, Henley, thank you for inspiring me to work hard and conduct research to ensure teaching and learning is conducted in a manner fit for students as special as you. I am who I am today because of my family.

I offer my overwhelming gratitude to my friends including my LTT crew - Alex, Lauren, and Lindsay as well as Brian Rohman, and Justin Rudnick for your support along the way. Thank you for providing sources and feedback when needed and encouraging me through this seemingly endless process. Your love and support meant the world to me.

I would like to give a special thanks my dear friend, Stevie Munz, who provided me an endless supply of long-distance support. Since our master's program, she has always been a great colleague and an even better friend. I would not be the academic I am today without her continued encouragement through Facebook chat and video chat. From the beginning of my doctoral program until the very end, she has provided the strongest words of encouragement. Thank you, Stevie, for always answering my message and never letting me quit. 
Thank you to my family at ISU - my fellow NTTs - Bryan, Lee Anne, Jen, and Lisa. These individuals have been my biggest cheerleaders, always stopping in my office to tell me to keep going. During tough times, we have always known we had each other's backs, and you all did not disappoint during the dissertation process. Thanks for the Cheez-Its, the cards, the Kleenexes, the encouraging text messages, and the laughs. I will miss each of you more than you will ever know, and I look forward to watching all of you grow in your careers.

Finally, I will forever be grateful to everyone in the School of Communication at ISU. I have spent the last 12 years in the $\mathrm{SoC}$ - as a student and faculty member - and now that I have earned all of the degrees I can, I have to go. I will be forever grateful to all of the people I worked with and the students I taught. It has been my privilege to have worked with such wonderful people.

As Abraham Lincoln said when he left Springfield for Washington D.C.: "My friends, no one, not in my situation, can appreciate my feeling of sadness at this parting. To this place, and the kindness of these people, I owe everything."

A. M. W. 


\section{CONTENTS}

ACKNOWLEDGMENTS

Page

CONTENTS

iv

TABLES

viii

CHAPTER I: INTRODUCTION

Statement of Problem

Purpose

Definition of Terms

Clear Assignment

Ambiguous Assignment

Strategically Ambiguous Assignment

Tolerance for Ambiguity

Mindset

Learning Orientation and Grade Orientation

Learner Empowerment

Affective Learning

Research Questions and Hypotheses

Description of Study

Significance

Chapter Summary

Clarity 
$\begin{array}{lr}\text { Strategic Ambiguity } & 18\end{array}$

$\begin{array}{ll}\text { Impact of Strategic Ambiguity } & 20\end{array}$

$\begin{array}{lr}\text { Assessment } & 24\end{array}$

$\begin{array}{ll}\text { Strategic Ambiguity in Assessment } & 27\end{array}$

$\begin{array}{ll}\text { Tolerance for Ambiguity } & 30\end{array}$

$\begin{array}{ll}\text { Mindset } & 34\end{array}$

$\begin{array}{ll}\text { Learning Orientation and Grade Orientation } & 39\end{array}$

$\begin{array}{lr}\text { Learner Empowerment } & 42\end{array}$

$\begin{array}{ll}\text { Motivation } & 45\end{array}$

$\begin{array}{lr}\text { Affective Learning } & 47\end{array}$

$\begin{array}{lr}\text { Instructor Messaging } & 50\end{array}$

Chapter Summary $\quad 52$

CHAPTER III: METHODS

Hypotheses and Research Questions $\quad 53$

$\begin{array}{ll}\text { Procedures } & 56\end{array}$

$\begin{array}{lr}\text { Pilot Study } & 58\end{array}$

$\begin{array}{lr}\text { Primary Study Participants } & 59\end{array}$

$\begin{array}{ll}\text { Measures } & 60\end{array}$

$\begin{array}{ll}\text { Tolerance for Ambiguity } & 60\end{array}$

$\begin{array}{ll}\text { Learning Orientation and Orientation Grade Orientation } & 61\end{array}$

$\begin{array}{ll}\text { Mindset } & 62\end{array}$

$\begin{array}{ll}\text { Instructor Messaging Manipulation Check } & 62\end{array}$

$\begin{array}{ll}\text { Learner Empowerment } & 63\end{array}$ 
$\begin{array}{ll}\text { Affective Learning } & 64\end{array}$

$\begin{array}{ll}\text { Data Analysis } & 65\end{array}$

$\begin{array}{ll}\text { Chapter Summary } & 66\end{array}$

CHAPTER IV: RESULTS

$\begin{array}{ll}\text { Factor Analysis } & 67\end{array}$

$\begin{array}{ll}\text { Learning Orientation and Grade Orientation } & 68\end{array}$

$\begin{array}{ll}\text { Mindset } & 70\end{array}$

Tolerance for Ambiguity

Instructor Messaging Manipulation Check $\quad 72$

$\begin{array}{ll}\text { Learner Empowerment } & 75\end{array}$

$\begin{array}{ll}\text { Affective Learning } & 76\end{array}$

$\begin{array}{ll}\text { Scale Development } & 76\end{array}$

$\begin{array}{ll}\text { Instructor Messaging Manipulation Check } & 78\end{array}$

$\begin{array}{ll}\text { Correlations among Variables } & 80\end{array}$

$\begin{array}{ll}\text { Research Questions } & 81\end{array}$

$\begin{array}{ll}\text { Hypotheses } & 84\end{array}$

$\begin{array}{lr}\text { Chapter Summary } & 90\end{array}$

CHAPTER V: DISCUSSION 91

$\begin{array}{ll}\text { Summary of Findings } & 92\end{array}$

$\begin{array}{ll}\text { Scale Development } & 92\end{array}$

Instructor Messaging Manipulation Check 93

$\begin{array}{ll}\text { Correlation among Variables } & 94\end{array}$

Research Question One $\quad 95$ 


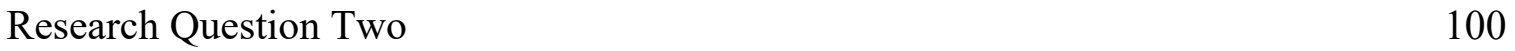

$\begin{array}{ll}\text { Hypotheses } & 104\end{array}$

$\begin{array}{ll}\text { Theoretical Implications } & 108\end{array}$

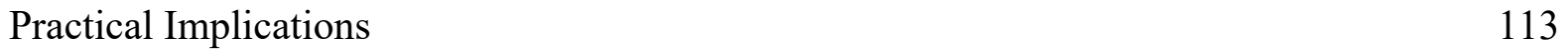

$\begin{array}{ll}\text { Messaging Matters } & 113\end{array}$

Ambiguity Verses Strategic Ambiguity 115

$\begin{array}{ll}\text { Student Background } & 117\end{array}$

$\begin{array}{ll}\text { Student Characteristics } & 120\end{array}$

$\begin{array}{ll}\text { Scaffolding } & 121\end{array}$

Multivariate Classroom Environment $\quad 122$

$\begin{array}{ll}\text { Overall Practical Implications } & 123\end{array}$

$\begin{array}{ll}\text { Limitations } & 124\end{array}$

$\begin{array}{ll}\text { Suggestions for Future Research } & 126\end{array}$

$\begin{array}{ll}\text { Conclusion } & 128\end{array}$

$\begin{array}{ll}\text { REFERENCES } & 130\end{array}$

APPENDIX A: SURVEY CONDITIONS 143

$\begin{array}{ll}\text { APPENDIX B: SURVEY INSTRUMENT } & 146\end{array}$ 


\section{TABLES}

Table

Page

1. Factor Loadings for Learning Orientation Scale

2. Factor Loadings for Grade Orientation Scale

3. Factor Loadings for Mindset Scale

4. Factor Loadings for Tolerance for Ambiguity Scale

5. Factor Loadings for Instructor Messaging Manipulation Check Scale

6. Factor Loadings for Learner Empowerment Scale

7. Factor Loadings for Affective Learning Scale

8. Summary of Correlations and Descriptive Statistics for All Scales

9. Observed Descriptive Statistics for ANOVA Dependent Variables

10. Observed Descriptive Statistics for Tolerance for Ambiguity MANOCVA 


\section{CHAPTER I: INTRODUCTION}

Businesses and educational scholars have recognized the importance of having employees who can respond to the constantly changing landscape of the workplace (Banning, 2003; Herman, Stevens, Bird, Mendenhall, \& Oddou, 2010; Rippin, Booth, Bowie, \& Jordan, 2002). Anecdotally, educators understand the importance of students being able to think for themselves and problem solve in a myriad of ways. Unfortunately, the United States education system and society at large seem to be preparing students for the opposite. Rather than helping students learn to adapt to uncertain expectations, educators are frequently helping students find a single correct answer. Fried (2005) explained that educators are teaching students to play "the Game of School” (p. ix). Rather than determining how to gain knowledge and skills, students are learning how to do the least amount of work possible while still receiving the grade they desire. Consequently, it is reasonable to argue that schoolwork has become the means to an end rather than a process in which students learn for the sake of learning.

I, too, have fallen victim to this type of thinking. Recently, I took a statistics class online that was very difficult for me. Due to the nature of my research, I went into the class intending to put in the time and effort to learn the material because I was capable, and it would help me with future research. During the second week of class, I fell behind. The material was challenging for me and I found myself "giving up." My narrative switched form, "this is going to be difficult, but I can do it," to "I just have to get a C." I still put in a great amount of time and effort; but rather than trying to learn for the sake of learning, I was just trying to pass the course so I could continue my doctoral studies.

This attitude was reflected in my interactions with my instructor, as well. After taking quizzes, I would go to his office to ask questions. In the beginning, I was genuinely trying to 
grasp the material related to the questions I missed and determine how I could improve moving forward. As the class became more difficult for me and there was a greater demand on my time, learning the material well took a back seat for me. After a couple of visits with my instructor, I began going to him to establish face-time given the online instruction, correct my answers, and demonstrate to him that I was putting in time and effort. Eventually, the class became a "game" for me. I would go to the instructor and show him my notes, haphazardly attempt to demonstrate what I knew, and he would give me points back on the quiz because it appeared I was truly attempting to grasp the material. He told me he could tell that I was putting in a lot of effort for the class; and, in many regards, I was. The problem, however, was that it was unlikely I was learning to the best of my ability. Instead, I was simply meeting the requirements to receive the grade. This experience highlighted how easy it is to learn to "play the game" of school and fall into a pattern of going through required motions without regard for what is being learned. From my experiences, it seems that the classroom can function as a means to an end rather than a productive learning space.

My experience and sentiment are mirrored by Gibbs and Simpson (2005), when they suggested that "students can tackle assignments that are intended as learning activities so as to maximize the marks they obtain rather than maximizing the learning achieved from engaging with the assessment" (p. 16). I was intrigued by the idea that many students may have similar experiences that lead to a focus on the grade or outcome rather than the process of learning.

\section{Statement of Problem}

When students are able to complete classroom assessments without taking an active role in the process of learning, it is easy to see how schooling can become a "game." Although classroom assessments are typically seen as the end result for demonstrating proficiency on a 
skill or concept, it is possible that they can be used to change the scope of education to focus on the process of learning and the ability to be adaptive, as required in the workplace. Responding to an ever-changing workplace environment is desired by employers (Banning, 2003; Herman et al., 2010; Rippin et al., 2002); therefore, it could be said that employers seek employees who can respond appropriately to ambiguous situations; thus, to prepare students for the workplace, ambiguity should be present in education. While instructors are often aware of students' desires for them to be clear in their teaching and assignment instructions, less attention is paid to the concept of ambiguity as a means for strategically creating different learning outcomes. We are constantly surrounded by ambiguity, or "a condition where there is insufficient information for the particular situation" (Sweeney \& Owen, 2002, p. 1). Budner (1962) asserted that ambiguity occurs in three situations, including a lack of familiar clues regarding what to do, a complex situation that lacks cues altogether, and contradictory situations where context cues suggest different ideas. The ability to respond appropriately to uncertain conditions is not often seen as a direct outcome of education; however, classroom assessment is one means through which instructors can introduce ambiguity to enhance student's ability to respond to the uncertainty they will encounter later in life while also engaging them with and assessing them on course material.

Consider the role of classroom assessment in education. When given a classroom assessment, students are commonly told exactly how to do what is expected of them. They are given rubrics, clear guidelines, step-by-step instructions, and a gamut of other tools that lay out precisely what the teacher expects. Wootton (2002) argued that our educational landscape does not promote an appreciation of learning and instead promotes only learning outcomes because when educators stress the final outcome, or one correct answer, the process of learning is 
devalued. More recently, Ingman and Moroye (2019) argued that in K-12 education we focus too much on instructional objectives and not enough on the student experience, which is what allows students to relate course content to their lived experiences and apply it to their future. Recently, higher education has taken an interest in student-centered learning as a means to engage students in meeting course goals (Wright, 2011); however, many forms of educational assessment do not translate into the creation of shared meaning. There is still a right answer or an expected outcome on final assessments. In fact, Rippin et al. (2002) conducted a qualitative study exploring the use of case studies to enhance uncertainty and ambiguity in business education. They found that college students were not used to being asked for their opinions and instead were accustomed to being given notes they used to pass exams. As such, classroom assessments that employed ambiguity were uncomfortable experiences for students because they were unfamiliar with this type of assessment. Nonetheless, ambiguity is something that students will face in their future careers, despite being uncomfortable and unfamiliar with it. Therefore, it is necessary to explore how our education system came to value such rigid learning outcomes.

In 1983, the United States government released A Nation at Risk, a report which blasted the perceived failing American education system. This report received significant attention from the national media and politicians. The document argued for higher standards for students and more accountability for teachers. Since the release of $A$ Nation at Risk, elementary and secondary educators have been bombarded with standardized education reforms that promote high stakes and standardized tests (Mehta, 2013). This has manifested itself through mandates such as No Child Left Behind and, more recently, Race to the Top. Problematically, this level of accountability and assessment has also been introduced in higher education. Eaton (2010) 
suggested that the Higher Education Act of 2003 brought the same level of accountability used in secondary schools into higher education.

This degree of emphasis on accountability and high stakes assessment has created students who focus primarily on the outcome or grade. Further, the focus on assessment outcomes has hindered student creativity (Beghetto, 2005). Kohn (1993), author and lecturer on education, has made compelling arguments for why educators should get rid of grades entirely as they are an extrinsic reward that damage motivation for learning. Specifically, Kohn argued that grades create a myriad of problems, including encouraging students to focus more on how what they are doing ensures they receive the grade they want from the teacher and focusing less on learning something new from the task that they are completing. Understandably, just removing grades and reward from education is a daunting task and one that is not necessarily desirable. Instead, the present study seeks to explore the use of strategic ambiguity in assessment through a less prescriptive grading criteria and more ambiguous assignment guidelines, as one way to enhance student learning outcomes and to determine if strategic ambiguity can refocus students' attention on the learning process less obtrusively within the confines of the current educational system.

\section{Purpose}

Standardization in education has created an environment that heavily relies on the reproduction of knowledge in a straightforward manner (Wootton, 2002). Ambiguity pervades our lives in a variety of ways (Sweeney \& Owen, 2002) and should exist in the educational landscape. As such, the purpose of this study is to explore how college instructors can communicate about strategically ambiguous assignments to students in a manner that allows them to be more accepting of that ambiguity, especially considering the variety of characteristics 
students bring with them to the classroom. Specifically, since students seem reticent to accept the application of ambiguity (Rippin et al., 2002), this study seeks to understand whether the way in which a college instructor communicates the purpose of ambiguous assignments can impact student learning outcomes such as learner empowerment and affective learning. Further, the study seeks to understand how college student characteristics such as tolerance for ambiguity (TFA), mindset, and learning orientation and grade orientation might impact a student's reaction to an instructor's use of strategic ambiguity.

\section{Definition of Terms}

This research project employs a variety of terms that are defined differently in various disciplines and contexts. To ensure there is a shared understanding of key terms and variables in the study, the following definitions are provided.

\section{Clear Assignment}

In this study, a clear assignment is an assignment that is deliberate in outlining exactly what a student should do, both in the written directions and in the verbal directions given by the instructor. The clear assignment will include a paragraph explaining the assignment in detail with step-by-step instructions for how to complete it. The instructor message, delivered via video, will verbally communicate these expectations to students, providing specific examples for the steps.

\section{Ambiguous Assignment}

In this study, an ambiguous assignment is one that is intentionally vague in hopes of fostering different student learning outcomes. The ambiguous assignment will include a paragraph explaining the assignment in detail to students. The instructor message will verbally communicate the details in the paragraph to students. This is considered an ineffective use of strategic ambiguity. 


\section{Strategically Ambiguous Assignment}

In this study, a strategically ambiguous assignment is one that is intentionally vague in hopes of fostering different student learning outcomes that also includes a rationale for why the instructor chose to be ambiguous. The strategically ambiguous assignment will include a paragraph explaining the assignment in detail to the students. The instructor message will verbally communicate that the use of ambiguity in this assignment is to allow for student autonomy. The instructor will explain benefits of working through ambiguity and point out that it is relevant to students' futures as students and in the workplace.

\section{Tolerance for Ambiguity}

TFA is a personality variable that Budner (1962) defined as an individual's understanding of ambiguous situations as either threatening or undesirable. An ambiguous situation lacks specific cues, which make it difficult for a person to process (Budner, 1962). A low TFA indicates an individual will view ambiguous situations as threatening, whereas a high TFA indicates an individual is more comfortable with ambiguous situations. Within this research project, TFA will also refer to students' general attitudes toward ambiguous situations and contexts; specifically, their comfort level related to uncertain or new circumstances.

\section{Mindset}

Mindsets are born out of implicit theory and refer to dispositions a person possesses regarding whether personal attributes are static or malleable (Dweck, Chiu, \& Hong, 1995). A person has a mindset for different personal attributes; however, within this research study, mindset is concerned with an individual's view of their intelligence. Specifically, someone with a fixed mindset, or an entity theorist, thinks that intelligence cannot be changed. Someone with a growth mindset, or an incremental theorist, believes that intelligence can be fostered through 
learning experiences (Dweck, 2000). Mindset in this study is defined as a person's belief that intelligence is static (fixed mindset) or malleable (growth mindset).

\section{Learning Orientation and Grade Orientation}

Learning orientation and grade orientation refer to the extent to which students view education as learning verses the extent to which they focus on grades as the outcome to learning (Pollio \& Beck, 2000). Grade-oriented students are concerned with the evaluation of their work; whereas, learning-oriented students are concerned with the experience and knowledge gained when completing their work. Learning orientation and grade orientation refer to whether students' personalities are more oriented toward learning or toward the final grade.

\section{Learner Empowerment}

Learner empowerment refers to a student who is motivated to complete tasks, finds them meaningful, and is confident in their ability to complete the task (Houser \& Frymier, 2009). In this study, learner empowerment refers to the degree to which a student finds a task impactful, the extent to which they find the assignment meaningful, and their competence completing the assignment. Impact is the extent to which a person thinks the task has implications on a larger level (Thomas \& Velthouse, 1990). Meaningful work refers to work that students think will be beneficial to them presently or in the future (Rubin, 2011). Competence refers to whether or not a student can complete the task at hand (Thomas \& Velthouse, 1990).

\section{Affective Learning}

The affective domain of intelligence is concerned with emotions associated with an idea (Barkley, 2010). Affective learning is defined as, "an increasing internalization of positive attitudes toward the content or subject matter" (Kearney, 1994, p. 81) and it impacts a student's ability to complete a task (McCroskey, Richmond, \& McCroskey, 2006). The affective domain 
operates on a continuum that has five categories that work through identifying and valuing stimuli (Krathwohl, Bloom, \& Masia, 1964). As such, affective learning is defined as the positive attitude's students have regarding learning and learning tasks.

\section{Research Questions and Hypotheses}

This study seeks to understand how clarity and strategic ambiguity in assessment impacts learning outcomes. Additionally, the study explores which student characteristics impact a student's reaction to these varying types of assignments. This will allow instructors to better understand what level of clarity to employ in assigning classroom assessments and how varying types of students may respond. This serves as a first step to understanding how, or if, we can employ strategic ambiguity in the classroom to improve student learning. Accordingly, the following research questions are asked:

$\mathrm{RQ}_{1}$ : Do the dimensions of student learner empowerment differ when faced with instructors' use of clear assignments, ambiguous assignments, or strategically ambiguous assignments?

$\mathrm{RQ}_{2}$ : Does student affective learning differ when faced with instructors' use of clear assignments, ambiguous assignments, or strategically ambiguous assignments?

Further, this study advances the following hypothesis:

$\mathrm{H}_{1}$ : TFA is related to the combination of affective learning and learner empowerment $\left(\mathrm{H}_{1 \mathrm{a}}\right)$, and while controlling for TFA, instructor messaging will predict student affective learning $\left(\mathrm{H}_{1 \mathrm{~b}}\right)$ and learner empowerment $\left(\mathrm{H}_{1 \mathrm{c}}\right)$ for that assignment.

$\mathrm{H}_{2}$ : Mindset is related to the combination of affective learning and learner empowerment $\left(\mathrm{H}_{2 \mathrm{a}}\right)$, and, while controlling for student mindset, instructor messaging will predict student affective learning $\left(\mathrm{H}_{2 b}\right)$ and learner empowerment $\left(\mathrm{H}_{2 \mathrm{c}}\right)$ for that assignment. 
$\mathrm{H}_{3}$ : Learning orientation and grade orientation are related to the combination of affective learning and learner empowerment $\left(\mathrm{H}_{3 \mathrm{a}}\right)$, and while controlling for student learning orientation and grade orientation, instructor messaging will predict student affective learning $\left(\mathrm{H}_{3 \mathrm{~b}}\right)$ and learning empowerment $\left(\mathrm{H}_{3 \mathrm{c}}\right)$ for that assignment.

\section{Description of Study}

This study employed a quasi-experimental design in which students responded to a series of items asking them about their characteristics and, then responded to an assignment that they read about and watched a video of an instructor assigning it. Initially, all participants responded to the same student characteristic scales, which measured their TFA, mindset, along with learning orientation and grade orientation. The TFA and mindset variables were measured using existing scales, whereas the learning orientation and grade orientation variables were measured using a scale created for the purposes of this study. Then, participants were randomly assigned to one of three experimental conditions: clear assignment and message, ambiguous assignment and message, and strategically ambiguous assignment and message. The three conditions tested the varying level of detail provided in both the written and verbal directions of the assignment. Each condition included a classroom assignment presented in text form and a video recording of an instructor message regarding that assignment. The clear condition included a paragraph explaining the assignment and step-by-step instructions for completing the assignment. The teacher verbally communicated all of the expectations to students. The ambiguous condition assignment included the same paragraph explaining the assignment, but not step-by-step instructions. The instructor gave a brief message that simply presented students with the assignment, without providing any rationale. Finally, the strategically ambiguous condition included the same paragraph description of the assignment, much like the ambiguous condition. 
Conversely, the instructor message intentionally pointed out that the instructor is being ambiguous to purposefully allow for student autonomy. Furthermore, the instructor pointed out the benefits of working through ambiguity as it is relevant in life and the workplace. After viewing the video and reading the assignment, participants were asked to recall the assignment as they completed remaining survey items concerning their affective learning and learner empowerment regarding that assignment. The affective learning scale was written for the purposes of this study, whereas the learner empowerment scale was a modified version of an existing scale.

\section{Significance}

A focus on accountability and assessment in education has led to the implementation of assessments that ask students to find one clear, correct answer. When students focus on one correct answer, they do not critically evaluate other options and their thinking suffers (Torrance, 1970). Additionally, when focusing on one correct answer they do not learn to enjoy the process of learning (Wootton, 2002). In response, this research project introduces strategic ambiguity in classroom assessment to determine if it helps college students learn differently given varying levels of instructor messaging regarding the ambiguous assignment. Past research indicates that students who report their instructors use strategic ambiguity in a variety of classroom situations scored higher on self-reports of student motivation, learner empowerment, and learning indicators (Klyukovski \& Medlock-Klyukovski, 2016). However, research has not explored if strategic ambiguity in classroom assessment produces similar outcomes. Further, despite the benefits of strategic ambiguity, students' dispositions affect their reaction to the implementation of the construct in assessment. This study will help instructional communication researchers begin to resolve the question of how strategic ambiguity aligns with clarity. Clarity has served as 
the norm in instructional communication literature; however, if educators are attempting to produce independent learners, they may not have to be so clear to highlight exactly what students should do and how they should do it. Instead, assessment should ask students to employ flexibility and innovation to foster independent thinking. Research on the use of strategic ambiguity in assessment will help instructors determine if clear assignment guidelines are always the most beneficial to student learning outcomes or if there is a place for strategic ambiguity in assessment.

Similarly, there is a great deal of research, especially in instructional communication, that suggests how teacher characteristics impact the learning environment. On the other hand, there is far less research that suggests how student characteristics affect the learning environment. Arguably, teacher behaviors are only part of the classroom dynamic. This research study will illustrate how student dispositions influence what happens in the classroom and, as such, will allow future research to explore what instructors can do to influence student characteristics to ultimately create a more positive learning environment. This will allow educators to better understand the varying needs of students in their classrooms.

It seems that some educators are growing weary of cookie cutter responses to classroom assessments. In instances where accountability is ever-present and at various levels where this occurs, educators, students, and the education system as a whole may be trapped in a cycle of accountability that appears to have lost sight of students' ability to take initiative for their learning and problem solve on their own. For example, Beghetto (2005) asserted that standardized assessments in the K-12 system hurt student creativity. Similarly, Gibbs and Simpson (2005) suggested that a focus on assessment allows students to take tasks intended for learning and use them as a means to simply enhance their grade. Accordingly, a focus on 
assessment may come at the expense of student learning in some contexts. This study seeks to determine how the aforementioned educators can get back to a style of learning that promotes problem solving and creativity, as well as determine how to communicate the benefits of this type of assignment to students, especially given the norm of clarity. The results seek to provide insight into how our educators can produce student work that is inspiring and outstanding rather than simply satisfactory. This research is a first step in reclaiming assessment practices in an educational landscape dominated by standardized assessments.

\section{Chapter Summary}

Students are working their way through our educational system without the ability to think outside of clearly defined conditions (Beghetto, 2005; Torrance, 1970). Our education system prepares students to complete a task and receive a reward, typically a grade (Gibbs \& Simpson, 2005; Kohn, 1993). As such, this study explores how strategic ambiguity can be used in classroom assessments to bolster students' learner empowerment and affective learning. Furthermore, student characteristics of TFA, mindset, learning orientation, and grade orientation may influence their reaction to strategic ambiguity, and this study seeks to determine how. The next chapter more thoroughly examines literature related to this topic. 


\section{CHAPTER II: REVIEW OF LITERATURE}

Educators are faced with the daunting task of engaging and assessing an array of learners. In doing so, they face many decisions regarding how they should enact various lessons and classroom assessments. In a given classroom assignment teachers are trying to determine what a student knows about a course objective, and teachers often face a dilemma regarding how many details of the assignment they should clearly outline for students. Research on instructional clarity is plentiful in communication research. Clarity is defined as, "the perception that various low- and intermediate-inference behaviors, enacted by a teacher, assist students in selecting, understanding, and remembering the structure and details of information" (Titsworth \& Mazer, 2016, p. 112). The way instructional communication defines teacher clarity implies that the goal of teaching, when clarity is used, is for students to take information that is presented to them and understand and remember that information. While memorization is not a "wrong" goal of teaching, it leaves out additional types of learning where students are responsible for constructing meaning and learning on their own, which could be a goal of strategic ambiguity. Klyukovski and Medlock-Klyukovski (2016) found a positive relationship between clarity and strategic ambiguity. As such, strategic ambiguity stands as a similar, yet distinct construct from clarity. Accordingly, clarity research will be reviewed as a means of contextualizing its relationship with strategic ambiguity. Further, assessment research will be reviewed to contextualize the use of strategic ambiguity in classroom assessment in this study. Research on the variables measured, TFA, mindsets, learning orientation, grade orientation, learner empowerment, and affective learning will be reviewed. Additionally, since instructor messaging is the means through which students understand classroom endeavors, it will be reviewed in this chapter and manipulated as a variable in this study. 
Strategic ambiguity in education is a relatively new construct and has been researched in various disciplines. The fields of education, communication, psychology, and business education often research similar constructs; however, they operate in silos and the research often lives only within distinct disciplines. Unfortunately, this leads to reproduction of research in different disciplines, creating an incomplete picture of research on the topic. As such, research in aforementioned disciplines will be explored. This literature review identifies the various disciplines each study is taken from and is organized thematically.

\section{Clarity}

Teacher clarity has been researched in a number of ways and has shown to have several positive benefits. Recall that clarity includes teacher behaviors that help students select, understand, and remember information (Titsworth \& Mazer, 2016). There are two overarching theoretical foundations of clarity. The first is an information-processing theory where clarity is viewed linearly as teachers sharing information with students and students processing that information. The second is adaptive instruction, which views clarity as a communication behavior with teachers adapting their messages to varying contexts and students and teachers negotiating meaning together (Titsworth \& Mazer, 2010; Titsworth \& Mazer; 2016; Titsworth, Mazer, Goodboy, Bolkan, \& Myers, 2015). Teacher clarity was first researched in education as high inference behaviors through student perception; however, later studies in education began exploring the construct through low inference behaviors, or directly observable teacher behaviors (Titsworth et al., 2015). In education and educational psychology journals, Land (1979) identified five low inference behaviors that constituted teacher clarity including behaviors such as vagueness of terms and redundant words. Further education studies indicated that the low inference behaviors influence student learning (Land \& Smith, 1979a; Land \& Smith, 1979b). In 
communication, the clarity construct has been extended to include a variety of different variables. Clarity has been shown to reduce student anxiety when processing teacher messages (Chesebro, 2003; Chesebro \& McCroskey, 1999; Chesebro \& McCroskey, 2001) and increase student motivation to learn (Bolkan, Goodboy, \& Kelsey, 2016; Myers, Goodboy, and Members of COMM 600,2014), and has been explored as a variable linked with teacher immediacy to impact student learning (Chesebro, 2003; Chesebro \& McCroskey, 2001; Comadena, Hunt, \& Simonds, 2007; Mottet et al., 2008). The following literature review will focus mostly on the communication literature of clarity research, which provides a rich understanding of that work.

As a result of the differing theoretical foundations, there has been a great deal of clarity research focusing on the definition of clarity. Titsworth and Mazer (2010) asserted that much of the clarity research has focused on defining exactly what clarity is and has ranged from clarity as an instructor behavior to clarity as a student perception. As such, the authors asserted that:

Instructional clarity has natural, intuitive appeal for researchers, instructors, and students. From the perspective of researchers, clarity provides a key variable in the link between teaching and learning; for instructors, clarity is the tool, or process, that helps them guide students to deeper levels of learning; and for students, clarity is likely the difference between confident understanding and sheer confusion. (Titsworth \& Mazer, 2010, p. 254) Despite differences in the conceptualization of clarity, it has been promoted as the standard in education and instructors often feel they need to be clear to be effective.

Due to the ironically unclear definition and operationalization of teacher clarity, Titsworth et al. (2015) conducted two meta-analyses to determine the effect that teacher clarity has on student learning. Although the two meta-analyses used different methods, they both yielded similar conclusions. The first meta-analysis found that teacher clarity does have a 
positive effect on student learning; however, there are moderating variables that the authors speculate could include methodological choices, different understandings of teacher clarity, and discipline of study. Further, findings suggested that teacher clarity had a larger impact on affective learning than cognitive learning (Titsworth et al., 2015). Similarly, the second metaanalyses found that clarity does have a positive impact on learning and more of an impact on affective learning than cognitive learning. Results also indicated that for affective learning, moderating variables included the differences between survey reports and experimental design, but not between sample type, including grade level studied (Titsworth et al., 2015). For cognitive learning, results indicated that although there was variance in effect size across studies, the moderating variables tested included type of cognitive learning, perceived and self-reporting verses achievement tests, study design, and sample type, and did not reveal a significant difference (Titsworth et al., 2015). Although both studies found a positive impact on learning as a result of teacher clarity, the moderating variables lead the authors to conclude that, "something in the way clarity behaviors are practiced, experienced, or studied likely influences the relationship between clarity and learning outcomes" (p. 409). As such, the authors recommend that clarity should be studied as a multidimensional construct, viewed as a process, and understood as a construct which supports a positive bias. Due to this, they argued that "sometimes strategic ambiguity in the classroom may be warranted" (p. 411). The unclear nature of clarity supports an argument to various types of clarity which may include strategic ambiguity.

For example, some instructors may wish to be strategically less clear to have students think in a different manner. Klyukovski and Medlock-Klyukovski (2016) found a positive relationship between clarity and strategic ambiguity. As such, strategic ambiguity stands as a 
similar, yet distinct construct from clarity. Although instructor clarity is well researched and shown to promote positive learning outcomes for students, the notion that an intentional use of less clarity, or strategic ambiguity, to enhance positive learning outcomes has not been explored and should be researched.

\section{Strategic Ambiguity}

If the opposite of clarity is being unclear, strategic ambiguity should fall somewhere in between the two constructs. Ambiguity is central to our everyday lives since we are often exposed to and must deal with ambiguous situations (Matin, Nejad, Colmar, \& Liem, 2013; Sweeney \& Owen, 2002) and, therefore, should be included in education. There are a variety of different definitions of strategic ambiguity. Sweeney and Owen (2002) defined ambiguity as a "condition where there is insufficient information for that particular situation" (p. 1). Gabella (1995) asserted that in the classroom, ambiguity is created through situations of doubt where there is not a clear answer. Budner (1962) defined it as follows:

A completely new situation in which there are no familiar cues, a complex situation in which there are a great number of cues to be taken into account, and a contradictory situation in which different elements of cues suggest different structure. (p. 30)

Klyukovski and Medlock-Klyukovski (2016) suggested that strategic ambiguity occurs when an instructor presents concepts in a manner that has multiple interpretations in an attempt to motivate students and help them learn. The present study defines strategic ambiguity as learning opportunities where students are presented with an unfamiliar task, there are many interpretations of the correct answer, and/or there are a variety of methods for completing a task. Strategic ambiguity has been studied in varying capacities in educational psychology, 
communication, higher education technology and business education. As such, strategic ambiguity research from a variety of disciplines will be reviewed here.

The idea of strategic ambiguity in communication was introduced in organizational communication research. Eisenberg (1984) sought to understand how individuals in organizations use strategic ambiguity to meet their goals. In doing so, he was specific about delineating strategic ambiguity and clarity. He wrote that clarity, "is a continuum which reflects the degree to which a source has narrowed the possible interpretations of a message and succeeded in achieving a correspondence between his or her intentions and the interpretation of the receiver" (p. 229-230). Of importance in this definition is the identification of the sender's intention. While clarity is useful, and, at times, necessary, strategic ambiguity can be used intentionally to vary outcomes.

Despite the presence of ambiguity in many situations, it is often unwanted in schools, which are faced with demands for assessment and efficiency (Gabella, 1995). Nevertheless, ambiguity is still a healthy component of a classroom (Visser \& Visser, 2004). Research on attitudes toward ambiguity in the classroom has yielded mixed results. For example, Brunson and Vogt (1996) conducted a case study in a communication course on group dynamics and leadership. The authors developed a class that sought to empower students by building trust, collaborative thinking, and TFA in the classroom. They sought to employ a fair amount of ambiguity in the classroom to position themselves as less authoritarian than most classroom environments. Throughout the class, students were empowered to make decisions regarding course content and procedures and instructors were clear about their purposes for doing so. The authors concluded that students find comfort in being told exactly what to do (Brunson \& Vogt, 
1996). Although the instructors strategically used ambiguity in the classroom, the students were still frustrated and confused.

Conversely, Gabella (1995) reflected on two case studies she conducted in high school history classes where she sought to enhance student inquiry through the use of strategic ambiguity. Arguing for the Deweyan concept that doubt is central to inquiry, Gabella asserted that a lack of a correct answer requires students to engage in meaning making processes. She asserts that there are two types of doubt that are fundamental to inquiry: "The first is the doubt presented by multiple possible alternatives, or ambiguity. The second is the doubt presented by our ignorance of what is to be - uncertainty of the outcomes of inquiry" (p. 237). Gabella found that when uncertainty was promoted, only a few students reacted negatively, while most students reported their work was more meaningful and understood that ambiguity is central to knowing and learning. Importantly, Gabella also noted that students were more likely to take risks due to the strategically ambiguous nature of the classrooms because they knew they had teachers that supported their failure, thus, strategic ambiguity should be implemented with teachers who prioritize the learning of their students. The mixed feelings of strategic ambiguity in the classroom create tension for instructors when they are deciding whether or not to use ambiguity in their teaching. These mixed feelings could explain Huber's (2003) assertion that even though college instructors know that the business world requires an ability to cope in ambiguous situations, many still provide students with assessments that have a clear right and wrong answer. In this vein, the benefits of strategic ambiguity will be discussed.

\section{Impact of Strategic Ambiguity}

Allowing students to learn through ambiguity is beneficial to them when they enter the professional world. In a report from a task force for a professional organization in technology, 
Visser and Visser (2004) explained that ambiguity should be included in education because it is an everyday facet of life. Rippin et al. (2002) acknowledged the changing landscape of businesses and sought to determine how higher education business schools could change their curriculum as a result. They determined that there were two approaches to business educationone which sought to teach specific management skills and content and one that sought to develop critical thinking skills that students can transfer from their coursework to the workplace.

Consequently, the authors conducted a two-year qualitative case study to determine how the case method can help prepare students for the ambiguous nature of the business world. There were two modes of case studies used in the classes. The first mode lead to a correct answer. The second mode was more of an open-ended conversation about possible solutions. The researchers conducted interviews and focus groups to ask both students and staff about their experiences using case studies. Their findings suggested that students did not like the use of case studies as an open-ended activity and instead wanted a tangible outcome or correct answer. Although instructors liked this method as a real-world application, students resisted. The authors offered an explanation for why students may resist.

They were used to being fairly passive participants in their learning and were given a set of notes that were needed to pass the examination. To pass the examination they needed to give the right answer. Nuances of interpretation, or creative and critical insights would not be rewarded and therefore students did not develop the skills to provide them. (p. 439)

Although students disliked case methods, the authors concluded that "what can seem to students to be an unnecessarily unstructured exercise is actually a near approximation of the complex and unbounded reality that they are likely to face outside the classroom" (p. 439) and accordingly, 
should be included in business education curriculum. Beyond business education, DeRoma, Martin, and Kessler (2013) argued that ambiguity is a central part of being a counselor; therefore, higher education psychology educators should work to build a student's TFA. The authors argued for the use of case studies to promote ambiguity. Ambiguity is present in the professional realm. thus, preparing students for their professional lives serves as a benefit to strategic ambiguity in the classroom.

Furthermore, research has shown benefits to employing strategic ambiguity in the classroom. Klyukovski and Medlock-Klyukovski (2016) conducted a study in communication which sought to determine how instructors use strategic ambiguity, develop a scale for instructor strategic ambiguity, and determine how strategic ambiguity impacts various positive learning outcomes. The first part of their two part-study asked instructors to respond to open-ended questions identifying how they use strategic ambiguity in their classes. They identified four main categories for how instructors used strategic ambiguity. The first category suggested that strategic ambiguity was used to promote student active learning in the classroom. The second category was that it changed the learning requirement as it "introduced learners to the intellectual tools to foster self-directed learning and the expectation to rely on critical thinking" (p. 257). The third category was that strategic ambiguity was a means to teach students transferable skills as opposed to specific content. Finally, the fourth category was to allow students to take a leadership role in the learning environment. The second part of the study used the results from study one to create and test an instructor strategic ambiguity measure. Their quantitative study found that students' reports of college instructors' use of strategic ambiguity in many facets of the classroom was positively related to student self-reports of student motivation, learner empowerment, learning indicators, and need for cognition. Student motivation was 
conceptualized as students taking ownership of their learning. Building on motivation, learner empowerment occurs when students are intrinsically motivated to learn and confident that they can do so. Learning indicators referred to students' ability to make meaning of course content outside of class. Finally, need for cognition referred to the enjoyment students found in complex learning tasks (Klyukovski \& Medlock-Klyukovski, 2016). The authors concluded that although strategic ambiguity may not be liked by students, it serves a purpose. They wrote:

Instructor strategic ambiguity offers insight into the innovative and individualized process of instructors intentionally creating situations which engage students by fostering uncertainty - there are multiple paths students may take in the learning process. Students achieve effective learning by means of their own efforts which may require struggle, active study, cooperation, and taking risks on leadership. (p. 268-269)

Arguably, it is not necessary for students to struggle in order to learn; however, the authors argued that struggling through an assignment or processing of content requires students to be active in putting forth effort to learn and struggle is one way for them to do that. Importantly, this study only used correlations and it did not account for how instructors communicate about strategic ambiguity. Despite hesitance among college students, the use of strategic ambiguity in the classroom is encouraged by researchers as it offers real world application and it has been found to be beneficial to positive learning outcomes.

Research suggests benefits of strategic ambiguity in the classroom that address both academic and professional outcomes. Most of the research on strategic ambiguity and clarity have focused on what happens in the classroom, specifically, teacher messages related to content. This is only part of the picture. It stands to reason that, if a teacher uses strategic ambiguity in the classroom, there is likely little threat to the student. It is easy for students to simply disengage in 
class if they do not know how to respond, thus, they would not benefit from the use of strategic ambiguity. Strategic ambiguity, then, becomes a threat for students when they must deliver a tangible product. If strategic ambiguity is utilized when a student must create something to be assessed, the student cannot disengage and, instead, must rely on critical thinking and problemsolving skills to complete the task. Since strategic ambiguity in assessment requires students to take an active part in their learning and prevents them from disengaging in classroom discussions, strategic ambiguity in assessment should be explored.

\section{Assessment}

Educators use the term assessment to mean a variety of different concepts. Assessment in education takes a variety of formats including summative and formative assessment, formal and informal assessment, and graded and ungraded assessment. Assessment is broadly defined as "a process for gathering and interpreting information for use in making decisions about students, instruction, curriculums, programs, and educational policies" (Guskey \& Jung, 2013, p. 16). Assessment occurs on many different levels. Classroom assessment, in this study, is defined as an assignment a teacher employs in a given class to measure the learning of the students.

Conversely, grading occurs when we apply a judgement to the assessment to signify achievement (Guskey \& Jung, 2013). The emergence of high stakes, standardized assessment has brought about the necessity of instruction that prepares students for one particular type of assessment with objective grading criteria. Currently, many individuals are looking at different assessment practices and examining new ideas (Guskey \& Jung, 2013; Marzano, 2010). To understand the use of strategic ambiguity in this research study, it is important to understand the distinction between assessment and grading. 
Education researchers have explored many different types of assessments. These range from very critical, free-flowing assessment ideas such as removing grades entirely (Kohn, 2011) to rigid grading criteria that create consistency across many sections of the same course (Stitt, Simonds, \& Hunt, 2003). The use of strategic ambiguity in assessment employed in this study falls in between these two extremes. Stitt et al. suggest that evaluation fidelity, a shared understanding of performance criteria between those grading and those being graded, is of utmost importance for graders, particularly when consistency among different instructors of the same course is warranted. On the other end of the spectrum, Kohn (2011) suggested that grading all together is a detriment to student learning and should be eliminated. In the middle of the spectrum, Percell (2014) observed that it is the points in grades that are problematic and argued for a type of mastery grading. Mastery grading takes place when an instructor measures student learning based on pre-set criteria to determine if they can meet objectives (Lalley \& Gentile, 2009). One type of mastery grading model is standards-based grading, which is gaining popularity in elementary and secondary education and is defined as "grading that references student achievement to specific topics within each subject area" (Marzano, 2010, p. 17). Standards based grading is based on a performance standard and criteria for approaching, meeting, and exceeding are developed for the standard (Marzano, 2010); thus, the arbitrary use of points is eliminated. Students often use the points in traditional grading systems to manipulate how much effort to give on any one assignment and even whether or not they need to complete an assignment at all (Percell, 2014). As a result, Percell began experimenting with what he calls "a pointless education," in his high school class, where he created criteria for meeting and exceeding expectations, but without giving points. His rationale was that points are viewed simply as a means to an end, points are an extrinsic reward, and points give meaning or value to 
assignments, intentional or not. He suggested that the pointless grading system defines a minimum standard for performance and then allows students to exceed that, on their own terms, to receive a higher evaluation in the end. This requires students who want the highest grade to go above and beyond minimum standards and demonstrate higher levels of thinking (Percell, 2014). In a higher education study on students' attitudes of pointless grading, authors implemented pointless grading at a higher education institution in Asia and then surveyed students regarding their experiences. Findings suggested an overwhelmingly positive response to pointless grading with students suggesting that it reduced stress, allowed them to take risks, helped them maintain a high grade point average (GPA), and helped them adapt to university life. Findings also suggested some negative results, though they were mentioned far less, which included poor learning attitudes and behaviors, confusion about how the policy worked, and systemic issues (McMorran, Ragupathi, \& Luo, 2015). The authors concluded that while there were some negative reactions to pointless grading, the biggest challenge is teaching students to appreciate learning beyond simply receiving a grade.

Although removing grades from the educational landscape is a systemic issue that is potentially beyond a teacher's control, strategic ambiguity in classroom assessments could help students appreciate learning beyond simply receiving a grade because the assignment outcome can reflect a student's ability to problem solve and find an answer without clear guidelines of how to complete an assignment. When answers are clearly outlined, and students can easily complete an assignment, teachers are not stretching students to learn. Vygotsky (1978) referred to this stretch as the zone of proximal development, which is when educators push students just outside of their current development level to begin to see what they are capable of achieving. While students may initially dislike strategic ambiguity because they are unfamiliar with it, 
introducing it in classroom assignments can provide them the opportunity to learn how to demonstrate what they are capable of achieving beyond the simple reproduction of course content. Instructors can be clear in their use of ambiguity to help students work through the initial uncertainty and discomfort, which may ultimately create more meaningful classroom assessment. Undoubtedly, instructors need to balance how they employ strategic ambiguity with an understanding of student's desire for clarity.

\section{Strategic Ambiguity in Assessment}

Classroom assessment is one way in which instructors can intentionally apply ambiguity to challenge students. Students are overly focused on the outcome of assessments rather than the journey of learning (Wootton, 2002). When given an assessment, students tend to focus more on grades rather than learning (Kohn, 2011). Students often prefer rubrics because they give them targets for their work, allow them to regulate their progress and determine if grading is fair (Reddy \& Andrade, 2010). This is because students find "a great deal of comfort from having someone else lay the foundation, chart the path, give them tools, take them by the hand and navigate them" through their courses (Brunson \& Vogt, 1996, p. 78). However, there appears to be a tension that exists between being overly clear in assessment and allowing for meaning construction on the part of the student.

Often, instructors feel the need to be very clear in their assessments to meet the desire of students and there are reasons that clarity is warranted. For example, Frey, Simonds, Hooker, Meyer, and Hunt (2018) conducted a study in communication where they trained students how to use the criterion-based evaluation criteria that instructors use when grading prior to completing speaking assignment. The authors found that this training helped students better understand and meet expectations for the assignment and helped them evaluate their own speaking. If the goal of 
an assessment is for students to meet pre-defined criteria, this level of detail makes sense.

Further, helping students learn to evaluate their own performance is also an important component of a public speaking course; thus, if meeting pre-established criteria and evaluating oneself against that criteria is a course goal, clear grading criteria may be warranted. Additionally, Stitt et al. (2003) conducted a study in communication to highlight the importance of evaluation fidelity in large, multi-section courses such as their required public speaking course which is aligned to general education outcomes. They found that criterion-based grading improves the consistency of grading for students in different sections with different instructors. The authors wrote, "providing students with specific criteria that they must meet to obtain a particular grade should decrease students' uncertainty about instructors' expectations" (p. 343), indicating that uncertainty reduction is important for assessments. This implies that uncertainty is contrary to learning outcomes; however, this is not always the case. Nonetheless, in the instance of standardizing experiences for students across many sections of the same course to reduce inconsistencies in grading, the benefits of clearly defined grading criteria may outweigh the benefits of strategic ambiguity.

Conversely, one disadvantage to this level of detail in a grading criterion, as noted by Torrance (1970) is that students are overly focused on finding one correct answer and as a result, they do not think through and evaluate additional options. Further, the pressure of evaluation can decrease a student's willingness to express their creativity (Beghetto, 2005). Kohn (2011) argued that a specific grading criterion tells students' exactly what to do, thus reducing the critical thinking required of them. In this sense, too much clarity could negatively impact students learning as they will not think as hard about what they are learning, rather, they will focus on how to use points as a means to an end. This may be true in some instances; however, it is not 
always the case. Recall that instructional clarity has been found to have a positive effect on student learning (Titsworth et al., 2015). This can still be true. Because clarity and strategic ambiguity can occur on a spectrum and are not necessarily at odds, the positive effect of student learning when employing clarity and the potential positive effects of student learning when employing strategic ambiguity are not at odds; rather, a different learning outcome may be promoted.

Wright (2019) conducted a qualitative study that sought to determine student's reactions to clear and unclear assignments. Students were first asked general questions about their preferences toward classroom assessments. Then, students were given three assignments to look at: clear, unclear, and moderately clear. The assignments had varying levels of descriptions and grading criteria. Participants were then asked questions about which assignments they preferred and why. Results suggested that at first, students preferred the clear assignment as it told them exactly what to do; however, "when questioned specifically about which assignments lead to greater creativity, ownership of learning, and critical thinking, they all said that the more ambiguous assignments did" (p. 24). The author concluded that if instructors want to use strategic ambiguity, they should be clear in their explanation of why it is being employed (Wright, 2019). Strategic ambiguity allows instructors to provide opportunities for students to work through scenarios where there is not always a correct answer. Arguably, students may feel uncomfortable with the lack of clarity in assessments; however, DeRoma et al. (2003) suggested that although ambiguity may create student anxiety, instructors should still create evaluations that require students to use explorative thinking rather than being overly concerned with mastering content. Klyukovski and Medlock-Klyukovski (2016) reported that instructors sometimes gave ambiguous assignments to "foster creativity and to develop critical thinking 
skills by encouraging students to analyze different strategies they could utilize to approach the assignment" (p. 260). This allows students to learn while struggling with the best way to complete an assignment.

Using strategic ambiguity in classroom assessment could have ramifications for college instructors such as students being frustrated and evaluating the instructor negatively; therefore, strategic ambiguity should be carefully employed. As research suggests, students sometimes dislike the use of strategic ambiguity. In that vein, it is necessary to determine what student characteristics might impact their response to the use of strategic ambiguity.

\section{Tolerance for Ambiguity}

The use of strategic ambiguity is only one piece of the puzzle. Arguably, if we want to know how students will react to the use of strategic ambiguity, we need to understand their TFA. Again, within this research project, TFA refers to students' general attitudes toward ambiguous situations and contexts, specifically, their comfort level related to uncertain or new circumstances. TFA has been studied in education and psychology; therefore, research from those disciplines will be reviewed here. Surprisingly, studies have not explored TFA and strategic ambiguity together; thus, there is not have empirical evidence to suggest how a person's TFA may impact their response to strategic ambiguity. Tolerance or intolerance for ambiguity influences how a person behaves (Kajs \& McCollum, 2009), which has implications for how a person will react to the use of strategic ambiguity. In a quantitative study of graduate and undergraduate students, DeRoma et al. (2003), researchers in the field of psychology, explored how TFA impacts students' desire for course structure. They found that low TFA was most strongly related to valuing course structure and inducing anxiety when elements of course structure were missing for both graduate and undergraduate students. Additionally, low TFA was 
also related to discomfort with vague grading criteria for graduate students. Graduate students also experienced anxiety when evaluation went beyond rote memorization (DeRoma et al., 2003). The authors speculate that graduate students may be less comfortable with uncertain course structure because there is a greater demand on their time and less structured courses stretch their time management. The authors concluded that due to the nature of ambiguity in psychology professions, college psychology instructors should work to nurture higher levels of TFA. They wrote, “despite student anxiety, educators should construct evaluations that emphasize explorative, rather than restrictive, exam responses and creativity over mastery of learned content" (DeRoma et al., 2003, p. 107). Likewise, integrating strategic ambiguity in the classroom in any manner warrants an exploration of students' TFA.

Sorrentino, Short, and Raynor (1984) conceptualized a comparable construct, uncertainty orientation, which is defined as, "the degree to which situations of certainty or uncertainty are cognitively relevant” (p. 190). Their quantitative study in the psychology discipline concluded that individuals perform better on tasks that are consistent with their certainty orientation. From this, it can be inferred that uncertainty orientation, or TFA, does impact a college student's reaction to strategic ambiguity. Furthermore, Carver (2006) conducted a quantitative study to determine how TFA affected college students' inferential reasoning in an undergraduate statistics class. Students in the class were primarily business students and the measurements were imbedded into class assignments via activities and survey instruments. Contrary to past research, findings suggested that high TFA students exhibited lower performance on inferential reasoning; however, these students could apply effort to overcome this setback. This could potentially be because extra effort, as opposed to giving up, is required to work through a situation that is uncomfortable for a student. Further, the subject matter studied could impact this. Statistics is a 
course in which ambiguity is not expected because it is perceived to be straight-forward; thus, students who like ambiguity, or high TFA students, may be students who do not excel in a statistics class, regardless. As such, students may need to be taught coping strategies regarding how to overcome setbacks related to the use of strategic ambiguity in the classroom. Further, studies should explore how a student's TFA is impacted in varying disciplines.

Banning (2003) conducted a quantitative, experimental study to determine whether the use of case studies could improve a college student's TFA in a strategic management course. The premise of the study hinged on the idea that TFA is necessary in business situations; therefore, understanding how to improve a student's TFA is warranted. The study employed a pre- and posttest design in an undergraduate capstone strategic management course. Students were divided into two groups: an experimental group, which used case studies in the class and a control group, which did not use case studies. At the beginning of the semester, students responded to questions regarding their locus of control and their TFA. At the end of the semester, students answered questions on these variables again. Pertinent to this research study, findings suggested that the use of case studies did improve students' TFA and students with higher TFA were more successful in the course. The exposure to these pedagogies can make students more tolerant of ambiguity, which, in turn, could alter their perceptions of strategic ambiguity. Because TFA affects students' acceptance of ambiguity, it is a necessary component of strategic ambiguity research. Luckily, Huber (2003) used her experiences teaching business students to argue that TFA can be taught to business students through the use of activities that require students to apply their learning.

Similar to TFA, adaptability has implications for student's response to strategic ambiguity in the classroom. In educational psychology, Martin et al. (2013) defined adaptability 
as, "individuals' adjustments of psycho-behavioral functions in response to novel and/or uncertain circumstances" (p. 733). In the workplace, Ployhart and Bliese (2006) defined an individual's adaptability as, "ability, skill, disposition, willingness, and/or motivation to change or fit in different task, social, and environmental features" (p. 113). TFA explores students' attitudes toward ambiguity whereas adaptability examines their reactions to it. Likewise, TFA has been studied primarily in business and business education, whereas adaptability has been studied primarily in educational psychology. Accordingly, research on adaptability is relevant to the exploration of TFA in that they measure similar constructs in different disciplines.

Adaptability promotes positive learning behaviors. For example, educational psychology researchers Collie, Holliman, and Martin (2017) studied first year undergraduate student's adaptability with their behavioral engagement and academic achievement. Their quantitative study suggested that adaptability was related to greater positive behavioral engagement and lower negative behavioral engagement. Examples of positive behavioral engagement include being better able to persevere in the face of new challenges, plan and monitor school work, and manage learning tasks. Negative behavioral engagement refers to self-handicapping and disengagement in school. Further, the authors found that adaptability had an indirect effect on GPA (Collie et al., 2017). Likewise, Holliman, Martin, and Collie (2018) conducted a quantitative study in educational psychology which they surveyed undergraduate students on their adaptability and behavioral engagement and compared that to their university completion status. Findings reported that adaptability predicts positive and negative behavioral engagement, but only negative behavioral engagement predicts degree completion. They concluded that interventions targeting adaptability and/or negative behavioral engagement could help university 
students avoid non-degree completion. A student's adaptability helps them to succeed in their education.

Adaptability has been shown to be influenced by a few different student characteristics. Martin et al. (2013) conducted a longitudinal, quantitative study that showed that personality and mindset impact adaptability in high school students. The study found that adaptable students are better able to keep pace with differentiated lessons, had more positive learning outcomes, and were less likely to default to self-handicapping, a characteristic of entity theorists. Similarly, findings suggested that adaptable students are better able to work through every day challenges, a characteristic of incremental theorists. Also, LePine, Colquitt, and Erez (2000) concluded through a quantitative study in psychology that adaptability in changing contexts was predicted by cognitive ability, conscientiousness, and openness to experience. They asserted that adaptability was impaired by a desire to be orderly and deliberate, which has implications for the unstructured nature of strategic ambiguity. Since adaptability informs how students respond to uncertainty, a student's adaptability is predictive of their reactions to strategic ambiguity in the classroom.

\section{Mindset}

Beyond measuring a student's disposition toward ambiguity, students' mindsets regarding their ability to learn are an important construct. Implicit theory has been well researched in the field of psychology and can help us understand how individuals think about learning or intelligence and how that thinking impacts their reactions to various situations. Dweck et al. (1995) stated that "implicit theories refer to the two different assumptions people may make about the malleability of personal attributes" (p. 267). These assumptions are referred to as a person's mindset. Entity theorists, referred to as having a fixed mindset, believe that 
people have a fixed amount of intelligence. Conversely, incremental theorists, referred to as having a growth mindset, believe that intelligence is something that can be cultivated through learning (Dweck, 2000). Individuals with a fixed mindset are more negatively affected by failure, making broad inferences about their ability in the face of failure. Conversely, individuals with a growth mindset view failure as a means to learn and are more focused on effort and strategy to improve (Dweck, Hong, \& Chiu, 1993). A fixed mindset is associated with a desire to look intelligent and individuals will self-handicap, which is choosing not to exert effort when faced with a difficult task in an attempt to not look unintelligent. Dweck (2000) stated:

The entity theory, then, is a system that requires a diet of easy successes. Challenges are a threat to self-esteem. In fact, students with an entity theory will readily pass up valuable learning opportunities if these opportunities might reveal inadequacies or entail errors and they readily disengage in tasks that pose oscillates, even if they were pursuing them successfully before. (p. 3)

Individuals with a growth mindset, on the other hand, view difficult tasks as a means for learning and will exert more effort in these cases. These students are less concerned with avoiding challenges and more concerned with having a new opportunity to learn (Dweck, 2000). Put simply:

The entity theory world is about measuring your ability, and everything (challenging tasks, effort setbacks) measures your ability. It is a world of threats and defenses. The incremental world is about learning and growth, and everything (challenges, effort, setbacks) is seen as being helpful to learn and grow. It is a world of opportunities to improve. (Yeager \& Dweck, 2012, p. 304)

In short, incremental theorists thrive in the face of challenge whereas entity theorists give up. 
Implicit theory has been explored both academically and behaviorally. In a given situation, a person is either an entity theorist or an incremental theorist, but their mindset can change in different contexts (Dweck et al., 1995). Implicit theory has been studied in a variety of educational settings. Yeager and Dweck (2012) reviewed research, including their own, regarding how mindset interventions impact students' academic successes. Their findings suggested that there are many examples of research where mindsets can improve students' resilience in the face of academic challenges. The authors suggested that the reason for this is that the interventions changed the meaning of the challenges presented to students from one that makes them look unintelligent to one that helps them learn.

Blackwell, Trzesniewski, and Dweck (2007) conducted a two-part longitudinal intervention study for junior high math students. For the first study, the researchers measured student's mindset when they entered junior high and then assessed their academic achievement throughout junior high. The researchers also gathered data regarding the student's mathematics achievement before entering junior high and every year during junior high. They found that a growth mindset was associated with stronger learning goals, more of a belief that hard work would lead to achievement, less helplessness, and a decreased likelihood to attribute failure to a lack of ability. For the second study, some students received an intervention which taught two groups of seventh grade math students that intelligence was either fixed or malleable. Results suggested that students who were taught that intelligence was malleable saw less of a decrease in math scores. The second part of their study also asked teachers to indicate their perceptions of motivation levels for both groups of students. The teachers indicated that they perceived students who were taught that intelligence was malleable to be more motivated. The authors concluded that teaching a growth mindset to middle level math students helped them become more 
motivated and halted the decrease in math performance that is common for students at this grade level (Blackwell et al., 2007). A growth mindset appears to lead to greater learning outcomes in students.

Additional studies have explored how shaping mindsets can help traditionally underserved populations in a few different ways. Aronson, Fried, and Good (2001) conducted a quantitative study in psychology that manipulated mindsets for African-American college students. Findings suggested that students who were encouraged to see intelligence as malleable reported more enjoyment in academics, greater academic engagement, and higher GPAs. Likewise, psychology researchers have examined the influence of implicit theory pedagogy on low income, minority, female math students in middle school. Their experimental design placed students into two groups who were mentored by college students who encouraged them to believe that intelligence is malleable. Results demonstrated that students in the experimental group received higher standardized tests scores in both math and reading (Good, Aronson, \& Inzlicht, 2003). Finally, a quantitative study on high school students in Chile found that a growth mindset, or incremental theory of intelligence, was a predictor of academic achievement for students of low socioeconomic background (Claro, Paunesku, \& Dweck, 2016). A growth mindset can enhance academic outcomes for more vulnerable students.

In communication studies, Mazer and Graham (2015) recently made a call for a cross disciplinary approach to communication research. Accordingly, Nordin and Broeckelman-Post (2019) conducted a quantitative study to determine how college students' mindsets impacted their performance in an introductory public speaking class. Results suggested that students with a growth mindset performed better on speeches, interpersonal communication competence, and had less public speaking anxiety. Stewart, McConnell, Stallings, and Roscoe (2017) also found 
that growth mindset was related to lower communication apprehension. Overall, implicit theory has been shown to impact a variety of positive academic learning outcomes in different disciplines. As such, educational changes such as the implementation of strategic ambiguity should consider how a student's mindset will mediate responses to that change.

Although implicit theory has gained a lot of traction in education recently, the theory has also been criticized. Sisk, Burgoyne, Sun, Butler, and Macnamara (2018) conducted two metaanalyses to determine the impact mindsets actually have on academic achievement. The first meta-analysis sought to determine the strength of the relationship between mindset and academic achievement. Results suggested that the overall effect size of mindset theory and academic achievement is weak. The second meta-analysis sought to determine the effectiveness of mindset interventions on academic achievement. Results suggested that mindset interventions were not significant for many populations; however, results were significant for at-risk populations. In many ways this is a strong argument against implicit theory; however, the theory still holds merit in some capacities. First, as with much social scientific research there could be confounding variables that impede the results for each of these studies. Second, there are situations in which mindset interventions work and, as the authors admit, these interventions are a relatively simple task to take on if they help lower advantaged populations (Sisk et al., 2018). As such, studies are still needed to determine the extent of how mindset theory impacts academic achievement because results suggest that even if at a weak level, mindset is enhancing academic achievement.

While the literature shows mixed results on the impact mindset has on academic achievement, it is important to note that within this study, mindset is not being used to explore academic achievement. Instead, this study seeks to explore how mindset impacts student's motivation or desire to complete a strategically ambiguous assignment. The meta-analyses 
addressed only academic achievement, thus, the implications of mindset theory as addressed above are still relevant to this study.

\section{Learning Orientation and Grade Orientation}

The amount a student focuses on grades as the outcome of learning could have implications for their reaction to strategically ambiguous assignments. Researchers have used varying terms for a similar construct, learning orientation and grade orientation along with achievement goals, and both will be referenced in this section. Learning orientation and grade orientation reflects the extent to which students view education as a means to learn versus the extent to which they focus on grades in learning (Pollio \& Beck, 2000). Dweck (2000) conceptualized a term similar to learning orientation and grade orientation--achievement goals. Within achievement goals, performance goals are related to the desire for a positive evaluation of learning in order to appear intelligent, which is similar to grade orientation. Conversely, learning goals, which are similar to learning orientation, are concerned with gaining knowledge. When completing assessments, many students are focused on the grade rather than the journey of learning (Wootton, 2002). Unfortunately, research suggests that students who focus on grades turn to helplessness in the face of failure, unlike students with learning goals who assert more effort when faced with failure (Dweck, 2000). In her research, Accordingly, it seems that learning focused students will exhibit more positive learning outcomes.

The extent to which our classrooms promote learning versus grade orientation is unclear. Pollio and Beck (2000), psychology researchers, conducted a three-part study to determine college students learning orientation and grade orientation and its impact on their schooling. They suggested that learning-oriented students have better study skills, less test anxiety, more reasoning ability, and more motivation than grade-oriented students. Additionally, their study 
explored student and instructor preferences in regard to learning orientation and grade orientation. The first study in their three-study design asked students to complete a scale that assessed their learning orientation and then complete another scale that assessed their ideal orientation. The study found that students generally want to be more learning-oriented than they perceive that they are actually. Follow-up focus groups suggested that students fault instructors for their focus on grades because they feel instructors promote this grade-oriented attitude in the classroom. The second study had students complete a faculty learning orientation scale for how they think faculty would respond and how they would like faculty to respond. Results suggested that students perceive instructors to be very grade-oriented, but they wish they would be more learning-oriented. The final study asked instructors to fill out the student scale as they think typical students would respond and again how they would like their students to respond. They found that faculty perceive students to be very grade-oriented while they would like them to be learning-oriented. Follow-up focus groups suggested that faculty wished students would be more learning-oriented; however, encouraging this behavior in the classroom was not important to most instructors. Findings suggested that both students and faculty were dissatisfied with the learning orientation of one another and both blamed the other for the current attitudes in the classroom. In reality, both students and professors indicated that they want the same thing, which is less of a focus on grades and more of a focus on learning. The authors speculated that this is because both the students and professor are making a fundamental attribution error, which is when a person seeks to blame something outside of their control for their present situation. In this case, both students and instructors are blaming one another; however, they are failing to dialogue about how to fix their concerns (Pollio \& Beck, 2000). An over-reliance on performance goals causes students to forgo positive learning opportunities (Dweck, 2000). 
Overall, a focus on grades is undesirable for both students and instructors; however, the authors did not address why students and instructors still focus on grades.

Furthermore, college student grade orientation has been explored in instructional communication research. A quantitative study was conducted to understand how student predispositions, including grade and learning orientation, impacted their expected instructor communication behavior. Frymier and Weser (2001) found that college students who were more grade-oriented had higher expectations for teacher clarity. The authors concluded that this was likely because grade-oriented students are focused on getting a good grade and, consequently, they want to be told exactly what to do to achieve the grade they desire. They wrote:

Grade-oriented students are focused on performing the necessary tasks for receiving a good grade. They probably want to be told exactly what to do. All teachers have encountered such students who ask a dozen questions all focused on “doing it right.' Learning-oriented students who are focused on what can be learned from the task, may find too much guidance to be restrictive or maybe even an insult to their intelligence. ( $\mathrm{p}$. 324)

This could have implications for strategic ambiguity in classroom assessments because gradeoriented students may be less willing to accept strategic ambiguity because those assignments do not clearly tell students what to do. Conversely, learning-oriented students may struggle with very clear classroom assessments because they may feel restricted. Another communication study explored college student characteristics including grade and learning orientation, teacher characteristics including clarity, and their effect on learner empowerment (Houser \& Frymier, 2009). Learner empowerment motivates students to complete a task and makes them feel competent doing so. Findings suggested that learning orientation was positively associated with 
learner empowerment, whereas grade orientation was negatively associated with learner empowerment. The authors concluded that the teacher characteristics of nonverbal immediacy and clarity, as well as student learning orientation, enable students to become empowered (Houser \& Frymier, 2009). Pollio and Beck (2000) suggested that learning-oriented students have more motivation and better reasoning ability than grade-oriented students. This has implications for strategic ambiguity in the classroom because it is plausible that students with more motivation and better reasoning ability will be less threatened by strategic ambiguity and can better persevere under such conditions.

TFA, mindset, learning orientation, and grade orientation are student characteristics that are intertwined and potentially impact a student's response to strategic ambiguity in classroom assessment. To understand how these characteristics, impact a student's reaction to ambiguity, desired outcomes of strategic ambiguity need explored. Based on the aforementioned research and positive learning behaviors desired by instructors, it is reasonable that the use of strategic ambiguity in classroom assessment would positively impact learner empowerment and affective learning. These variables will be explored in the following sections.

\section{Learner Empowerment}

Ideally, in a class, students will not only learn, but they will also feel compelled to learn. Frymier, Schulman, and Houser (1996) suggested that learner empowerment falls within intrinsic motivation and includes students who believe they can do the work. Learner empowerment has been studied primarily in instructional communication. Research has shown that various instructor behaviors affect learner empowerment. Thomas and Velthouse (1990) suggested that empowerment consists of four dimensions: sense of impact, competence, meaningfulness, and choice. Impact is viewed as if someone feels their efforts completing a task make a difference by 
accomplishing the task. Competence is whether or not a person can perform the task adequately. Meaningfulness is the extent to which the person finds the task to be valuable to their lives. Choice refers to an individual's perception that they have agency in the task (Thomas \& Velthouse, 1990). Houser and Frymier (2009) refined learner empowerment to include only three dimensions: meaningfulness, competence, and impact. When these constructs are present, students should have more intrinsic motivation.

Learner empowerment has been shown to impact a few different variables. In a quantitative study in communication that sought to establish an empowerment scale, Frymier et al. (1996) surveyed college students regarding their learner empowerment, state motivation, learning, as well as learning orientation and grade orientation. They found that empowerment was associated with state motivation, learning, and learning orientation and grade orientation. Further, they found that learner empowerment was associated with teacher immediacy and relevancy behaviors. Accordingly, the researchers concluded that learner empowerment is impacted by both the learning environment and teacher communication behaviors, thus, teacher communication behaviors are important in the classroom. Houser and Frymier (2009) conducted a quantitative study that sought to include both college student and college teacher characteristics in a study on empowerment. Specifically, the authors examined the student temperament and learner orientation and teacher nonverbal immediacy and clarity on learner empowerment. They found that student temperament and student empowerment were not related. They also found that learning orientation was positively associated with learner empowerment, but grade orientation was not. Regression analysis indicated that clarity was the strongest predictor of student empowerment. Although this study speaks to the importance of clarity, it is important to note 
that the clarity measure used included process clarity, which includes communication between the student and instructor; thus, these findings to not exclude the clear use of strategic ambiguity.

Similarly, Finn and Schrodt (2012) conducted a quantitative study in communication to determine how students perceived understanding from teachers mediates the relationship between students' perceptions of teacher clarity, nonverbal immediacy cues, and learner empowerment. The researchers surveyed undergraduate students regarding the teacher clarity, nonverbal immediacy, and perceived understanding of the teacher in their current class as well as their learner empowerment for that course. Results found that college students perceptions of teacher clarity and nonverbal immediacy had an impact on their learner empowerment. Further, perceived instructor understanding was a partial mediator of the two instructor variables for the impact and competence dimensions of learner empowerment, whereas instructor misunderstanding was a partial mediator of the two instructor variables for the impact dimension of learner empowerment. The authors concluded that college student perceptions of teacher clarity and nonverbal immediacy improved their perceptions of instructor understanding and, in turn, predicted their learner empowerment. This study explored clarity in teacher presentation of content and response to student's questions and contribution, not in classroom assessment. Finally, Brooks and Young (2011), higher education researchers, conducted a quantitative analysis to explore how choice-making opportunities in the college classroom impact student motivation and learner empowerment. Results suggested that students exhibited more learner empowerment when the teacher had consistent policies regarding how much choice students had. For example, they found that if teachers had a mandatory attendance policy but gave choice in assignments, students had less empowerment than when instructors had a mandatory attendance policy and no choice on assignments. They concluded that educators should be consistent with 
student choice-making to ensure students feel empowered. Additionally, they suggested that under certain conditions, providing students with too much autonomy could have adverse effects. In summary, instructor behaviors are strongly tied to learner empowerment. Since learner empowerment includes student's confidence in their ability to complete an assignment, it could have implications for the use of strategic ambiguity in assessments. Many students have not been faced with strategically ambiguous assessments, thus, they may lack confidence in carrying out the task. Further, learner empowerment should lead to motivation, thus, motivation research is reviewed in the next section.

\section{Motivation}

Arguably, teachers want students who are motivated to learn and engage in learning tasks. Recall that learner empowerment falls within intrinsic motivation (Frymier et al., 1996). Much research has been conducted on the role of motivation in education; however, for the purposes of this research study, research within communication will be discussed. Frymier (2016) defined motivation as, "energy one brings to the task" (p. 385). There are two types of student motivation: trait and state. Trait motivation is a person's attitude toward learning in general, whereas state motivation is a person's attitude toward a specific class or learning task (Christophel, 1990). Motivation is important to the use of strategic ambiguity in the classroom because students will need to be motivated to complete an ambiguous task.

Research has explored instructor behaviors that impact student motivation in the classroom. In a landmark study in communication, Christophel (1990) conducted a quantitative study to explore the relationship between college teacher immediacy and college student motivation. Students' self-reported data regarding their levels of motivation, perceptions of teacher immediacy, and perceptions of learning. Findings suggested that student state motivation 
was positively correlated with instructor immediacy and that both trait and state motivation were positively associated with student learning. The author concluded that "a portion of student state motivation was directly modified by teacher immediacy behaviors" (Christophel, 1990, p. 337). Hence, teacher communication behaviors can influence student motivation.

Consistent with the aforementioned clarity research, Bolkan et al. (2016) conducted a quantitative study to explore the relationship between college instructor clarity and student motivation. Study participants watched a short lecture that was either clear or unclear and then answered questions regarding the lecture. They found that there is a significant relationship between clarity and a student's motivation to process course content. Specifically, students who listened to lecturers and were motivated to think about the content performed better academically than students who were unmotivated. Interestingly, the authors asserted that instructor clarity only matters if students are motivated to learn and consequently, they suggested that instructors should work to increase motivation. One way to do so is by creating lessons that are relevant for students (Bolkan et al., 2016). For the sake of this research, motivation is presumed to be the result of learner empowerment, which is measured in this study.

Clarity is just one instructor behavior related to student motivation. Further, Bolkan and Griffin (2018) conducted a study that looked at what instructional interventions impacted student interest, attention, and motivation. Their quantitative analysis revealed that instructional interventions did have an impact on how students became interested in and reacted to course lessons. Specifically, they found that catching student interest motivated students to pay attention in class, but holding their interest helped them become more motivated to learn and understand the content. The authors surmised that teacher communication behaviors, especially those that showed the relevance of a lesson, helped motivate students to pay attention in class (Bolkan \& 
Griffin, 2018). Research suggests that particular teacher behaviors positively impact student motivation. Another way to motivate students is to make assignments meaningful, a factor measured through learner empowerment. Several studies have pointed to the necessity of meaningful assignments as a means to motivate students (Bolkan et al., 2016; Bolkan \& Griffin, 2018; Weber, 2003). This can be done through student interest, which Weber defined as assignments that show the meaningfulness of the task to the student, clearly illustrate that the task matters for an end product or goal, and students' beliefs about their ability to complete the task. A quantitative study found a positive association between student interest and student motivation (Weber, 2003). Overall, the instructor behaviors outlined in this section positively influence student motivation. When employing strategic ambiguity in the classroom, these same behaviors could motivate students to complete assignments.

\section{Affective Learning}

With any instructional intervention students should learn something and have positive feelings regarding that learning. Affective learning is a positive learning outcome that has been explored in instructional communication. There are three domains of learning: cognitive concerned with knowledge, affective - concerned with attitudes, and psychomotor - concerned with motor-skills (Bloom, Engelhart, Furst, Hill, \& Krathwohl, 1956). In education, the affective domain is associated with feelings toward a task (Barkley, 2010). In this study, affective learning is defined as the positive attitude's students have regarding learning orientation and learning tasks. Positive student affect is integral to student learning (McBride et al., 2016). When students have positive emotions toward learning, they are more likely to exhibit effort, which results in greater achievement (Barkley, 2010). Further, it is related to a student's behavior. For example, in their textbook on communication in the classroom, McCroskey et al. (2006) claimed that a 
student can know what to do and how to do it, but for something to be done, they must have a positive attitude toward it. This is the affective domain of learning, which the authors argue receives the least attention from teachers. Recall that students sometimes feel frustrated toward ambiguity in the class (Brunson \& Vogt, 1996). If given a classroom assignment that employs strategic ambiguity, frustration may lead to a negative attitude, thus negatively impacting their academic learning. Fortunately, teacher characteristics can impact affective learning. Both teacher immediacy and clarity are important variables for improving student affective learning (Chesebro \& McCroskey, 2001; Comadena et al., 2007). Communication researchers Chesebro and McCroskey (2001) conducted a quantitative study of higher education that sought to determine how student characteristics of motivation, affect, and cognitive learning as well as instructor characteristics of clarity and immediacy impact receiver apprehension of messages. Students answered survey questions regarding a teacher they had in their previous class. Results indicated that students who have apprehension when listening to their teachers had less affective learning and less motivation to learn. Further, results indicated that students with immediate and clear teachers were less likely to experience receiver apprehension. Consequently, this study supports the necessity of clear and immediate teaching. Although this study argues for the necessity of clear teaching to reduce communication apprehension for students, it does not exclude the possibility that a clear use of strategic ambiguity could reduce apprehension, as well. In a like manner, Comadena et al. (2007) conducted a quantitative study in higher education that examined the effects of instructor clarity, immediacy, and caring on student motivation and affective and cognitive learning. Students were given a description of an instructor and the researchers manipulated the instructors level of nonverbal immediacy, clarity and caring. Students then kept their hypothetical class and instructor in mind when responding to questions 
regarding their motivation, affective learning, and cognitive learning. Relevant to this study, results indicated that teacher clarity, immediacy, and caring interacted to influence student affective learning. This study explored clarity in a classroom lecture, not clarity in a classroom assignment; thus, it does discredit the present study.

Additionally, a quantitative experimental study in communication by Pogue and Ahyun (2006) found that highly immediate and highly credible college teachers had a positive impact on college student affective learning and motivation. Another quantitative study sought to determine how high school students' perceptions of their teachers' communication behaviors impacted their affective learning in math and science (Mottet et al., 2008). Findings suggested that teacher clarity and content relevance positively impacted students affective learning as did student study habits. These three variables were equal predictors of student affective learning (Mottet et al., 2008). The authors asserted that these findings are contrary to what research reports when examining college students and that it could be due to the emphasis placed on high stakes testing in secondary schools that has created a disconnect from the emotional component of learning for students. Although the aforementioned study speaks to the importance of clarity, strategic ambiguity seeks to remove students from the rigid nature of high stakes assessment, thus, these results may be different when students understand the reasoning for the use of strategic ambiguity.

Moreover, Avtgis (2001) conducted a quantitative study to determine how a college student's desire to be able to predict an instructor's behaviors impacted their affect toward the course, their motivation, and their reports of teacher clarity. Results indicated that student affect toward the course, their motivation, and their reports of teacher clarity all increased when they were able to predict the behaviors of the teacher. While this may seem contrary to the study of 
strategic ambiguity, it cannot be assumed that students would not appreciate or be able to predict an instructor's behavior in employing strategic ambiguity. Importantly, Chory and McCroskey (1999) found that college student affective learning increased the more students and instructors interacted and when students engaged in the classroom decision making process. Further, they found that both teacher nonverbal immediacy and student attendance were positively related to student affective learning. Overall, research has identified affective learning as important to the overall learning of students and instructor behaviors can influence student affective learning. With an understanding of positive learning outcomes that can be enhanced by strategic ambiguity, instructor messaging as a behavior that can promote these positive learning outcomes will be employed.

\section{Instructor Messaging}

The student characteristics and positive learning outcomes above are important in educational settings; however, communication is the vehicle through which all of these variables are fostered in the classroom. Instructors make a variety of decisions in teaching, especially regarding the manner in which to present various information to students. Recall that Titsworth and Mazer (2010) concluded that clarity is a process and should be studied as a process wherein students and teachers communicate to establish clarity. Klyukovski and Medlock-Klyukovski noted that "there appears to be a dialogical relationship between teacher clarity and instructor strategic ambiguity where both contribute to student meaning negotiations" (p. 269); thus, instructor communication may be the vehicle for student acceptance of strategic ambiguity in classroom assessment. Instructional communication is defined as "the process by which teachers and students stimulate meanings in the minds of each other using verbal and nonverbal messages" (Mottet \& Beebe, 2006, p. 5). Instructional communication is dedicated to meaning 
making in the classroom. Instructor messages are one component of instructional communication and should be explored when discussing the implementation of strategic ambiguity in classroom assessment. Effective teachers will use many communication behaviors, including clarity, immediacy, and credibility, to present material in a way that helps students remember the content (Chesebro \& Wanzer, 2006). The manner in which strategic ambiguity is communicated has implications for how it is received.

In order to get student buy-in for strategic ambiguity in the classroom, DeRoma et al. (2003) suggested that instructors should have conversations with students regarding the benefits of strategic ambiguity. One way to show students the meaningfulness of assignments is through content relevance, which is the student's perception of whether or not course content has a positive impact on some component of their life (Chesebro \& Wanzer, 2006). Dannels (2015) advised that telling students why a course matters for their life can promote student engagement. Likewise, Visser and Visser (2004) argued that because ambiguity is relevant in everyday life, the use of ambiguity in the classroom should be clearly acknowledged, helping students understand that the use of ambiguity in the classroom will be beneficial to them in their futures. For this reason, instructors' messages regarding ambiguity could create the content relevance necessary for students to accept the use of strategic ambiguity. If students dislike strategic ambiguity, it could be because they are unfamiliar with the outcome, which makes them afraid of the unknown. This is consistent with the conclusions of Bledsoe and Baskin (2014) who contended that students experienced a lot of fear in the classroom, which was reduced by explaining the purpose of the assignment. Two types of fear the authors addressed in their research are performance-based anxiety and fear of failure, which could be enhanced if a strategically ambiguous assignment does not clearly outline how a student can get a good grade; 
therefore, explaining the purpose of using strategic ambiguity could reduce the students' fear of the assignment. Given the central role of communication in the classroom, it is probable that the successful implementation of strategic ambiguity in classroom assessment hinges on the manner in which the teacher communicates the construct to students.

\section{Chapter Summary}

This chapter provides an overview of constructs related to the implementation of strategic ambiguity in classroom assessments. First, an overview of clarity research highlighted the space

for strategic ambiguity in classroom research. Strategic ambiguity is relevant when students must create a product through classroom assessment. Further, a student's TFA, mindset, as well as learning orientation and grade orientation may impact their reaction to strategic ambiguity in assessment; however, if successful, the positive learning outcomes of learner empowerment and motivation should be enhanced. The means through which this can happen is instructor communication. This chapter provided an in-depth review of research relevant to the current study. 


\section{CHAPTER III: METHODS}

The overarching purpose of this study was to understand how clarity or strategic ambiguity in assessment impacts learning outcomes, especially given the various characteristics or dispositions that students possess. With an understanding of research related to these variables, specific research questions were posed, and hypotheses were advanced to quantitatively test each one.

\section{Hypotheses and Research Questions}

When giving an assignment, instructors have choices regarding how to communicate that assignment to students. The communication approach instructors choose can influence a variety of factors. These factors must be considered when employing strategic ambiguity in classroom assessments. Instructional communication research demonstrates that clearly communicating a message to students is good pedagogy (Titsworth \& Mazer, 2010). Problematically, though, explicit clarity is the main type of clarity that has been explored. The clear and intentional use of strategic ambiguity is under explored, which is the focus of the present study. Research has shown mixed results regarding student's reactions to strategic ambiguity in the classroom, even when instructors clearly explained their purpose for employing it (Brunson \& Vogt, 1996; Gabella, 1995; Rippin et al., 2002). Scholars have asserted that although students may feel uncomfortable with ambiguity in assignments, instructors should still use such assignments to help students learn (DeRoma et al., 2003; Vissor \& Vissor, 2004). Ideally, classroom assessments should promote learner empowerment and affective learning. An instructor's use of clear messages in lectures has implications for student motivation (Bolkan et al., 2016), which is the foundation for learner empowerment (Frymier et al., 1996). Frymier et al. found that clarity is a strong predictor of student empowerment; howevßer, clarity was studied as a process 
variable. Fittingly, they suggested that communication could be the primary factor impacting learning empowerment. Communication is central to the implementation of strategic ambiguity. As such, the following research question was asked:

$\mathrm{RQ}_{1}$ : Does the dimensions of student learner empowerment differ when faced with instructors' use of clear assignments, ambiguous assignments, or strategically ambiguous assignments?

Research has suggested that affective learning is important for student learning (McBride et al., 2016). Further, teacher clarity is important to student affective learning (Chesebro \& McCroskey, 2001; Hunt et al., 2007). Because affective learning is an important outcome for students, the following research question is posed:

$\mathrm{RQ}_{2}$ : Does student affective learning differ when faced with instructors' use of clear assignments, ambiguous assignments, or strategically ambiguous assignments?

Additionally, students come to the classroom with specific characteristics that may impact their reaction to strategically ambiguous classroom assignments. DeRoma et al. (2003) found that college students' TFA impacted their reaction to course structure and students with higher TFA were more comfortable with less course structure. Additionally, Sorrentino et al. (1984) found that college students perform better on tasks that are consistent with their certainty orientation. It seems, then, that TFA is relevant to students' reactions to classroom activities. Strategic ambiguity lacks structure; thus, the following hypothesis is advanced:

$\mathrm{H}_{1}$ : TFA is related to the combination of affective learning and learner empowerment $\left(\mathrm{H}_{1 \mathrm{a}}\right)$, and while controlling for TFA, instructor messaging will predict student affective learning $\left(\mathrm{H}_{1 b}\right)$ and learner empowerment $\left(\mathrm{H}_{1 \mathrm{c}}\right)$ for that assignment. 
Further, a student's mindset has been shown to impact the amount of effort they will put forth in a class or on an assignment (Dweck, 2000; Dweck et al., 1993). Incremental theorists are better able to work through every day challenges (Martin et al., 2013) and hold a belief that hard work can lead to success (Blackwell et al., 2007). Conversely, entity theorists are more likely to give up when faced with a challenge (Dweck, 2000). The structure of a strategically ambiguous assignment is a unique challenge for students who are not used to this type of assignment and it may require them to exert greater effort. This leads to the following hypothesis:

$\mathrm{H}_{2}$ : Mindset is related to the combination of affective learning and learner empowerment $\left(\mathrm{H}_{2 \mathrm{a}}\right)$, and, while controlling for student mindset, instructor messaging will predict student affective learning $\left(\mathrm{H}_{2 b}\right)$ and learner empowerment $\left(\mathrm{H}_{2 \mathrm{c}}\right)$ for that assignment.

Finally, student learning and grade orientation influences students' expected instructor communication behaviors (Frymier \& Weser, 2001). A student's learning or grade orientation has implications for their reactions to potential failure (Dweck, 2000). Students who are more grade-oriented are less likely to participate in learning opportunities (Pollio \& Beck, 2000). Additionally, teacher clarity is more important for students who are grade-oriented. Accordingly, the following hypothesis is advanced:

$\mathrm{H}_{3}$ : Learning orientation and grade orientation are related to the combination of affective learning and learner empowerment $\left(\mathrm{H}_{3 \mathrm{a}}\right)$, and while controlling for student learning orientation and grade orientation, instructor messaging will predict student affective learning $\left(\mathrm{H}_{3 b}\right)$ and learning empowerment $\left(\mathrm{H}_{3 c}\right)$ for that assignment.

A quasi-experimental, quantitative research design was employed to measure how student characteristics of TFA, mindset, along with learning orientation and grade orientation, influence students' response to assignments with varying instructor messages. Specifically, 
students completed a survey regarding their general characteristics. They were then shown one of three assignment and message conditions in which deliberate instructor messages were manipulated. The three conditions were (1) clear, (2) ambiguous, and (3) strategically ambiguous instructor messages. Finally, they responded to another survey answering questions regarding the desired outcomes of assignments, which included learner empowerment and affective learning.

\section{Procedures}

All procedures were approved by the Institutional Review Board (IRB) before research began. The survey was administered electronically using Qualtrics software. Participants received the survey electronically, either from their instructor, through a university e-mail list, or from the School of Communication's research pool. Participants were asked to review an informed consent form that explained that participation is voluntary, responses are anonymous, and that all research has been approved through the university's IRB. After agreeing to participate in the survey, all participants responded to the same student characteristic scales, which measured their TFA, mindset, and learning or grade orientation. Then, Qualtrics randomly assigned participants to one of three experimental conditions: (1) clear condition, (2) ambiguous condition, and (3) strategically ambiguous condition. Participants were then asked to review an assignment they could receive in a course and watch a short video of an instructor explaining that assignment (see Appendix A).

All three conditions received the same initial paragraph explaining the assignment. They then watched a video that explained the assignment. All of the videos used the same actor and assignment to keep them consistent. They were recorded in a mock classroom with an instructor standing in front of a white board that had information about the assignment on it. All of the visuals were the same except what was written on the board. Each video was screened by a panel 
of experts which included the researcher and the committee co-chairs. This ensured that nothing was different other than the script.

The clear condition also received a step-by-step list of directions for how to complete the assignment. In this condition, the instructor walked through the assignment, clearly telling students what to do to complete the assignment. The instructor offered guidance for completing the assignment, including the use of examples. Additionally, the step-by-step details of the assignments were listed on a while board behind the instructor while explaining the assignment. Finally, the grading criteria for the assignment was written on the board.

The ambiguous condition assignment included only the assignment description paragraph. The instructor gave a brief message to simply present students with the assignment. The board message indicated the grading criteria in the same format as the clear condition. However, the only additional message on the board said, "Sell a product, use persuasive principles."

Finally, the strategically ambiguous condition included only the assignment paragraph; however, the instructor provided more detail regarding the nature of the assignment. The instructor message intentionally pointed out that the assignment was ambiguous on purpose to allow for student autonomy. Further, the instructor pointed out the benefits of working through ambiguity as it is relevant in life and the workplace. The grading criteria were presented on the board in the same way as the other conditions. The same message from the ambiguous assignment was presented with the additional of the phrase, "be creative." For the purposes of this study, it is possible that employing ambiguity could be strategic without providing an explanation; however, for the purposes of this study, strategic ambiguity includes the use of a rationale, whereas ambiguity does not. 
Before reviewing the assignment, participants were instructed that they were going to see an assignment they could receive in a class and watch a video of a teacher explaining that assignment. They were asked to keep that assignment and message in mind as they answered the remaining questions. After reading the scenario and watching the video, all participants were asked to complete scales regarding their learner empowerment and affective learning. Finally, participants answered demographic questions including gender, age, race, year in school, GPA, and major.

\section{Pilot Study}

Before distributing the official survey, an informal pilot study was conducted. First, a panel of experts comprised of the researcher and dissertation committee collaborated to trim down the pool of questions and ensure questions used wording consistent with what was being studied. Next, the researcher identified individuals not eligible to be participants in the primary study and asked them to take the survey. Participants were close acquaintances with the researcher and were all college graduates. Participants received the survey link and took the survey. They then had an interview with the researcher to answer questions that sought to determine if the survey direction were clear and easy to follow and if there were any errors in the survey construction. Participants were then asked what they thought the outcome of an assignment like this would be and if they could understand why an instructor would offer an assignment like this. Finally, participants were asked if they felt the instructor in the video was clear and/or offered guidance to determine if the conditions were manipulated correctly. Through this process some questions were clarified, but overall, results indicated that the survey was sufficient, and the conditions were appropriately manipulated. Exploratory factor analysis (EFA)

procedures were conducted on the final scales, and those will be discussed in the next chapter. 


\section{Primary Study Participants}

A convenience sample of graduate and undergraduate students at Illinois State University (ISU) were invited to participate in the research study. They were solicited to participate in the study in a variety of ways. First, this research was available on the School of Communication's research pool, which is available to all students in the department with some instructors offering credit or extra credit for participating. Further, specific instructors in both the School of Communication and School of Teaching and Learning were asked to encourage their students to participate in the study. Finally, undergraduate and graduate students who subscribe to a campus list agreeing to participate in research studies were sent an e-mail that asked them to participate in the research.

There were initially 586 respondents. Factor analysis was conducted using the full dataset. Before conducting tests to answer the researcher questions and hypotheses, participants who did not make it past the survey condition were removed, making the dataset 488 cases. Finally, the data were screened for outliers, which indicates that participant scores were more than three standard deviations from the mean. There were 62 cases removed due to outliers. The final dataset was included 426 completed surveys comprised of students at a large Midwestern university in the Spring 2019 semester. The sample consisted of 316 females $(74.2 \%), 98$ (23\%) males, two transgender individuals (.5\%), two (.5\%) chose not to specify gender, and six $(1.4 \%)$ did not respond to the question. The average age of the participants was $21.52(S D=4.80)$, ranging from 18 to 60 years old. The sample was comprised of primarily White/Caucasian individuals (80.3\%), followed by Black/African American (7\%), Hispanic/Latino(a) (7.5\%), Asian/Pacific Islander (3.1\%), multiracial (.7\%), other (.2\%), Native American (.2\%), and four $(.9 \%)$ did not respond. Most of the participants were freshman $(29.3 \%)$, followed by junior 
$(24.2 \%)$, senior $(21.8 \%)$, graduate student, master's or doctoral $(12.4 \%)$, sophomore $(11.7 \%)$, and two participants $(.5 \%)$ did not respond to this survey item. The mean GPA was $3.31(S D=$ .54), ranging from .40 to 4.00 . Students from a variety of majors took the survey including majors from criminal justice, technology, business, and nursing. There were over 20 different majors represented. Only four majors had over 30 participants each and only two majors had over 100 participants, so Communication (30.5\%) and Education (22.3\%) majors stood alone, and all other majors $(42.5 \%)$ were grouped together for comparison purposes. There were 20 $(4.7 \%)$ of participants that did not report their major. Finally, very few students $(6.1 \%)$ reported that they had taught a course and the rest (93.4\%) reported they had not been the instructor of record. Two students $(.5 \%)$ did not respond to this question.

Cell sizes for each of the three conditions were equal with 134 students $(31.5 \%)$ completing the clear condition, 150 (35.2\%) completing the ambiguous condition, and 142 (33.3\%) completing the strategically ambiguous condition.

Measures

The survey included 72 items measured on Likert response scales as well as seven demographic questions (see Appendix B). Items that are marked as recoded were reverse coded to flip the polarity of the statement as the items were negatively worded.

\section{Tolerance for Ambiguity}

TFA was measured using McLain's (2009) shortened TFA scale. The scale is titled Multiple Stimulus Types Ambiguity Tolerance - II (MSTAT-II) and consists of 13 items on a five-point Likert Scale ranging from 1 (strongly disagree) to 5 (strongly agree). This scale is recommended to be used in place of the original MSTAT-I scale when space on a survey is limited (Furnham \& Marks, 2013). Alpha reliability for the scale is .83 (McLain, 2009). TFA is 
operationalized as a student's general attitude toward ambiguous or uncertain situations. The scale seeks to understand a person's rejection or attraction to situations, or which are unfamiliar, complex, uncertain, or have multiple interpretations. When completing the scale, students were asked to think of this in consideration of their role as a student in an educational context. Example items include, "I don’t tolerate ambiguous situations well," and "I enjoy tackling problems that are complex enough to be ambiguous." After reverse coding necessary survey items, the scores of this scale were summed to provide a score for TFA, where higher scores indicate higher TFA. EFA procedures were calculated on this scale, the results of which will be reported in Chapter 4.

\section{Learning Orientation and Orientation Grade Orientation}

A scale was written to measure learning or grade orientation. The scale consists of 16 items on a 5-point Likert Scale ranging from 1 (strongly disagree) to 5 (strongly agree). The scale was developed to measure the extent to which students focus on grades verses learning as an outcome of education, with eight items indicating a grade orientation and eight items indicating a learning orientation. Example items for grade orientation include, "When completing an assignment, I am most concerned with my grade," and "My end goal when taking a course is to get a good grade." Example items for learning orientation include, "I enjoy learning new information," and "Learning is the most important component of college." For each scale, scores were summed to determine a score for learning orientation and grade orientation, where higher scores indicated higher levels of learning orientation and grade orientation, respectively. EFA procedures were calculated on this scale, the results of which will be reported in Chapter 4. 


\section{Mindset}

To measure mindset, Dweck’s (2000) Theories of Intelligence Scale-Self Form was employed. The survey was designed to explore ideas about intelligence as either static or malleable. It consists of six items on a 6-point Likert scale ranging from 1 (strongly agree) to 6 (strongly disagree). Blackwell et al. (2007) reported a respectable internal reliability of .78 for the scale. Mindset is operationalized as the extent to which students feel they can change their level of intelligence. There are three items related to entity theory mindsets and three items related to incremental theory mindsets. This scale was used to understand a student's general disposition toward intelligence. An example entity theory mindset item is, "You have a certain amount of intelligence and you can't really do much to change it.” An example incremental theory mindset item reads, "No matter who you are, you can significantly change your intelligence level." The incremental theory items were reverse scored to get a mean intelligence score with one representing more of an entity theory and six representing more of an incremental theory. After reverse coding the items, scores of this scale were summed to provide a score for mindset, with higher scores indicating more of an incremental mindset. EFA procedures were calculated on this scale, the results of which will be reported in Chapter 4.

\section{Instructor Messaging Manipulation Check}

Instructor messaging was controlled for in the writing of the scenarios. Participants received one of the following conditions: clear assignment, ambiguous assignment, strategically ambiguous assignment. Instructor messaging was operationalized as the amount of guidance, both written and oral, the instructor offered when giving the assignment. Four items were added to the survey as a manipulation check to ensure participants perceived the instructor messaging correctly. Example items include, "This assignment has very clear guidelines" and "I thought the 
instructor specifically communicated that they were being vague on purpose. This variable was included to determine if participants perceived varying levels of instructor messaging in their condition. EFA procedures were calculated on this scale, the results of which will be reported in

\section{Chapter 4.}

\section{Learner Empowerment}

Learner empowerment was measured using a modified version of the Learner Empowerment Scale developed by Weber, Martin, and Cayanus (2005) and questions from Frymier et al.'s (1996) scale. Learner empowerment is operationalized as the extent to which students view the assignment presented as meaningful and how confident they are in their ability to complete the assignment. Weber et al. (2005) developed an 18-item scale measuring learner empowerment, which has been used as either a five or seven-point Likert scale. The present study provided response options ranging from 1 (completely disagree) to 5 (completely agree). The scale has three factors: impact, meaningfulness, and competence. For this study, the impact factor does not apply so it will be removed. As such, the total number of items for this portion of the scale will be 12. Example items include, "The work I will do on this assignment is meaningful to me," and "I believe in my ability to do well on this assignment." Weber et al. (2005) found that both factors for the scale were reliable with the meaningfulness factor reporting a .91 reliability and the competence factor reporting an excellent reliability of .92 .

Additionally, the language of the scale was written to be about a specific class, and for this study it was re-worded to be about the assignment participants read in the study. Although the items from Weber et al.'s (2005) impact scale were not relevant, there were relevant impact item's on Frymier et al.'s (1996) impact scale. These items were measured on a Likert-type Scale- anchored by 0 (never) and 4 (very often). Seven items from this scale were modified to 
ask about a specific assignment. They were measured on a 5-point Likert Scale ranging from 1 (strongly disagree) to 5 (strongly agree). Example items include, "I have a choice in the methods I can use to complete this assignment" and "I cannot influence what happens on this assignment." After reverse coding necessary items, the scores of this scale were summed to provide a score for each subscale of learner empowerment, with higher scores indicating higher levels of learner empowerment. EFA procedures were calculated on this scale, the results of which will be reported in Chapter 4.

\section{Affective Learning}

A scale was written to measure affective learning. There are currently affective learning scales; however, they are not adequate for the purposes of this study. The commonly used affective learning scale in instructional communication asks students to respond to bipolar scales regarding their judgement on conditions in a specific class, asking about concepts including instructor behaviors and likelihood of taking the course again (Kearney, 1994). Because this study seeks to explore students perceived affective learning regarding a specific assignment given to them in the survey and not affect related to a specific class, an affective learning scale was written to account for this difference. Adjectives from the initial scale were used in the creation of this scale. The scale consists of 14 items measured on a 5-point Likert Scale ranging

from 1 (strongly disagree) to 5 (strongly agree). Example items include, "This assignment would allow me to learn," and "I like this type of assignment." After reverse coding necessary items, the scores of this scale were summed to provide a score for scenario flexibility, where higher scores indicate higher levels of affective learning. EFA procedures were calculated on this scale, the results of which will be reported in Chapter 4 . 


\section{Data Analysis}

Multiple tests were run to analyze the data. Two different one-way analysis of variance tests (ANOVAs) were conducted to ensure the conditions were manipulated correctly. The first was run to ensure that instructor clarity was manipulated correctly and the second was run to ensure that assignment vagueness was manipulated correctly. When analyzing an ANOVA, researchers also examine the post hoc test that the ANOVA produces. Additionally, correlation analysis was run to determine relationships among variables.

To answer RQ1, a one-way ANOVA was run to determine if the survey condition had an impact on learner empowerment. Alpha was set at .05. The independent variable was survey condition (clear assignment, ambiguous assignment, or strategically ambiguous assignment) and the dependent variables was learner empowerment. To answer RQ2, a one-way ANOVA was run to determine if the survey condition had an impact on affective learning. Alpha was set at .05. The independent variable was survey condition (clear assignment, ambiguous assignment, or strategically ambiguous assignment) and the dependent variable was affective learning.

To test the hypotheses, several multivariate analysis of covariances (MANCOVA) procedures were run. MANCOVAs were used for data analysis due the presence of multiple dependent variables and covariates. For each MANCOVA, the independent variable was survey condition (clear assignment, ambiguous assignment, or strategically ambiguous assignment) and the dependent variables were affective learning (H1a, H2a, H3a) and learner empowerment (H1b, H2b, H3b). The covariates were run separately, so three MANCOVAs were run with TFA (H1), mindset (H2), and learning or grade orientation $(\mathrm{H} 3)$ serving as covariates in each. 


\section{Chapter Summary}

Multiple scales were found or created to measure the variables. After the study was approved by IRB a light pilot study was conducted to determine clarity in the survey directions and instrument. The pilot test was successful, determining that the conditions were manipulated correctly, and scales were finalized; thus, the data was ready for analysis. The next chapter will show the results of EFA procedures which determined validity and reliability of the measures and results of the data analysis. 


\section{CHAPTER IV: RESULTS}

\section{Factor Analysis}

For scale development purposes and to validate the survey measures, a series of EFA procedures were run to ensure accuracy, test the validity of the questions, and analyze the dimensionality of the variables while examining factors or subscales. Scale development is discussed in the results chapter since original scale development was conducted. EFA procedures were conducted using the full dataset before removing cases. Kaiser-Meyer-Olkin (KMO) was used to verify sampling accuracy, where .6's are acceptable (Wrench, Thomas-Maddox, Richmond, \& McCroskey, 2008) and .8's are ideal (Mertler \& Vannatta, 2005); as well as Bartlett's test of sphericity, which should be significant. Items were not retained if they did not meet a $60 / 40$ loading criteria, meaning the primary loading is at least .60 and the secondary loading of .40 or below. The higher the primary factor loading is, the better the survey item loads to a particular factor. Secondary loadings should be opposites, meaning the numbers while be low or even negative. Low secondary loadings indicate that the factor analysis worked. Eigenvalue scores and a visual inspection of the scree plot were checked; only factors with eigenvalue scores greater than 1.00 were retained. Eigenvalues help to identify which factors should be extracted and how many factors should be extracted. An iterative data reduction process was completed during the series of EFAs all necessary scales contained in the survey using SPSS. As EFA procedures were conducted, items were removed one at a time in an attempt to create cleaner factor loadings with has many items as possible. Survey items for each variable were analyzed through a series of EFAs and scale reliability procedures. EFAs were calculated for six variables. Also, reliability was evaluated according to DeVellis' (2003) criteria where .64 and below is unacceptable, .65-.70 is minimally acceptable, $.70-.80$ is respectable, $.80-$ 
.90 is very good, and .90 and above is excellent. DeVellis uses very particular words to describe the level of quality of scale's reliability based on the Cronbach's alpha coefficient. Alpha helps to demonstrate how consistently a scale will perform. Variance was also examined. Variance refers to the percent of variance the factors determine. For example, if a variable can fluctuate by one hundred percent, the variance number explains how much of that one hundred percent is accounted for by the factors present. Generally, numbers over $50 \%$ are a good predictive model as they can predict at least $50 \%$ of the variance in a variable.

\section{Learning Orientation and Grade Orientation}

An initial EFA was conducted with all learning orientation and grade orientation items together. This produced a three-factor solution, but the factors did not meet the loading criteria, generally. Next, analysis was run forcing a single factor solution. Several items did not meet the loading criteria and items were iteratively removed; however, this still did not produce a viable scale. Although this scale was written for the present study, past research has tested learning orientation and grade orientation as separate factors since they are not conceptually related (Pollio \& Beck, 2000). For this reason, the final EFAs were conducted on the eight-item learning orientation and eight-item grade orientation scales separately. Items are labeled in Appendix B. First, the learning orientation scale was analyzed. Through a series of EFA procedures, three original survey items were iteratively eliminated due to low primary factor loadings that did not meet the $60 / 40$ criteria. Specifically, items 11,8 , and 4 were removed in that order. The final EFA for learning orientation produced an acceptable one-factor solution. Both the KMO (.790) and Bartlett's test $\left[\chi^{2}=741.107(10), p<.001\right]$ were acceptable. The factor had an eigenvalue of 2.09 , which was confirmed by the scree plot. The single factor solution explained $41.81 \%$ of variance. The final factor was comprised of four items and produced an overall alpha coefficient 
reliability of .75 for the scale, which is respectable. The factor analysis indicates that the learning orientation variable is measured on a scale comprised of five items that load on one factor. Items ask participants about their regard for learning in the classroom. See Table 1 for factor loadings.

Table 1

Factor Loadings for Learning Orientation Scale

Survey Item

Learning

Orientation

6. When taking a class, I enjoy the process of learning.

15. I came to college to learn.

10. Learning is the most important componenat of college.

.622

2. I enjoy learning new information.

14. I like to learn new information, even if I am never tested on that information.

$\begin{array}{rr}\text { Eigenvalue } & 2.09 \\ \text { \% of Variance } & 41.81 \\ & \\ \text { Cronbach's Alpha } & .75\end{array}$

Note. Underlined factor coefficients show acceptable factor loadings. Items that are not underlined did not load on the corresponding factor.

The grade orientation scale began with eight items and, through a series of EFA procedures, four items were iteratively eliminated due to low primary factor loadings that did not meet the 60/40 criteria. Specifically, items 12, 1, 7, and 13 were removed in that order. The final EFA for grade orientation produced an acceptable one-factor solution. Both the KMO (.745) and Bartlett's test $\left[\chi^{2}=642.039(6), p<.001\right]$ were acceptable. The factor had an eigenvalue of 1.88 , 
which was confirmed by the scree plot. The single factor solution explained $47.01 \%$ of variance. The final factor was comprised of four items and produced an overall alpha coefficient reliability of .77 for the scale, which is respectable. The factor analysis indicates that the grade orientation variable is measured on a scale comprised of four items that load on one factor. Items ask participants about their focus on grades in academia. See Table 2 for factor loadings.

Table 2

Factor Loadings for Grade Orientation Scale

$\begin{array}{lr}\text { Survey Item } & \text { Grade } \\ \text { Orientation }\end{array}$

Orientation

3. When completing an assignment, I am most concerned with my grade.

5. My end goal when taking a course is to get a good grade.

9. Grades are the most important thing in college.

16. I am only satisfied when my learning if a receive a good grade.

$\begin{array}{rr}\text { Eigenvalue } \quad 1.88 \\ \text { \% of Variance } & 47.01\end{array}$

Cronbach's Alpha

Note. Underlined factor coefficients show acceptable factor loadings.

\section{Mindset}

This scale was comprised of six items. All original survey items were kept because they met the 60/40 criteria. The final EFA produced an acceptable one-factor solution. Both the KMO (.843) and Bartlett's test $\left[\chi^{2}=3033.764(15), p<.001\right]$ were acceptable. The factor had an eigenvalue of 3.85, which was confirmed by the scree plot. The single factor solution explained 
$64.28 \%$ of the variance. The factor produced an overall alpha coefficient reliability of .91 for the scale, which is excellent. The factor analysis indicates that the mindset variable is measured on a scale comprised of six items that load on one factor. Items ask participants about whether or not they think their intelligence is fixed or malleable. See Table 3 for factor loadings.

Table 3

Factor Loadings for Mindset Scale

\begin{tabular}{lc}
\hline Survey Item & Mindset
\end{tabular}

5. You can always change how intellegent you are. [Recoded]

6. No matter how much intelligence you have, you can always change it quite a bit. [Recoded]

.821

4. No matter who you are, you can change your intellegence a lot. [Recoded] $\underline{.813}$

3. You can learn new things, but you can't really change your basic intelligence.

.792

1. You have a certain amount of intelligence and you can't really do much to $\quad \underline{.788}$ change it.

2. Your intelligence is something about you that you can't change very

.775 much.

$\begin{array}{rr}\text { Eigenvalue } & 3.85 \\ \text { \% of Variance } & 64.28 \\ \text { Cronbach's Alpha } & .91\end{array}$

Note. Underlined factor coefficients show acceptable factor loadings.

\section{Tolerance for Ambiguity}

The TFA scale was comprised of 13 items. First, an EFA procedure was run on the entire scale. This produced a three-factor solution that had poor primary loadings. Past research has 
reported this as a single factor solution, but with poor validity (McLain, 2009). For the next EFA, a single factor was forced. This still had poor ladings; however, items were iteratively removed. Specifically, items $9,5,2,6,10,13,7,8,4$, and 12 were removed in that order. This produced a three-item scale. Another EFA was run allowing for the original three-factor solution and items were iteratively removed. This resulted in in a scale producing the same items. As a result, the EFA with a forced one-factor solution with three items reported. Both KMO (.700) and Bartlett's test $\left[\chi^{2}=515.802(3), p<.001\right]$ were acceptable. The one-factor solution had an eigenvalue of 1.67 , which was confirmed by the scree plot. The solution explained $55.76 \%$ of the variance. The final solution produced an overall alpha coefficient reliability of .78, which is excellent. The factor analysis indicates that the TFA variable is measured on a scale comprised of three items that load on one factor. Items ask participants how they respond to ambiguous situations. See Table 4 for factor loadings. This factor likely performed poorly due to the poor validity of the original scale that is commonly used.

\section{Instructor Messaging Manipulation Check}

This scale was comprised of four questions. The EFA produced an acceptable two-factor solution. KMO (.548) was slightly below acceptable, but Bartlett's test $\left[\chi^{2}=440.992(6), p<\right.$ .001] was significant. Although KMO was lower than desired, Bartlett's test was significant and there was a sufficient number of participants. Additionally, it did account for over $50 \%$ of the variance and the factor loadings were acceptable. The first factor had eigenvalues over 1.00, while the second factor had an eigenvalue of .90. The two-factor solution collectively explained $57.57 \%$ of the variance. See Table 5 for factor loadings.

The first factor, which was labeled Clear, explained $35.04 \%$ of the variance with an eigenvalue of 1.40 . The second factor, which was labeled Vague, explained $22.52 \%$ of the 
variance with an eigenvalue of .90 . Both factors consisted of two items. The Clear subscale had items related to participants' perception that the instructor gave clear guidelines. The Vague subscale asked items related to participants perception that the assignment was vague. The final two-factor solution produced an overall alpha coefficient reliability of .17 for the scale. The Clear factor $(\alpha=.76)$ produced respectable reliability and the Vague factor $(\alpha=.56)$ produced unacceptable reliability. The manipulation check worked as participants who received the clear condition reported the assignment as clearer and less vague. There were no definite differences between the ambiguous and strategically ambiguous conditions, which is understandable since both conditions were meant to be vague. While the manipulation check worked, the manipulation of instructor messaging could have been cleaner as there were not distinct differences between each condition and the manipulation check loaded on two dimensions. Despite poor overall reliability, the manipulation check worked on some level, thus, both factors were retained in order to explain the two factors used in the one-way ANOVA used for the manipulation check. The factor analysis indicates that the instructor messaging is a variable that is measured by four items and loads on two factors, clear and vague. See Table 5 for factor loadings. 
Table 4

Factor Loadings for Tolerance for Ambiguity Scale

Survey Item

Tolerance for Ambiguity

3. I don't tolerate ambiguous situations well. [Recoded]

11. I dislike ambiguous situations.

1. I don't tolerate ambiguous situations well.

$$
\begin{array}{rr}
\text { Eigenvalue } & 1.67 \\
\text { \% of Variance } & 55.76
\end{array}
$$

Cronbach's Alpha $\quad .78$

Note. Underlined factor coefficients show acceptable factor loadings.

Table 5

Factor Loadings for Instructor Messaging Manipulation Check Scale

Survey Item

Clear

Vague

3. This instructor offers the appropriate amount of guidance.

$\underline{.863}$

.054

1. This assignment has very clear guidelines.

.729

$-.230$

2. I felt the instructor specifically communicated that they were being vague on purpose.

$.063 \quad .713$

4. This assignment is ambiguous.

Eigenvalue $\quad 1.40$

Note. Underlined factor coefficients show acceptable factor loadings for the corresponding items and factors. 


\section{Learner Empowerment}

The learner empowerment scale was comprised of 19 items. In other studies, the first six items were one factor, titled Meaningfulness, the second six items were a second factor, titled Competence, and the final seven items were a third factor, titled Impact (Frymier et al., 1996; Weber et al., 2005). It was assumed the factors were related enough conceptually so they were analyzed in the same EFA procedure. The first EFA procedure produced a four-factor solution; however, since past studies have produced three-factor solutions, three factors were forced in the next analysis. After forcing three factors, items were iteratively removed that did not meet loading criteria. Specifically, items 17, 18, and 19 were removed. This produced an acceptable

three-factor solution consisting of 16 items. Both the KMO measure (.850) and Bartlett's test $\left[\chi^{2}\right.$ $=4592.758$ (136), $p<.001]$ were acceptable. Three factors had an eigenvalue over 1.00, which was confirmed by the scree plot. The three-factor solution collectively explained $54.38 \%$ of the variance. See Table 6 for the factor loadings.

The first factor explained $19.98 \%$ of the variance with an eigenvalue of 3.39 , the second factor explained $19.90 \%$ of the variance and had an eigenvalue of 3.38 , while the third factor explained $14.49 \%$ of the variance and had an eigenvalue of 2.45 . The first factor, Competence, consisted of six items, the second factor, Meaningfulness, consisted of six items, and the third factor, Impact, consisted of four items. The final three-factor solution produced an overall alpha coefficient reliability of .87, which is very good. The Competence factor $(\alpha=.87)$ produced very good reliability, the Meaningfulness factor $(\alpha=.87)$ produced very good reliability, and the Impact factor $(\alpha=.78)$ produced respectable reliability. The factor analysis indicates that the learner empowerment variable was comprised of a 16-item scale, loading on three factors: 
competence, meaningfulness, and impact. This is consistent with past scales that measured learner empowerment.

\section{Affective Learning}

The original scale consisted of 14 items. The first EFA produced a three-factor solution; however, loadings were not sufficient. Next, an EFA was run with a forced one-factor solution to attempt to simplify the factor. Through a series of EFA procedures, three items were iteratively removed. Specifically, items 3, 14, and 6 were removed in that order. The final EFA produced an acceptable single factor solution comprised of 11 items. Both KMO (.925) and Bartlett's test $\left[\chi^{2}\right.$ $=3765.015(55), p<.001]$ were acceptable. The one-factor solution had an eigenvalue of 6.03, which was confirmed by the scree plot. The solution explained $54.86 \%$ of the variance. Since this was an acceptable, more simple solution, the single factor solution was used. The final solution produced an overall alpha coefficient reliability of .92 , which is excellent. The factor analysis indicates that the affective learning variable is measured on a scale comprised of 11 items that load on one factor. Items ask participants about their feelings about a specific assignment. See Table 7 for factor loadings.

\section{Scale Development}

Based on the results of the EFA procedures, the final survey instrument consisted of 48 items. The independent variable scales learning orientation, grade orientation, mindset, tolerance for ambiguity, and instructor messaging manipulation check were retained for data analysis. The dependent variables consisted of all three learner empowerment scales, competence, meaningfulness, and impact, as well as the affective learning scale. 
Table 6

Factor Loadings for Learner Empowerment Scale

\begin{tabular}{|c|c|c|c|}
\hline Survey Item & Competence & Meaningfulness & Impact \\
\hline 7. I can do well on this assignment. & .801 & .029 & .224 \\
\hline $\begin{array}{l}\text { 9. I believe in my ability to do well on this } \\
\text { assignment. }\end{array}$ & .770 & .057 & .269 \\
\hline $\begin{array}{l}\text { 8. I don't think that I can do well on this assignment. } \\
\text { [Recoded] }\end{array}$ & .766 & .089 & -.020 \\
\hline 10. I have what it takes to do well on this assignment. & .723 & .068 & .223 \\
\hline $\begin{array}{l}\text { 11. I don't have the confidence in my ability to do } \\
\text { well on this assignment. [Recoded] }\end{array}$ & .677 & .076 & -.053 \\
\hline 12. I feel very competent on this assignment. & .616 & .162 & .252 \\
\hline $\begin{array}{l}\text { 2. The work that I will do for this assignment is } \\
\text { valuable to me. }\end{array}$ & .012 & .817 & .197 \\
\hline $\begin{array}{l}\text { 1. The work that I will do on this assignment is } \\
\text { meaningful to me. }\end{array}$ & .025 & .786 & .222 \\
\hline $\begin{array}{l}\text { 6. This assignment would not be important to me. } \\
\text { [Recoded] }\end{array}$ & .143 & .742 & -.071 \\
\hline $\begin{array}{l}\text { 5. The work I will do on this assignment is a waste of } \\
\text { time. [Recoded] }\end{array}$ & .231 & .699 & -.061 \\
\hline $\begin{array}{l}\text { 3. The little things I will learn from this assignment } \\
\text { are useful. }\end{array}$ & .108 & .676 & .277 \\
\hline $\begin{array}{l}\text { 4. This assignment will help me achieve my goals in } \\
\text { life. }\end{array}$ & -.014 & .668 & .159 \\
\hline $\begin{array}{l}\text { 13. I have a choice in the approaches I can use to } \\
\text { complete this assignment. }\end{array}$ & .189 & .018 & .701 \\
\hline $\begin{array}{l}\text { 14. I have freedom to choose among options for this } \\
\text { assignment. }\end{array}$ & .252 & .035 & .677 \\
\hline $\begin{array}{l}\text { 16. I have the option to make important decisions on } \\
\text { this assignment. }\end{array}$ & .104 & .250 & .661 \\
\hline $\begin{array}{l}\text { 15. Alternative approaches to learning are } \\
\text { encouraged through this assignment. }\end{array}$ & -.044 & .195 & .620 \\
\hline $\begin{array}{l}\text { 18. I can determine how to perform tasks for this } \\
\text { assignment. }\end{array}$ & .130 & .061 & .505 \\
\hline Eigenvalue & 3.39 & 3.38 & 2.45 \\
\hline$\%$ of Variance & 19.98 & 19.90 & 14.49 \\
\hline Cronbach's Alpha & .87 & .87 & .78 \\
\hline
\end{tabular}

Note. Underlined factor coefficients show acceptable factor loadings for the corresponding items and factors. Items that are not underlined did not load on the corresponding factor. 
Table 7

Factor Loadings for Affective Learning Scale

Survey Item

Affective

Learning

4. I would enjoy completing an assignment like this.

$\underline{.826}$

5. I would like to have more assignments like this.

.812

12. I think I could learn a lot from an assignment like this.

$\underline{.808}$

11. Assignments like this are valuable to learning experiences.

.769

13. This assignment would allow me to learn.

.760

1. I like this type of assignment.

7. I appreciate the type of thinking required of me through this assignment.

$\underline{.742}$

2. This assignment will improve my thinking ability.

8. I feel good about completing this assignment.

10. This assignment is worthless to me. [Recoded]

9. My initial reaction to being asked to complete this assignment is negative. [Recoded]

$\begin{array}{rr}\text { Eigenvalue } & 6.03 \\ \text { \% of Variance } & 54.86\end{array}$

Cronbach's Alpha $\quad .92$

Note. Underlined factor coefficients show acceptable factor loadings.

\section{Instructor Messaging Manipulation Check}

Two different one-way ANOVAs were conducted to ensure that instructor messaging was manipulated correctly. The first ANOVA was conducted to compare the survey condition (clear, ambiguous, strategically ambiguous) to the participants perception of the instructor being 
clear and findings were significant $\left[F(2,423)=25.51, p=.001, \eta^{2}=.10\right]$. A post hoc GamesHowell test revealed that there was a significant difference between the ambiguous $(M=3.43$, $S D=.88)$, and clear conditions $(M=3.97, S D=.72)$, with participants in the clear condition rating their instructors as using more clarity than those in the ambiguous condition, $p=.001$, $95 \%$ CI $[-.78,-.30]$. If there is not a zero between the lower bound and upper bound confidence intervals, we assume the population means are significant (Pituch \& Stevens, 2016). There was also a significant difference between the strategically ambiguous condition $(M=3.28, S D=.88)$, and the clear condition $(M=3.97, S D=.72)$, with participants in the clear condition rating their instructors as being clearer than those in the strategically ambiguous condition, $p=001,95 \% \mathrm{CI}$ $[-.92,-.44]$. There was no statistically significant difference between participants in the ambiguous condition and the strategically ambiguous condition. Although it may initially be expected that students in the strategically ambiguous condition would perceive more clarity than students in the ambiguous condition, this lack of significance in the manipulation check is understandable given that the instructor message in both the ambiguous condition and the strategically ambiguous condition were intended to be less clear with assignment details, so there should not have been difference between these groups on this scale, so this manipulation check was successful.

The second one-way ANOVA was conducted to compare the instructor messaging condition (clear, ambiguous, strategically ambiguous) to participants perception of the instructor being intentionally vague and findings were significant $\left[F(2,423)=60.96, p=.001, \eta^{2}=.22\right]$. A post hoc Games-Howell test revealed that there was a significant difference between the ambiguous condition $(M=3.95, S D=.74)$, and the strategically ambiguous condition $(M=3.36$, $S D=.70$ ), with participants in the strategically ambiguous condition reporting their instructors as 
being less vague than those in the ambiguous condition, $p=.001,95 \%$ CI $[.37, .81]$. There was a statistical difference between the ambiguous condition $(M=3.95, S D=.74)$, and the clear condition $(\mathrm{M}=2.93, S D=.89)$, with participants in the clear condition ranking their instructors as being less vague than participants in the ambiguous condition $p=.001,95 \%$ CI $[.79,1.24]$. Finally, there was a significant difference between the strategically ambiguous condition $(M=$ $3.36, S D=.70)$ and the clear condition $(\mathrm{M}=2.93, S D=.89)$, with participants in the clear condition reporting their instructors as being less vague than students in the strategically ambiguous condition $p=.001,95 \% \mathrm{CI}[.20, .65]$. The level of vagueness was perceived correctly in each condition; thus, the manipulation check was successful.

\section{Correlations among Variables}

Bivariate correlation tests were used to identify potential relationships between the variables: learning orientation, grade orientation, mindset, TFA, meaningfulness, impact, competence, and affective learning. A weak, positive correlation exists between learning orientation and mindset, $r(426)=-.24, p<.01$. Grade orientation had a negative, weak correlation with learning orientation $r(426)=-.18, p<.01$. Affective learning had a weak, positive correlation with mindset $r(426)=.15, p<.01$, a moderate, positive correlation with learning orientation $r(426)=.31, p<.01$, and a weak, negative correlation with grade orientation $\mathrm{r}(426)=-.13, p<.01$. Meaningfulness had a weak, positive correlation with learning orientation $r(426)=.23, p<.01$, and a strong, positive correlation with affective learning $r(426)=.72, p<$ .01. Impact had a weak, positive correlation with learning orientation $r(426)=.23, p<.01$, and meaningfulness $r(426)=.33, p<.01$, and a moderate, positive correlation with affective learning $r(426)=.43, p<.01$. Competence had a weak, positive correlation with mindset $r(426)=.14, p$ $<.01$, meaningfulness $r(426)=.22, p<.01$, and a moderate, positive correlation with impact 
$r(426)=.36, p<.01$, learning orientation $r(426)=.30, p<.01$ and affective learning $r(426)=$ $.35, p<.01$. Finally, TFA had a weak, positive correlation with mindset $r(426)=.15, p<.01$ and affective learning $r(426)=.16, p<.01$. A full list of correlation statistics is available in Table 8 .

\section{Research Questions}

The first research question asked if student learner empowerment differed when faced with instructors' use of clear assignments, ambiguous assignments, and strategically ambiguous assignments. Three different one-way ANOVAs were conducted to answer this question as the learner empowerment scale consisted of three factors (meaningfulness, impact, competence). The first one-way ANOVA showed that the effect of the survey condition on meaningfulness was significant $\left[F(2,423)=5.97, p=.02, \eta^{2}=.01\right]$. The post hoc Bonferroni test revealed that there was a significant difference between the ambiguous condition $(M=3.53, S D=.71)$ and the strategically ambiguous condition $(M=3.25, S D=.74)$. Participants in the ambiguous condition reported more impact than those in the strategically ambiguous condition, $p=.002,95 \% \mathrm{CI}[.08$, .48]. There were not statistically significant differences between the ambiguous and clear condition or the strategically ambiguous or clear condition. Mean scores are reported in Table 9. 
Table 8

Summary of Correlations and Descriptive Statistics for All Scales

\begin{tabular}{|c|c|c|c|c|c|c|c|c|}
\hline Measure & 1 & 2 & 3 & 4 & 5 & 6 & 7 & 8 \\
\hline 1. Mindset & - & - & - & - & - & - & - & - \\
\hline 2. LO & $.248 * *$ & - & - & - & - & - & - & - \\
\hline 3. GO & -.030 & $-.188 * *$ & - & - & - & - & - & - \\
\hline 4. $\mathrm{AL}$ & $.154 * *$ & $.319 * *$ & $-.139 * *$ & - & - & - & - & - \\
\hline 5. Meaning & .073 & $.237 * *$ & -.091 & $.727 * *$ & - & - & - & - \\
\hline 6. Impact & .067 & $.231 * *$ & -.081 & $.435 * *$ & $.333 * *$ & - & - & - \\
\hline 7. Comp & $.141 * *$ & $.301 * *$ & -.076 & $.354 * *$ & $.223 * *$ & $.362 * *$ & - & - \\
\hline 8. TFA & $.153 * *$ & .079 & -.080 & $.164 * *$ & .050 & -.031 & .089 & - \\
\hline$M$ & 4.41 & 4.19 & 3.84 & 3.47 & 3.41 & 3.89 & 3.95 & 2.82 \\
\hline$S D$ & .97 & .50 & .68 & .68 & .72 & .57 & .58 & .78 \\
\hline
\end{tabular}

Note. For all scales, a higher mean indicates a more extreme response in the direction of the variable. $\mathrm{LO}=$ Learning Orientation; $\mathrm{GO}=$ Grade Orientation; $\mathrm{AL}=$ Affective Learning; Meaning = Meaningfulness; Comp =

Competence; TFA $=$ Tolerance for Ambiguity; ${ }^{*} p<.01 ;{ }^{*} p<.05$ 
The next one-way ANOVA showed that the effect of the survey condition on competence was significant $\left[F(2,426)=3.64, p=.02, \eta^{2}=.01\right]$. A post hoc Bonferroni test revealed that there was statistical significance between the strategically ambiguous condition $(M=3.85, S D=$ $.57)$, and the clear condition $(M=4.03, S D=.59)$, with students in the clear condition reporting more competence than those in the strategically ambiguous condition, $p=.02,95 \% \mathrm{CI}[-.35$, .01]. Additionally, there was no statistically significant difference between the ambiguous condition and the strategically ambiguous condition or between the ambiguous condition and the clear condition. Mean scores are reported in Table 9.

The second research question asked if student affective learning differed when faced with instructors' use of clear assignments, ambiguous assignments, or strategically ambiguous assignments. To answer this question, a one-way ANOVA was conducted and results showed that the effect of instructor messaging condition on affective learning was significant, $[F(2,423)$ $\left.=4.95, p=.007, \eta^{2}=.02\right]$. A post hoc Bonferroni test revealed that there was a significant difference between the ambiguous $(M=3.59, S D=.66)$ and the strategically ambiguous conditions $(M=3.34, S D=.72)$, with students in the ambiguous condition reporting more affective learning than those in the strategically ambiguous condition, $p=.006,95 \% \mathrm{CI}[.05$, .44]. Moreover, there was no significant difference between the ambiguous condition and the clear condition or between the strategically ambiguous condition and the clear condition. Mean scores are reported in Table 9. 
Table 9

Observed Descriptive Statistics for ANOVA Dependent Variables

\begin{tabular}{lccccccccc}
\hline & \multicolumn{3}{c}{ Ambiguous } & \multicolumn{3}{c}{ Strategically Ambiguous } & \multicolumn{3}{c}{ Clear } \\
\cline { 2 - 9 } \multicolumn{1}{c}{ Variable } & $M$ & $S D$ & $N$ & $M$ & $S D$ & $N$ & $M$ & $S D$ & $N$ \\
\hline Affective Learning & 3.59 & .66 & 150 & 3.34 & .72 & 142 & 3.50 & .64 & 134 \\
Meaningful & 3.53 & .71 & 150 & 3.25 & .74 & 142 & 3.44 & .68 & 134 \\
Impact & 4.15 & .57 & 150 & 3.73 & .53 & 142 & 3.78 & .53 & 134 \\
Competence & 3.97 & .58 & 150 & 3.85 & .57 & 142 & 4.03 & .59 & 134 \\
& & & & & & & & & \\
\hline
\end{tabular}

\section{Hypotheses}

The study advanced three different hypothesis which predicted that student characteristics (TFA, mindset, learning orientation and grade orientation) are related to the combined dependent variables of affective learning and learning empowerment, and while controlling for those student characteristics, instructor messaging will predict the combined dependent variables. To test the hypotheses, multiple MANCOVAs were conducted to determine the effect of the assignment condition (clear, ambiguous, strategically ambiguous), or independent variable, on student learning, as measured by the dependent variables (affective learning and learner empowerment), while controlling for the covariates (TFA, learning orientation and grade orientation, and mindset). One MANCOVA procedure was run for each covariate after bivariate correlations among variables were explored to determine that the covariates were significantly correlated with the dependent variables. It is ideal for covariates and dependent variables to be significantly correlated (Pituch \& Stevens, 2016). In this case, the variables had low correlations among themselves; thus, the use of MANCOVA was appropriate (Pituch \& Stevens, 2016). 
Table 8 displays a correlation matrix of all variables in the study. With the exception of two covariates not correlating significantly to two different dependent variables, most did; thus, MANCOVAs were conducted.

Importantly, covariate measures appeared on the survey instrument prior to exposure to assignment condition and the dependent variable measures. This order avoids the treatment group confounding or altering the covariate responses (Pituch \& Stevens, 2016). In doing so, the MANCOVA separates out the variance the covariate has on the dependent variable from the variance that the assignment condition has on the dependent variable. In other words, the MANCOVA procedure was appropriate since the covariates were measured prior to participants being exposed to the assignment condition.

The first hypothesis posited that TFA is related to the combined dependent variables and, while controlling for TFA, instructor messaging will predict affective learning and learner empowerment for that assignment. A MANCOVA was conducted to test this hypothesis. The assumptions of the MANCOVA were met. First, tests of the homogeneity of regression assumption indicated that there was no interaction between instructor messaging condition and TFA $[\Lambda=.976 F(8,834)=1.30, p=.23]$ for any outcome. Thus, the homogeneity of regression assumption was not violated. In addition, no violation of the variance-covariance matrices assumption was indicated (Box's $M=26.46, p=.16$ ), which indicates that Wilk's Lambda is used in interpreting the output, as it was not significant at the .001 level (Mertler \& Vannatta, 2005); thus, the variance-covariance matrices assumption was not violated. The variance of the residuals was not different across groups for affective learning, Levene's $F(2,423)=1.65, p=$ .19 , meaningfulness, $F(2,423)=1.00, p=.36$, impact, $F(2,423)=1.58, p=.20$, and 
competence, $F(2,423)=.13, p=.87$. Thus, the variance of residuals assumption was not violated.

Test results from the MANCOVA indicated that TFA is related to the combination of dependent variables $\left[\Lambda=.943, F(4,419)=6.35, p<.001, \eta^{2}=.01\right]$; thus, H1a was supported. MANCOVA results indicated that the adjusted group means differ on the outcomes $[\lambda=.859$, $F(8,838)=8.27, p<.001]$, which means there was a difference in each instructor messaging condition on the set of outcomes while controlling for TFA. Univariate ANCOVAs indicated that group adjusted mean differences are present for affective learning, $[F(2,422)=4.89, p=.008]$, meaningfulness $[F(2,422)=5.92, p=.003]$, impact $[F(2,422)=24.75, p<.001]$, and competence $[F(2,422)=3.68, p=.02]$, thus, H1b and H1c are supported since when TFA is controlled for, instructor messaging predicts affective learning and all three dimensions of learner empowerment. Table 10 displays the group means, which show that participants in the ambiguous condition reported highest mean scores for affective learning, meaningfulness, and impact while participants in the clear condition reported higher mean scores for impact. The strategically ambiguous condition had the lowest mean scores for all dependent variables.

It was hypothesized that mindset would be related to the combination of the dependent variables and, while controlling for student mindset, instructor messaging will predict affective learning and learner empowerment for that assignment. A MANCOVA was conducted to determine the effect of the assignment condition on student learning while controlling for student mindset. The assumptions of the MANCOVA were not met. Box's test was not significant (Box's $M=26.46, p=.16$ ); thus, Wilk's Lambda was used in interpreting the output. Tests of the homogeneity of regression assumption indicated that there was interaction between instructor messaging condition and student mindset $[\Lambda=.961 F(8,834)=2.10, p=.03]$ Thus, the 
homogeneity of regression assumption was violated as there was an interaction between mindset and video condition. Similarly, mindset was not correlated with competence; which is not ideal for MANCOVA procedures. Because the homogeneity of regression assumption was violated, MANCOVA was not the appropriate test for this hypothesis.

Table 10

Observed Descriptive Statistics for Tolerance for Ambiguity MANCOVA

\begin{tabular}{lcccccc}
\hline & \multicolumn{2}{c}{ Ambiguous } & \multicolumn{2}{c}{ Strategically Ambiguous } & \multicolumn{2}{c}{ Clear } \\
\cline { 2 - 7 } Variable & $M$ & $S D$ & $M$ & $S D$ & $M$ & $S D$ \\
\hline Affective Learning & 3.58 & .05 & 3.34 & .05 & 3.50 & .05 \\
Meaningful & 3.53 & .05 & 3.25 & .06 & 3.44 & .06 \\
Impact & 4.15 & .04 & 3.75 & .04 & 3.78 & .04 \\
Competence & 3.96 & .04 & 3.85 & .04 & 4.04 & .05 \\
& & & & & & \\
\hline
\end{tabular}

To determine the impact of mindset on student affective learning and learner empowerment, a multivariate analysis of variance (MANOVA) procedure was run. Mindset was split into a categorical variable using a mean split $(M=4.39)$, with cases above the mean considered growth mindset and cases below the mean considered fixed mindset. The four dependent variables included in the MANOVA were affective learning, meaningfulness, and competence. The independent variables were video condition and mindset. Preliminary testing of MANOVA assumptions was conducted to check for normality, linearity, univariate and multivariate outliers, homogeneity of variance-covariance matrices, and multicollinearity. The assumptions were violated. As a result, $\mathrm{H} 2 \mathrm{a}, \mathrm{H} 2 \mathrm{~b}$, and $\mathrm{H} 2 \mathrm{c}$ are not supported. 
The final hypothesis theorized that learning orientation and grade orientation were related to the combined dependent variables and, that instructor messaging would predict student affective learning and learner empowerment while controlling for student learning orientation and grade orientation. A final MANCOVA procedure was conducted to determine the effect of the assignment condition on student learning while controlling for learning orientation and grade orientation. The assumptions of the MANCOVA were met. First, tests of the homogeneity of regression assumption indicated that there was no interaction between instructor messaging condition and learning orientation and grade orientation $[\Lambda=.969 F(12,1098.278)=1.09, p=$ .36] for any outcome. Thus, the homogeneity of regression assumption was not violated. In addition, no violation of the variance-covariance matrices assumption was indicated (Box's $M=$ $26.46, p=.16$ ), which indicates that Wilk's Lambda is used in interpreting the output, as it was not significant at the .001 level (Mertler \& Vannatta, 2005); thus, the variance-covariance matrices assumption was not violated. The variance of the residuals was not different across groups for affective learning, Levene's $F(2,423)=3.00, p=.05$, meaningfulness, $F(2,423)=$ $1.27, p=.28$, impact, $F(2,423)=.29, p=.74$, and competence, $F(2,423)=.42, p=.65$. Thus, the variance of residuals assumption was not violated. Unfortunately, grade orientation and competence were not correlated; which is not ideal for MANCOVAs. However, in order to test all learner empowerment dimensions, both variables were included in the MANCOVA model.

For the MANCOVA, learning orientation and grade orientation were analyzed as separate variables since they loaded as two separate factors in the EFA. Test results from the MANCOVA indicated that learning orientation is related to the combination of dependent variables $[\Lambda=.873$, $\left.F(4,418)=15.15, p<.001, \eta^{2}=.06\right]$, but grade orientation is not $[\Lambda=.993, F(4,418)=.74, p=$ $\left..56, \eta^{2}=.002\right]$. Thus, H3a is partially supported since learning orientation, but not grade 
orientation, was related to the combination of dependent variables. Because this level of analysis is not significant for grade orientation, the univariate analysis for these results is not reported.

MANCOVA results indicated that the adjusted group means differ on the outcomes $[\lambda=$ $.871, F(8,836)=7.49, p<.001]$, which means there was a difference in each instructor messaging condition on the set of outcomes while controlling for learning orientation and grade orientation. Univariate ANCOVAs indicated that group adjusted mean differences are present for affective learning, $[F(2,421)=3.12, p=.04]$. Therefore, H3b is supported because instructor messaging did predict affective learning while controlling for learning orientation and grade orientation. Additionally, adjusted mean differences were present for meaningfulness $[F(2,421)$ $=4.43, p=.01]$, and impact $[F(2,421)=22.98, p<.001]$, but not for competence $[F(2,421)=$ $2.86, p=.05]$. Thus, $\mathrm{H} 3 \mathrm{c}$ is partially supported since when learning orientation and grade orientation are controlled for, instructor messaging predicts two dimensions of learner empowerment, meaningfulness and impact, but not the third dimension, competence. Table 11 displays the group means, which show that participants in the ambiguous condition reported highest mean scores for affective learning, meaningfulness, and impact while participants in the clear condition reported highest mean scores for impact. The strategically ambiguous condition had the lowest mean scores for each dependent variable. 
Table 11

Observed Descriptive Statistics for MANCOVA on LOGO Scale

\begin{tabular}{lcccccc}
\hline & \multicolumn{2}{c}{ Ambiguous } & \multicolumn{2}{c}{ Strategically Ambiguous } & \multicolumn{2}{c}{ Clear } \\
\cline { 2 - 8 } Variable & $M$ & $S D$ & $M$ & $S D$ & $M$ & $S D$ \\
\hline Affective Learning & 3.56 & .05 & 3.37 & .05 & 3.50 & .06 \\
Meaningful & 3.51 & .05 & 3.27 & .05 & 3.44 & .06 \\
Impact & 4.13 & .04 & 3.75 & .04 & 3.78 & .04 \\
Competence & 3.94 & .04 & 3.87 & .04 & 4.03 & .04 \\
\hline
\end{tabular}

Note. LOGO = Learning orientation and grade orientation

\section{Chapter Summary}

In summary, EFA procedures confirmed the validity and reliability of scales.

Specifically, the learning orientation, grade orientation, learner empowerment (competence, meaningfulness and impact subscales) and affective learning scales were very good; whereas the TFA scale was poor due to a small number of items, low reliability, and low validity estimates. The manipulation test confirmed that instructor messaging was manipulated correctly. Correlation analysis showed the relationship among variables, which confirmed the suitability of conducting MANCOVAs for most variables. The one-way ANOVAs indicated that the instructor messaging affected impact, competence, meaningfulness, and affective learning. MANCOVAs showed that TFA and learning orientation are related to the combined dependent variables; however, grade orientation and mindset are not. While controlling for TFA, all dependent variables were significant; whereas while controlling for learning orientation, all dependent variables except competence were significant. Finally, a MANOVA procedure indicated that mindset does not significantly influence the dependent variables. 


\section{CHAPTER V: DISCUSSION}

The university classroom is a space where instructors consistently make choices about how to communicate with students. Although instructor clarity is a valued and widely researched construct in instructional communication research, there may be an advantage to intentionally using less clarity if one wishes to foster various learning outcomes for students. Scholarship suggests that employers value employees who can respond to the changing landscape of the workplace and perform well in ambiguous or ill-defined settings (Banning, 2003; Herman et al., 2010; Rippin et al., 2002). Alternatively, the American education system tends to promote students' focus on receiving a good grade for adhering to rigid assignment parameters (Gibbs \& Simpson, 2005; Kohn, 1993), which may have negative implications for their appreciation of learning. A gap exists in the scholarly literature regarding how strategic ambiguity can foster different learning outcomes for students. In addition to instructor messaging, student's reaction to strategic ambiguity is impacted by other factors worth of consideration, including student characteristics. A student's TFA, mindset, and learning orientation and grade orientation are all factors that impact the classroom environment.

The primary goal of this study was to determine which student characteristics impact a student's learning when faced with an instructor's use of a clear, ambiguous, or strategically ambiguous assignment message. Participants answered questions regarding their mindset, TFA, and learning orientation and grade orientation. Next, they read an assignment and watched a video of an instructor explaining the assignment in one of three survey conditions: clear, ambiguous, and strategically ambiguous. Finally, participants then answered questions regarding their affective learning and learner empowerment regarding that assignment. This chapter will 
summarize research findings, offer theoretical and practical implications, identify limitations of the study, and suggest ideas for future research.

\section{Summary of Findings}

\section{Scale Development}

Before analyzing the data to address the research questions and hypotheses, the validity and reliability of the scales were analyzed. The scales for TFA, mindset, and learner empowerment were previously established scales; whereas the scales for learning orientation and grade orientation and affective learning were developed for this study. Learning orientation and grade orientation were run as separate factors as past research indicates they are not conceptually related (Pollio \& Beck, 2000). EFA procedures showed that both scales were acceptable, but not strong as they had low variance and a small number of items on each scale, but the reliability was sufficient. The mindset scale was excellent, with high variance and reliability. The final TFA scale was short due to the elimination of several items. This is likely due to the poor validity of the original scale (McLain, 2009). The variance and reliability of the three-item TFA scale were acceptable; however, due to the low number of items retained from the original scale, the scale used in this study may or may not reflect the operationalization of TFA used by past researchers. The manipulation check worked; however, it loaded as two separate factors, which is not ideal because it indicates the questions were not as consistent as they could have been. For example, rather than varying the language between clear and vague, the questions could have used the terms clear and not clear to allow the items to load on one factor. Nevertheless, the twofactor solution represented an appropriate amount of variance.

The learner empowerment scale loaded on three factors: meaningful, competence, and impact, which is consistent with prior scale development research for this measure (see Frymier 
et al., 1996; Weber et al., 2005). All three factors had good variance and reliability; thus, this scale was considered strong. Finally, affective learning was a strong scale, reporting good variance and reliability. After EFA procedures, a large number of items were retained. Although it needs further development, this scale holds promise over the commonly used semantic differential scale written by Kearney (1994), as it is measured on a Likert scale, which provides richer data. After EFA procedures, the resultant scale for each variable was retained for data analysis.

\section{Instructor Messaging Manipulation Check}

Instructor messaging was manipulated in this study. Specifically, participants saw one scenario of either a clear instructor message, an ambiguous instructor message, or a strategically ambiguous instructor message, each of which related to a class assignment. Participants watched one of the three scenarios and then answered questions about the level of clarity or ambiguity they perceived in the assignment presentation. The results of two separate one-way ANOVAs indicated that the manipulation check was successful; participants who received the clear condition perceived the messaging of the instructors as clearer than those who received the ambiguous or strategically ambiguous conditions. There was no statistical difference for the perception of clarity between the ambiguous and strategically ambiguous conditions, which is understandable since both conditions were intended to be ambiguous. Participants in the clear condition reported instructors as less vague than in the ambiguous and strategically ambiguous conditions. Students in the strategically ambiguous condition reported their instructors as less vague than those in the ambiguous condition, providing further evidence that instructor messaging was correctly manipulated. While the manipulation check worked, the manipulation of instructor messaging could have been cleaner as there were not distinct differences between 
each condition and the manipulation check questions loaded on two dimensions. A clearer manipulation check may have resulted in different results for the strategic ambiguity condition.

\section{Correlation among Variables}

Bivariate correlations explored the relationship among the variables and to determine if a MANCOVA procedure was appropriate to test the hypotheses. There was a weak correlation between learning orientation and mindset, grade orientation and learning orientation, affective learning and mindset, affective learning and grade orientation, meaningfulness and learning orientation, impact and learning orientation, impact and meaningfulness, competence and mindset, competence and meaningfulness, TFA and mindset, and TFA and affective learning. There was a moderate correlation between affective learning and learning orientation, impact and affective learning, competence and impact, competence and learning orientation, and competence in affective learning. Finally, there was a strong correlation between meaningfulness and affective learning. Taken together, these bivariate correlations suggest that there were many relationships among the variables in the present study.

The findings of the present study are consistent with past research, which found that all dimensions of learner empowerment were correlated with affective learning (Frymier et al., 1996) and that all dimensions of learner empowerment are correlated with one another (Frymier et al., 1996; Thomas \& Velthouse, 1990). Of interest, meaningfulness and affective learning were strongly correlated despite consistently being studied as unique constructs. This is likely due to the similar manner in which the variables were operationalized in the study. Questions on both the affective learning and meaningfulness scales referred to the worth the assignment had in their lives and feelings toward those assignments, which would explain the strong correlation between the variables. Additionally, it is possible that meaningfulness and affective learning are 
too strongly correlated and are not actually measuring different constructs. Learning orientation had a moderate correlation with affective learning and competence. This highlights the extent to which learning orientation pervades all facets of student learning. If a student desires to learn it is reasonable that they would also enjoy learning and feel more competent learning. Overall, the correlations suggested that a MANCOVA was an appropriate statistical test for data analysis.

\section{Research Question One}

The first research question asked if the dimensions of learner empowerment (meaningfulness, impact, competence) differ when presented with instructors use of clear, ambiguous or strategically ambiguous assignment messages. To answer this research question, three separate one-way ANOVAs were conducted. The first ANOVA sought to determine if meaningfulness differed among the three instructor messaging conditions. The findings were significant, suggesting instructor messaging did influence student meaningfulness. Surprisingly, students in the ambiguous condition reported more meaningfulness than those in the clear and strategically ambiguous conditions, which indicates that providing ambiguous assignment messages increases student's perception that the assignment has meaning in their lives. The second ANOVA sought to determine if impact differed among the three conditions, and these findings were significant. Findings were contrary to expectations, again. Participants in the ambiguous condition reported more impact than those in the strategically ambiguous condition and the clear condition. This indicates that providing very open and ambiguous assignments increases the likelihood students will feel like they can make a difference through that assignment. The third ANOVA explored if competence differed among the survey conditions, and it was significant. Understandably, participants who received the clear condition reported more competence than those who received the strategically ambiguous condition, suggesting that 
providing clear assignment messages allows students to feel more capable of completing the task. An examination of the effect sizes for empowerment shows that impact stands out as being more influential than meaningfulness or competence.

All three dimensions of learner empowerment differed significantly across the three instructor messaging conditions, which was interesting. Meaningfulness and impact were the strongest in the ambiguous condition and competence was strongest in the clear condition. Meaningfulness and impact are similar because they both refer to transferring skills or tasks to personal experiences. Meaningfulness is the extent to which a person finds a task valuable and impact is the extent to which a person thinks completing a task has implications on a larger level (Thomas \& Velthouse, 1990). Since these two dimensions are similar, it is understandable that students would find the same task both meaningful and impactful. Surprisingly, meaningfulness and impact were strongest for the ambiguous condition, even though the ambiguous condition was intended to be the least effective. One reason for the ambiguous condition may have been strong is because operationalization of ambiguity in this study is consistent with past definitions of strategic ambiguity, which do not include providing a rationale for being ambiguous. Further, these findings mirror the sentiments of Titsworth and Mazer (2010) who noted that although researchers promote clarity as best, strategic ambiguity may better promote transfer of learning than clarity. In this case, ambiguity did promote transfer of learning better than clarity.

The present study sought to include a rationale for the use of ambiguity as past research suggests that providing a rationale for implementing strategic ambiguity is necessary in successfully employing it (DeRoma et al., 2003; Visser \& Visser, 2004). The results of this study fail to support the claim that a rationale is necessary in employing strategic ambiguity. There are a couple of reasons that the rationale in the strategically ambiguous condition lead to less 
meaningfulness and impact. It is likely that without a detailed justification for the use of ambiguity, students felt free to interpret the vagueness of the assignment. Once the rationale was provided, students were no longer able to determine the implications for their lives because the instructor clearly told them how the assignment matters on a larger scale. As a result, if students have a different idea for why the assignment mattered, it was dissuaded by the instructor message. The strategically ambiguous assignment deliberately explained that students would have to think on their own, indicating that the assignment was different from typical assignments. Wright (2019) found that when given an assignment, students want to know what the instructor desires from them. Since the strategically ambiguous condition explicitly stated that the instructor would not provide explicit guidance, students may have immediately had a negative reaction to the assignment, thus making the ambiguous condition more appealing. Another reason that the strategically ambiguous condition may have led to less meaningfulness and impact could be the amount of information presented. It is possible that the strategically ambiguous condition provided too many options for students and was therefore overwhelming. Supporting this concern, Brooks and Young (2011) concluded that providing students with too many choices may have negative implications in the classroom. It is possible that the strategically ambiguous condition revealed to students that they would have to make a lot of choices on their own, and they disliked that experience. Conversely, it stands to reason that the clear condition would have the least meaningfulness and impact because students are merely asked to complete a set of tasks. If students are exercising limited cognitive thought to complete an assignment, it is unlikely that they will view that assignment as meaningful to them or impactful on a larger scale. Instead, their focus when completing the assignment is on finishing the clearly defined steps as opposed to focusing on sense-making. 
Not surprisingly, the findings of the present study indicate that ambiguity can help students transfer knowledge, which is consistent with past research that suggests ambiguity is pivotal for transfer of knowledge. Titsworth and Mazer (2010) articulated that although clarity is the norm in teaching, strategic ambiguity may have a place. They articulated that students must be able to transfer what they learn "to novel instances not explicitly addressed by instructors" (p. 258). Accordingly, they suggested that teachers should scaffold instruction to get students to a point where they can do so, and, in such instances, strategic ambiguity may be warranted. The findings of the present study support this finding as the ambiguous condition was most preferred. Too much information upon initially receiving an assignment hampered students' attitudes for learning. Klyukovski and Medlock-Klyukovski (2016) found that one reason instructors use strategic ambiguity is to help students see patterns and make connections to content outside of class.

RQ1 indicated that students in the clear condition had more competence than those in the ambiguous or strategically ambiguous condition, which is consistent with past research. Competence is a person's feeling that the person can perform a task (Thomas \& Velthouse, 1990). Past research indicates that students are not accustomed to being asked for their opinion and instead prefer being given the information they need to pass exams (Rippin et al., 2002), are rarely given the opportunity to make choices in their classes (Frymier et al., 1996), and very clear assignments are easier to complete (Wright, 2019). Because the clear condition is consistent with students' typical educational experiences, it is reasonable that they would feel more prepared to complete it. Moreover, it seems plausible that student anxiety would be inconsistent with competence, and past research indicates that clarity reduced student anxiety (Chesebro \& McCroskey, 2001) and clear grading criteria reduced student's anxiety regarding 
instructor expectations (Stitt et al., 2003). Because the clear assignment provided a detailed outline of what students should do, it is likely that those students did not have anxiety about the assignment; thus, they felt confident that they could complete it. Students might ponder if they could complete each of the steps required, such as incorporating multiple sources, analyzing an audience, or writing three pages. The results of this study support the findings of Brunson and Vogt (1996) who posited that students find comfort in being told exactly what to do. The clear assignment outlines exactly what students should have done, and they felt competent in that. On the other hand, both the ambiguous and the strategically ambiguous conditions lacked details of exactly what students were supposed to do. Thus, it is understandable that they did not feel competent completing the task. Much of the ambiguous and strategically ambiguous conditions left decision up to student discretion, thus, they could not say with certainty that they could perform the task.

It is worth acknowledging that the present study did not account for all three components that impact learner empowerment. For example, Frymier et al. (1996) found that learner empowerment was impacted by the learning environment. The present study did not account for learning environment in any capacity, which could have adversely impacted findings. Specifically, the additional detail in the clear and strategically ambiguous conditions could have presented an idea of what the learning environment would be like; whereas, the ambiguous condition allowed for more individual interpretation. As a result, students may have made an inference regarding the learning environment in the ambiguous condition and that led to a more positive perception of learning. Finn and Schrodt (2012) found that instructor clarity led to student's perception that the instructor understood them. It is possible that the clear assignment 
condition, in this study, allowed for students to perceive the instructor as understanding and helpful, leading them to be more competent.

\section{Research Question Two}

The second research question asked if student affective learning differed when faced with instructors use of clear, ambiguous, or strategically ambiguous assignment messages. To answer this question, a one-way ANOVA was conducted. As expected, findings were significant, the assignment condition did impact affective learning. Specifically, the only statistically significant findings were between the ambiguous and strategically ambiguous conditions. Students in the ambiguous condition reported more affective learning than students in the strategically ambiguous condition. This indicates that students' feelings toward the learning task are most positive when given an assignment that employs a great deal of ambiguity as opposed to an assignment that uses deliberate messaging regarding ambiguity. This was interesting because the ambiguous condition was not intended to reflect good teaching practice. Although the difference between the ambiguous and clear assignment or clear and strategically ambiguous assignment were not significant, an examination of the mean scores shows that clarity leads to greater affective learning than strategic ambiguity.

Initially, the finding that the ambiguous condition leads to greater affective learning seems to contradict past research which indicated that clarity improves affective learning (Chesebro \& McCroskey, 2001; Comadena et al., 2007). In this study, ambiguity led to greater affective learning despite the intention for the condition to reflect inadequate teaching practices. Affective learning is concerned with feelings towards a task (Barkley, 2010), which, in this study, refers to students' feelings toward the assignment. Perhaps students liked the idea of learning from the ambiguous condition because they failed to acknowledge what they did not 
know; instead, they just thought about what they would do, which is different than carrying out the assignment. The lack of ecological validity in the experimental design is one reasonable explanation for this finding. The process of actually doing the assignment may have yielded different results because students would be forced to think through the assignment on a higher level. Further, students did not receive a grade for this assignment so the results may have been impacted by their lack of investment in the assignment.

In the same vein, it is possible that the rationale in the strategically ambiguous condition told students what they did not initially realize-that the assignment was ambiguous-and that may have changed their attitude. Past research indicates that students are initially uncomfortable with uncertainty (Rippin et al., 2002; Wright, 2019), and the findings of the present study support this. It is possible that students did not realize that the ambiguous assignment lacked clarity; however, they did realize that the strategically ambiguous condition lacked clarity because they were told as much. Accordingly, students in the strategically ambiguous condition knew that they were going to have to work through ambiguity, which may have been undesirable; however, if it was not pointed out to them, their feelings were more positive. Ambiguity became problematic when students were aware that it existed. It is possible that students find working through ambiguity to be more difficult and, as a result, react negatively to being told that are required to do it.

Surprisingly, the clear condition, which provided the most support, did not have the highest levels of affective learning. Past research suggests that students find a great deal of comfort in having the path to learning clearly laid out for them (Brunson \& Vogt, 1996). The findings of the present study do not support past research in this regard. It could be that students in the clear condition may have viewed the many details and requirements of the clear assignment as another task to complete, which, although desired, may reduce the positive 
feelings toward the task. Further, there are other teacher characteristics that also promote affective learning such as teacher immediacy (Chesebro \& McCroskey, 2001; Chory \& McCroskey, 1999; Comadena et al. 2007; Pogue \& Ahyun, 2006), caring (Comadena et al., 2007), credibility (Pogue \& Ahyun, 2006), and content relevance (Mottet et al., 2008). This study only manipulated teacher clarity; thus, it could be that teacher clarity, in combination with some other variables, would have a stronger impact on affective learning.

Another explanation for less affective learning in the clear condition is that the emphasis on ambiguity to promote student learning may have led students to draw conclusions about the quality of the teacher. Brooks and Young (2011) speculated that students may have perceived a teacher's lack of attendance policy as not caring. Wright (2019) found that students want teachers to tell them exactly what they are looking for and when they do not, students are frustrated. In this vein, providing less details in the assignment and telling students they did so may have caused students to perceive teachers as caring less or being lazy. It is likely that students would view detailed assignments as the teacher having their best interests in mind, as they are making sure the student knows exactly what to do to accomplish the assignment. When teachers admit they are not telling them exactly what to do, students might think they did not want to take the time to create the assignment. Students have expectations of teacher messaging; thus, the strategic ambiguous condition may have violated those expectations.

Relevant to both research questions, the way strategic ambiguity was manipulated in this study was always the least preferred by students. The findings of this research contradict past recommendations that explaining the impetus for ambiguity is important. Results of this study highlight that instructor messaging is vital in explaining classroom assignments; however, not in the way that was originally expected. It is possible that deliberately telling students that an 
assignment is ambiguous increases their anxiety regarding that assignment, which is consistent with past research that implies clarity reduces student anxiety (Chesebro, 2003; Chesebro \& McCroskey, 1999; Chesebro \& McCroskey, 2001). When students did not know ambiguity was present, they did not think about the lack of detail; however, when they were told they were missing clear direction, it could have triggered anxiety. Providing a rationale for the ambiguity led to less perception of learning. Past research suggests that making content relevant to students increases their learner empowerment (Frymier et al., 1996). The strategically ambiguous condition attempted to make the content relevant to students by explaining how ambiguity is helpful in their futures; however, it did not enhance their learner empowerment. It is possible that without the presence of actual course content and a resulting grade for the assignment, there is no way to create a classroom environment conducive to strategic ambiguity. Perhaps it is because strategic ambiguity is embodied in every part of the classroom and, as a result, should be strategically implemented over time as to not overwhelm or induce anxiety in students.

Another explanation for why strategic ambiguity was less preferred could be the finding that students have concerns with consistent grading practices by teachers when there is not a clearly defined grading criteria (Wright, 2019). It is possible that strategic ambiguity cannot be implemented without a trusting student-teacher relationship. Although strategic ambiguity, as operationalized in this study, was not a strong predictor of learner empowerment, ambiguity was. There is a need in instructional communication research to more fully address what strategic ambiguity is and how it functions in the classroom to improve implications for the construct. Nevertheless, this study supports the findings that ambiguity, on some level, enhances learner empowerment and affective learning. 


\section{Hypotheses}

A series of MANCOVAs were conducted to determine the effect of the instructor messaging condition (clear, ambiguous, strategically ambiguous) on student learning (affective learning and learner empowerment), while controlling for the covariates (TFA, learning orientation and grade orientation, and mindset). H1 advanced that TFA was related to the combined dependent variables and, while controlling for TFA, instructor messaging condition would be significant for affective learning and learner empowerment. As expected, this hypothesis was supported. This indicates that TFA is related to the combined effects of affective learning and learner empowerment and, when controlled for, significantly impacts affective learning and all dimensions of learner empowerment. Unfortunately, this does not answer how TFA impacts reactions to various messaging conditions.

$\mathrm{H} 2$ posited that mindset was related to the combined dependent variables of affective learning and learner empowerment, and that, when controlling for mindset, instructor messaging would predict affective learning and learner empowerment. Contrary to expectations, mindset was not a related to the combined set of dependent variables; thus, a MANCOVA was not appropriate. Because the MANCOVA was not appropriate, a follow-up MANOVA for mindset still violated the test assumptions. This hypothesis was not supported. This is particularly surprising because students' thoughts about their own learning should have implications for their perceived learning. One explanation for why mindset was not significant is that it was not correlated with one of the dependent variables, meaningfulness. Overall, these results indicate that mindset is not an important consideration when employing varying assignment messages.

H3 predicted that learning orientation and grade orientation would be related to the combined dependent variables, and when controlled for would predict affective learning and 
learner empowerment. Ironically, learning orientation is related to the combined dependent variables; however, grade orientation is not. Similarly, when controlling for learning orientation and grade orientation, affective learning, meaningfulness, and impact are significant, but competence is not. As a result, this hypothesis is only partially supported. From this, it is understood that learning orientation is an important variable when considering messaging, but it is not clear exactly how learning orientation is related to the dependent variables.

Several interesting conclusions can be drawn from the hypotheses test results. First, an important finding is that TFA was related to the combined dependent variables and all of the dependent variables were significant when TFA was controlled. Although the results of this study do not indicate exactly how TFA influences student learning, we know that this is an important variable when considering instructor messaging regarding assessments. Recall that DeRoma et al. (2003) found that student's TFA was related to their desire for course structure. Specifically, students with low TFA valued course structure more than those with high TFA. The findings of the present study support that idea; TFA was an important component of student perceived learning in the three conditions, which manipulated assignment structure. Sorrentino et al. (1984) found that individuals perform better on a task that is consistent with their certainty orientation, a similar construct to TFA. Of course, it is possible that students reacted to the assignment conditions more favorably if the condition was consistent with their TFA, but future research is warranted. Additionally, Banning (2003) found that the use of case studies in business courses can improve a student's TFA. Since it is known that TFA is related to student learning and that a student's TFA can be influenced, these findings create opportunity for researchers to begin to explore how to influence a student's TFA to enhance the learning outcomes desired by the teacher. 
The finding that mindset was not related to the dependent variables was surprising, given past research on the theory. Past research on implicit theory suggests that students with a fixed mindset view challenges as a threat to their self-esteem (Dweck, 2000); whereas students with a growth mindset view challenges as an opportunity to learn and grow (Dweck et al., 1993). Mindset research suggests that it has positive implications for academic achievement (Blackwell et al., 2007; Yeager \& Dweck, 2012). If students truly dislike ambiguity (Brunson \& Vogt, 1996), it would make sense that students with a fixed mindset would resist ambiguity. In fact, Aronson et al. (2001) concluded that students with a growth mindset found greater enjoyment in academics. The findings of the present study do not support that conclusion. One explanation for this could be the recent meta-analysis that suggest that the impact of mindset is not as strong as originally suggested (Sisk et al., 2018). The meta-analysis showed that the impact of mindset may not be strong for academic achievement as the sample size and conclusions drawn from mindset research were over-applied. It is possible that this transfers to feelings about achievement, too. Further, mindsets are more impactful for underserved populations (Sisk et al., 2018), which are not heavily represented in this research. Accordingly, the results of this study lend credence to the findings of Sisk et al. in that mindset may not be as influential on academic learning for general populations.

Learning orientation was related to the student learning; however, grade orientation was not. Recall that grade orientation was not correlated with the dependent variables of meaningfulness or competence, which could have implications for why it was not related to student learning in the MANCOVA. Beyond that, it is possible that if a student is grade-oriented, the grade they will receive is their primary focus. Frymier and Weser (2001) found that college students who were more grade-oriented had higher expectations for teacher clarity. It is possible 
that the hypothetical assignment created through the manipulation in this study never focused enough on grades for grade-oriented individuals. The grading criteria presented to students in this study simply stating the percentage that focused on content verses writing, which is vague. Grade-oriented students may only be reached using actual grades. The assignment in the present study was not an assignment they actually had to complete; thus, they may have had ambivalent feelings toward it, leading to insignificant results. This is one explanation for why grade orientation was not related to the dependent variables. Additionally, it makes sense that grade orientation would not impact affective learning because students who are grade-oriented are not seeking to learn, at all. Accordingly, the use of affective learning as a dependent variable will never be relevant for a student who is not concerned with learning. Dweck (2000) found that students who overly focus on grades are more likely to give up in the face of failure. While not failure, per se, it is possible that while completing the survey, grade-oriented students simply did not care enough to think about the impact of the assignment because they are accustomed to turning to helplessness. If these students have a defeatist attitude, it makes sense that the survey condition did not lead them to care about an assignment they will never do.

Learning orientation was related to the dependent variables, which is consistent with the findings of Houser and Frymier (2009) who found that learning orientation was positively associated with learner empowerment; however, their findings indicated that learning orientation and grade orientation had little impact on learner empowerment. The effect size of learning orientation was small in this study $(6 \%)$, indicating that learning orientation does not have a substantial impact on the dependent variables, which supports their research. Further, Pollio and Beck (2000) found that learning orientated students have better study skills, less test anxiety, more reasoning ability, and more motivation than grade-oriented students. In this study, students 
who were learning-oriented may have had more of a focus on learning regardless of scenario, which lead to learning orientation being related to student learning. Frymier et al. (1996) contended that learner empowerment falls within motivation; thus, if learning-oriented students are already motivated, that should have implications for learner empowerment, which was supported by this research.

Interestingly, an examination of the mean scores for the one-way ANOVAs and the MANCOVAs revealed interesting patterns. The mean scores for the clear condition almost never changed when other variables were not controlled or when controlling for the variables; the exception being that when controlling for TFA, competence increases by .01 . This suggests that when using clear teaching, TFA as well as learning orientation and grade orientation have negligible implications for student perceptions of learning. However, when employing ambiguous or strategically ambiguous assignments, student TFA as well as learning orientation and grade orientation are more important. This indicates that while TFA and learning orientation are important, they may not be as important as originally indicated. Further, these findings suggest that TFA and learning orientation are more prominent when employing ambiguity or strategic ambiguity than when employing clarity.

\section{Theoretical Implications}

The results of this study can be better understood through a discussion of theory and research. Although not theory, per se, instructional communication research integrates the concept of clarity into several models; therefore, it has theoretical implications. Strategic ambiguity, as operationalized in this study, never emerged in the data analysis as the best messaging tool for student learning. Ambiguity, on the other hand, did emerge as the strongest indicator of student learning more so than clarity. This research supports the findings of 
Titsworth et al. (2015), which suggests that there are moderating variables that are influencing teacher clarity and, as a result, there may be a place for strategic ambiguity. Clarity has been shown to impact a variety of different variables including reducing student anxiety (Chesebro, 2003; Chesebro \& McCroskey, 1999; Chesbro \& McCroskey, 2001), increasing student motivation to learn (Bokan et al., 2016; Myers, et al, 2014) and impact student learning (Chesebro, 2003, Chesebro \& McCroskey, 2001; Comadena et al, 2007; Mottet et al. 2008). However, these findings do not suggest that clarity is the only way to enhance these learning outcomes. Thus, instructional communication researchers, in particular, need to broaden their understanding of clarity to include the deliberate use of ambiguity.

The conceptualization of both clarity and strategic ambiguity need advanced. The findings of this research indicate that strategic ambiguity is a degree of clarity, which is consistent with the findings of Klyukovski and Medlock-Klyukovski (2016) who found a positive relationship between clarity and strategic ambiguity. Given the increasingly rigid nature of teaching and learning at all levels of education, it would be short-sighted of researchers to not seek ways to promote student inquiry beyond very clear, standardized assessments. This study supports the conclusion of Titsworth et al. (2015) that clarity should be studied as a multidimensional construct and viewed as a process. Strategic ambiguity needs explored as the exchanging of messages and meaning negotiation between students and teachers. Specifically, it should be studied as adaptive clarity, which Titsworth and Mazer (2016) define as occurring through conversations which reduce ambiguity. To extend this thought, perhaps the goal of adaptive clarity is not to reduce ambiguity, but, instead, reduce anxiety on the part of the student, which could happen in a variety of ways. Clarity research supports a positive bias (Titsworth \& 
Mazer, 2010) as it suggests that clarity is always best. Researchers need to continue this line of research to determine best practices for employing strategic ambiguity or ambiguity.

Interestingly, Titsworth et al. (2015) found that teacher clarity has a larger impact on affective learning than cognitive learning. While this may be the case, the findings of this research make an interesting contribution to scholarship in that the ambiguous assignment actually lead to greater student affective learning than the clear assignment. This further suggest that although clarity has become a standard in education, there is a place for ambiguity or strategic ambiguity, and it should be explored further.

Comparably, results of the correlations highlight implications for the conceptualization of variables and how they may work together. Consistent with past research, all learner empowerment dimensions were correlated with affective learning (Frymier et al., 1996). Specifically, meaningfulness has the strongest correlation with affective learning. Upon further examination, meaningfulness and affective learning may have been operationalized too similarly in this study. However, the impact and competence scales of learner empowerment also had moderate correlations with affective learning. Past research has found the dimensions of learner empowerment to be correlated with one another (Frymier et al., 1996; Thomas \& Velthouse, 1990), and the correlations in this study are consistent with those findings. Due to the similarities between variables, it would behoove scholars to parse out the differences between these variables to better understand if they are measuring different constructs. It is possible that learner empowerment and affective learning are similar constructs and should be explored together to better understand the implications of each variable.

Surprisingly, TFA was not strongly correlated to any other variables. This indicates the importance of addressing this variable moving forward. TFA has been explored primarily in 
education and psychology; however, communication scholars are beginning to explore strategic ambiguity and, as such, need to incorporate students TFA into those studies. To fully understand the impact of strategic ambiguity, students' dispositions toward ambiguity must be understood.

There were several variables that were identified in the literature review from different disciplines that have been studied in similar ways. There is a need in scholarship in general, but especially in instructional communication scholarship, to look outward from communication research to link research to other disciplines and help create a more cohesive picture of the multivariate nature of teaching and learning. Researchers in education, communication, psychology, business education have all been researching these constructs in silos, and this is problematic. For example, TFA has been studied and defined by some scholars (Banning, 2003; Carver, 2006; DeRoma et al., 2003; Huber, 2003; Kajs \& Collum, 2009), while other scholars refer to similar constructs as uncertainty orientation (Sorrentino et al., 1984) and adaptability (Collie et al., 2017; Holliman et al., 2018; LePine et al., 2000; Martin et al., 2013; Ployhart \& Bliese, 2006). Similarly, learning orientation and grade orientation was defined by Pollio and Beck (2000); however, Dweck (2000) coined a similar term for this construct-achievement goals. Having these disparate strands of research in varying disciplines provides an incomplete picture of each construct. Many constructs are being studied atheoretically, or absent a theoretical framework, which is problematic for understanding the dynamic classroom environment. This research supports the recommendation of Mazer and Graham (2015), who call for a crossdisciplinary approach to research in communication. In order to adequately make these constructs meaningful for students and educators, a stronger theoretical understanding of the variables that recognizes the classroom as a multivariate environment is needed. 
Mindset theory has been explored in a variety of contexts and has received a lot of attention. A lot of mindset research has shown that providing students with a mindset intervention, which seeks to make them have more of a growth mindset can improve their learning (Aronson et al., 2001; Blackwell et al., 2007). This study was not an intervention; rather, it just measured mindset, so it could be that in order to see positive results of mindset, students first need to understand what their mindset is, then be taught how to change their mindset. There could be a desirability bias to initially suggest that one has a growth mindset; however, when given a specific task or asked about a specific content area, students may realize they have more of a fixed mindset. While this study did not explore academic achievement, it is consistent with the findings of Sisk et al. (2018) who called into question the relationship between mindset and academic achievement. Results of the present study indicate that mindset is not related to feelings regarding learning. It is possible that mindset lacks implications for variables beyond academic achievement. The lack of significant findings for mindset in this study lend credence to the claims that mindset may be overvalued in educational research, which may be a problem. The body of research on mindset needs to be advanced to better understand if it is a vital component of education.

Although not a direct purpose for this study, this study provides a promising first step in developing a new affective learning scale. The commonly used semantic differential scale for affective learning (Kearney, 1994) is problematic. First, it sets everything up as a dichotomous relationship, which does not measure the full range of learning. Additionally, the scale is more impression based and not a reflection of whether or not students think they have developed a skill or have a take away. The development of the affective learning scale for this research project is promising for researchers moving forward. The scale produced as a result of this study 
measures affective learning on a Likert response scale and more accurately measures students' attitudes toward learning. This scale provides promise in advancing affective learning research in a more meaningful manner moving forward. While the present scale is not a final solution, it is a step in the right direction for providing a more accurate measure of affective learning.

\section{Practical Implications}

This study also has several practical implications for teachers. Specifically, implications include the idea that instructor messaging is important when giving an assignment, strategically ambiguous messages may be too much information for students, student characteristics play an important role in students reception of instructor messages, instructors should scaffold the messages they send when employing strategic ambiguity, and the classroom is a multivariate environment in which instructors have to balance many variables. This section will outline best practices for teachers in light of the findings of the present study.

\section{Messaging Matters}

One of the most notable findings is that there is a difference in student's perceived learning for varying assignment conditions. Past research suggested that clarity had a positive impact on student learning (Chesebro, 2003; Chesebro \& McCroskey, 2001; Comadena et al., 2007; Mottet et al., 2008; Titsworth et al., 2015), which provides a promising guideline for teachers seeking to understand how their messaging might impact student learning. Additionally, teachers have a number of reasons for employing clarity in assignments including ensuring evaluation consistency across multiple sections of courses (Stitt et al., 2003) and helping students meet assignment expectations and evaluate themselves (Frey et al., 2018). However, the results of the present study suggest that clarity may not be the only way to enhance student learning and 
indicates that there is a place for ambiguity or strategic ambiguity in classroom assessments. Based on this finding, considerations are offered for teachers.

In order to construct effective instructor messages, teachers ought to determine the desired outcome for an assignment. For example, if teachers are looking to enhance a student's competence, then a very clear assignment is warranted. In this study, the clear condition led to the most competence and it included detailed criteria such as a definitive paper length, examples of how to implement course content, and steps to follow to be successful. One instance where clarity might make sense, then, is when students are first learning a difficult concept as to not discourage them from continuing to learn. Giving very detailed directions will allow students to complete the task they are just learning and provide them the competence to be successful. Instructors need to consider the importance of competence when giving an assignment and then craft their messages accordingly.

Conversely, if a teacher wants students to transfer their learning by finding meaningfulness or impact, then an ambiguous assignment message is appropriate. Ambiguous assignments messages also lead to more affective learning, which means teachers can use ambiguity to promote students' positive feelings toward the task. In this study, the ambiguous condition excluded specific details and provided a large amount of autonomy to the student. The ambiguous condition did not provide a rationale for that autonomy. Teachers may wish to withhold information from students to assess the extent to students can work through uncertainty. The findings of the present study indicate that an ambiguous assignment provided students with more utility in their lives. For example, if instructors want to see if students can apply a number of course concepts to a product and there are a variety of ways they can do this, ambiguity may 
allow teachers to assess whether or not students have truly learned to apply the material on a higher level.

Teachers and researchers have a tendency to think of clarity and ambiguity as dichotomous, but they should not. There are reasons to implement both ideas and both clarity and strategic ambiguity can exist in the same classroom. Teachers should balance the extent to which the employ clarity and strategic ambiguity and carefully consider the implications of employing either construct. For example, if an instructor wants to use ambiguity to promote student transfer of learning, they should understand that it may have negative implications for student competence. Further, while clarity is sometimes warranted, an overreliance on clarity may stifle student learning. Students do not view clear assignments as allowing them to transfer their learning. To balance this, teachers should carefully consider the messages they are sending. For example, perhaps teachers can give clear assignment directions, but not provide a rubric that may serve as a checklist or provide an example, which may cause them to use the example as a standard of excellence. In doing so, it is possible that students will have enough clarity to promote competence, but not so much as to stifle transfer of learning.

\section{Ambiguity Verses Strategic Ambiguity}

Interestingly, students reported more perceived learner benefits in the ambiguous condition than in the strategically ambiguous condition. The primary difference between the ambiguous condition and the strategically ambiguous condition was the rationale that explained to students that they would need to reason through ambiguity for their own benefit and that this was intentional on the part of the instructor. Scholars have suggested that the focus on assessment and accountability in our education system is hindering student's creativity (Beghetto, 2005) and critical thinking (Torrance, 1970). Wootton (2002) argued that our 
educational system does not support an appreciation of learning, and the present research indicates this may be the case. The strategically ambiguous condition was deliberate in explaining that while the assignment was different than what students may be familiar with, the benefit to students was transfer of learning. Unfortunately, it was never perceived as the most positive learning experience by students. When students were blatantly told why they should appreciate this type of learning, they did not view it as beneficial; however, when they were not told that it was ambiguous, or why it was ambiguous, they consistently reported the learning as more desirable. This speaks to student's initial discomfort with strategic ambiguity indicated by past research (Rippin et al., 2002; Wright, 2019). It appears that students are uncomfortable with assignments when they know they are missing guidance, but not when they do not know they are missing guidance. It is possible that the rationale for employing strategic ambiguity is not necessary-students do not know what they do not know-and pointing out the ambiguity had negative implications. Accordingly, teachers must decide if and when an assignment is ambiguous. Results of the present study do not suggest that strategic ambiguity is bad, but they do indicate that when assigning an ambiguous assignment, it may be problematic to explain the rationale in the beginning. Importantly, although the operationalization of ambiguity and strategic ambiguity in this study suggest that an instructor must explain their use of ambiguity to be strategic, it is possible for an instructor to be strategically ambiguous without explaining the use of ambiguity to students.

When students are told something will be challenging or different from what they have come to expect, they take on a negative attitude. Perhaps when employing strategic ambiguity, instructors should not begin by deliberately telling students that they are being ambiguous. This research potentially supports the conclusion of Brooks and Young (2011) who asserted that too 
much choice making can have adverse effects for students. The strategically ambiguous condition presented students with many options at once, and that had negative implications. Additionally, it could be that because ambiguity hurts competence, that has negative implications for other outcomes. Accordingly, teachers could work to build students competence in other ways such as through classroom activities. For example, teachers could conduct a low-stakes, in class activity that employs ambiguity. When students complete that activity, teachers can emphasize the positive outcome and deliberately point out to students that they are capable of working through ambiguity. In doing so, instructors may help students build competence in their ability to work through ambiguity, which should promote the acceptance of strategic ambiguity. Whether or not to provide a rationale for ambiguity or not, and to what level, should be carefully considered by educators.

\section{Student Background}

Unfortunately, students have been raised in an era of accountability that hurts their ability to accept strategic ambiguity or ambiguity. Bledsoe and Baskin (2014) argued that students' expectations for learning are shaped primarily by their past educational experiences. Since $A$ Nation at Risk, elementary and secondary education students have been overwhelmed with standardized assessments (Mehta, 2013). In the same vein, the Higher Education Act of 2003 has introduced this same level of assessment and accountability in higher education (Eaton, 2010). As a result, students have been conditioned to view answers with a clear answer as the best reflection of their learning. Students are used to looking for one correct answer (Wootton, 2002); thus, when presented with opportunities for multiple correct answers, students were uncomfortable on many levels. Wright (2019) found that students are very grade focused and like a clear grading criterion. Past research suggests that students prefer clear grading criterion 
because it allows them to determine the importance of various parts of an assignment (Percell, 2014), gives them targets for their work, and allows them to determine if grading is fair (Reddy \& Andrade, 2010). Interestingly, in the present study, when students were told that they would not get a clear grading criterion and they had latitude in their completion of the assignment, they reported fewer positive feelings toward the learning that could take place than when the assignment was ambiguous with no justification. For this reason, teachers must work to overcome the systemic biases students bring with them to the classroom since strategic ambiguity is inconsistent with student's past experiences.

Further, students may not have thought the strategically ambiguous assignment was fair. Students also have a strong focus on fairness in procedures and grading (Chory-Assad, 2002; Horan et al., 2010; Wright, 2019). When students feel that instructors have fair policies and grading procedures, they expressed more enthusiasm toward the course and content (ChoryAssad, 2002) and felt nurtured and included (Bledsoe \& Baskin, 2014). It is possible that, because the strategically ambiguous assignment was unlike what students have experienced in the past, they felt that the assignment or the potential grades were unfair, thus negatively impacting their learner empowerment and affective learning. As such, instructors should employ strategic ambiguity over a period of time, after gaining the trust of students, so students can hopefully understand that teachers may have ambiguous assignments and still be fair in their assessment practices. This study supports the sentiments of Klyukovski and MedlockKlyukovski (2016) who asserted that there is a dialogical relationship between clarity and strategic ambiguity since they both contribute to student's ability to make meaning of the learning environment. 
Student's negative attitude toward ambiguity has implications for them throughout their schooling. Although students tend to be grade-oriented and prefer clarity, teachers should encourage them to pull away from their crutches for the betterment of their learning. When students are forced to think through the benefits of an ambiguous assignment, they see merit (Wright, 2019). For this reason, it would behoove students to acknowledge that discomfort and struggle can lead to learning, particularly as working in a changing environment is desired in the workplace (Banning, 2003; Herman et al., 2010; Rippin et al., 2002). To aid students in this process, instructors should point out to students that they tend to focus on clear, easy answers; however, that is not in their best interest long term. It is possible that this is dependent on the type of assignment, also. For example, assigning a speech using ambiguity may present different results than using ambiguity on an exam. The results of this study indicate that pointing out the benefits of strategic ambiguity is not advantageous; however, it still seems reasonable that students would be more accepting of ambiguity if they had a holistic understanding of the learning benefits. Additionally, it is possible that the use of clarity and strategic ambiguity should vary for different populations. For example, students in college for the first time who are used to the rigid nature of our secondary education system may need more coaching to accept strategic ambiguity or ambiguity than graduate students. Teachers must decide, based on their specific students, if they should employ strategic ambiguity and, if so, how to employ it. Arguably, there are instructors at various levels using less rigid forms of assessment, but determining how and when to integrate this practices on a larger scale is still of interest.

Further, instructors must consider when and how to unfold the rationale behind their teaching practices. Learning occurs best when students put further their best effort, which may require struggle (Klyukovski \& Medlock-Klyukovski, 2016). Teachers should help students 
understand this and give activities, beyond just assessment, that require struggle, and praise students for their efforts throughout. In doing so, students can complete low-stakes tasks that employ ambiguity and see first-hand the positive benefits obtained as a result. Students need to become comfortable with effort and struggle to enhance their learning outcomes. As a result, teachers ought to give students low-stakes opportunities to get comfortable with ambiguity.

\section{Student Characteristics}

Beyond students being conditioned to prefer clarity, this study found that two student characteristics, TFA and learning orientation, were related to the dependent variables. If a teacher wishes to employ strategic ambiguity, they need to understand that some students may be receptive to it, while other students may not. Although this study does not indicate exactly how TFA impacts the learning outcomes, it does tell us that it matters, and teachers need to recognize that there is a range of tolerance related to ambiguity. Similarly, learning orientation impacts the learning outcomes, so instructors need to be aware that a student's disposition has implications for their reaction to instructor messaging.

Banning (2003) found that case studies can improve students' TFA and students with high TFA performed better in their course. For teachers, this means that, if TFA is important to acceptance of ambiguous assignments, teachers should work to enhance students TFA. On the other hand, students should be aware that they may be holding on to traits that are stifling their learning and, that they can improve their reactions to ambiguous situations to be successful. Teachers can help students understand the manner in which students are holding on to these traits. When considering what to teach and assess and how to do it, instructors should consider the students in their class, also. The present study indicates that a student's TFA and learning 
orientation are impacting their learning outcomes; thus, teachers need to determine the best way to help these students appreciate and accept uncertainty.

\section{Scaffolding}

Perhaps the most important takeaway from this study is that instructors must make a conscious decision regarding how and when to disclose a rationale behind their decisions. Findings of the present study do not suggest that clarity or strategic ambiguity are bad, but they do suggest that there are implications for the messaging provided when initially giving an assignment. Teachers have reasons for everything they do in the classroom. Typically, they have thought through their assignments from start to finish. It is important to consider, then, when and if teachers should disclose this to students. The results of this study indicate that, when initially given a lot of details, whether through strategic ambiguity or clarity, students react adversely. This indicates that both clarity and the rationale for strategic ambiguity could be overwhelming. As a result, it seems that when giving an assignment, instructors should slowly release details. It is not advantageous for an instructor to provide all of the details about an assignment from the beginning. Instead, instructors should slowly provide details about the assignment over time. Teachers tend to want to talk about every detail of an assignment when they assign it, but this may be overwhelming to students. When presenting an assignment, it might be beneficial for instructors to tell students to think about the assignment topic and how to complete it as well as assure them not to concern themselves with the specific guidelines. For example, if a teacher were providing the persuasive paper assignment used for the manipulation in this study, they might begin by simply telling students they are going to write a persuasive paper selling a product and ask students to begin thinking about what product they might want to sell. Throughout the class, they can slowly release more details about specifics. Perhaps, instead of 
providing examples when explaining the assignment, teachers should provide them while explaining the content, after having mentioned the assignment at the beginning of the unit. In this way, teachers need to be very deliberate about their course planning.

This has implications for constructing a course as well as the messages sent on the first day of class. When planning a course, instructors tend to put a great deal of information regarding major assignments, assessments, and expectations in the syllabus. This could be overwhelming for students and create an adverse reaction to the course. When planning the course, instructors should consider when to release information to students, knowing that it is not best to do so all at the beginning. Regardless of whether an instructor wants to employ clarity or strategic ambiguity, a gradual introduction of information is warranted to ensure students do not feel overwhelmed — especially if instructors are concerned about student learning.

\section{Multivariate Classroom Environment}

Ultimately, the classroom is a multivariate environment that cannot be studied out of context. For teachers who use strategic ambiguity intentionally and in meaningful ways to facilitate student learning, strategic ambiguity is likely to be deeply integrated into everything a teacher does. There are multiple variables that impact student learning, for example, clarity and content relevance. Clarity research links the variable with immediacy to impact student learning (Chesebro, 2003; Chesebro \& McCroskey, 2001, Comadena et al., 2007; Finn \& Schrodt, 2012; Mottet et al., 2008). Further, variables such as teacher caring (Comadena, et al., 2007) and content relevance behaviors (Mottet et al., 2008) impact student learning. Learner empowerment is impacted by relevance strategies and teacher immediacy (Fymier et al., 1996). Frymier et al. concluded that the classroom environment has implications for learner empowerment. Past research reveals that teaching and learning is a dynamic process, impacting student learning and 
learner empowerment; therefore, making a case for integrating strategic ambiguity in a course in order to account for the complex nature of the classroom environment. Specifically, strategic ambiguity should be employed using scaffolding, slowly removing instructor prompts to promote student transfer of learning, as indicated by Titsworth and Mazer (2010). One explanation for why strategic ambiguity and clarity were not perceived positively is that this study did not account for the full classroom environment. Accordingly, teachers must understand that nothing they do in the classroom happens in a vacuum.

\section{Overall Practical Implications}

On a large scale, the current research sought to understand if the use of strategic ambiguity in assessments could yield positive learning outcomes and, if so, forward a line of research that could offer alternatives to the rigid philosophy of standardization plaguing the American education system. Fried (2005) argued that the American education system is teaching students how to play "the Game of School," rather than instilling a love for learning (p. ix). Teachers need to decide if they want to keep encouraging this "game," or if they want to change the course for the better. Gibbs and Simpson (2005) articulated that students know how to take an assignment and use it to enhance their grade as opposed to actually learn. With the foundational understanding that instructor messaging regarding an assignment can influence student learning, it is time for educators and stakeholders to determine how to navigate the tenuous balance between clarity and strategic ambiguity.

Educators cannot ignore the negative implications of continuously telling students what to do and how to do it. The classroom is a multivariate environment, meaning that at any given time, there is more than one variable impacting student/teacher interactions. Teachers and researchers need to consider the plethora of ways learning can be enhanced. It seems that 
education has approached a plateau where assessments promoting right and wrong answers have become expected by students. The messages presented regarding classroom assessments have implications for the learning outcomes met through those assessments. To fully appreciate the extent to which student learning can be promoted outside of clear assessments, it is time for teachers to push back on standardized assessments and introduce valid and fair assessments that leave room for student autonomy. In doing so, teacher will work toward reclaiming higher education as a venue which promotes student inquiry.

\section{Limitations}

Although this study makes meaningful contributions to instructional literature, it is not without limitations. To begin, there were some limitations related to variables. In conducting the MANCOVA to test the hypothesis, it is ideal for all covariates to be correlated with the dependent variables (Pituch \& Stevens, 2016). Unfortunately, mindset was not correlated with meaningfulness and grade orientation was not correlated with meaningfulness or competence. This may have contributed to the finding that neither mindset nor grade orientation were related to the dependent variables. Further, this study only measures some of the variables that potentially impact instructor messaging regarding assignments. Variables such as student motivation, instructor immediacy, and student trust in instructors were not accounted for. Likewise, not all of the positive learning outcomes that can be derived from the assignment conditions were accounted for. Specifically, variables such as cognitive learning, student emotions, and critical thinking were not reflected in this study. As such, the present study does not capture a full picture of the learning environment and, instead, only provides a snap shot of one instructor message that occurs at one point in time. Unfortunately, the conclusions that can be drawn from the covariates (TFA, mindset, and learning orientation and grade orientation) are 
limited. The results of this study do not indicate how or to what extent the covariates are impacting the dependent variables, which limits the conclusions that can be made regarding student characteristics.

There were also limitations in the design of the study. The study was limited by the use of a single institution to collected data and the narrow diversity among students. For example, students in this research were primary undergraduate students and, more specifically, underclassman. They were also largely female and White/Caucasian. These limitations hurt the generalizability of the findings. It stands to reason that graduate students and undergraduate students would respond to strategic ambiguity differently; however, this study did not account for that. Additionally, the study was conducted via a survey, so it lacks ecological validity. It is quite possible that strategic ambiguity is best implemented across a curriculum as opposed to in one assignment; and this study does not account for the longitudinal, dialectic nature of the classroom. Additionally, students did not actually complete the assignments they responded to; thus, the responses may not reflect responses in an actual classroom. Although the manipulation check indicated the manipulation worked, it was not as straight forward as it could have been. It is possible that students were overwhelmed with the amount of information and that should have been asked as a part of the manipulation check scale. Further, the research was conducted using self-reported data, which relies on students' perceptions of themselves and my not fully reflect student learning.

Finally, there were also limitations related to survey measures. First, the TFA scale was weak. Although past studies have employed this scale, it lacked strong reliability, so it is possible that it is not measuring TFA in the best manner. Similarly, the operationalization of meaningfulness and affective learning was similar, which could have implications for the 
findings as they may not have been measuring unique constructs. The scales for learning and grade orientation were also not ideal. The scales had low variance and a small number of items each. Accordingly, the scales may have not been the best measure of learning orientation and grade orientation. This research provides a glimpse of the way instructor messaging impacts student learner empowerment and affective learning; however, future research is needed to verify the results and advance this line of research.

\section{Suggestions for Future Research}

Per the limitations, there are many opportunities for future research. To begin, future research should further operationalize and parse out different variables. One of the most difficult tasks when completing this research was to integrate similar constructs from across disciplines and integrate them in one study. Future research should examine how the different constructs are studied to determine how similar they are related. For example, TFA, uncertainty orientation, and adaptability are all very similar constructs explored in different studies across different disciplines. Research should determine how these variables might be related and work to take a cross-disciplinary approach to develop a full understanding of current research. Moreover, future research is necessitated to explore the overlap between affective learning and learner empowerment. While the affective learning scale created for this study was promising, scholars should work to further validate and refine the scale. To fully capture the multivariate classroom environment, future studies should explore additional variables such as motivation, trust, and fairness as they relate to instructor messaging regarding assignments.

A longitudinal study on instructor messaging regarding assignments would be ideal. Future research should explore strategic ambiguity with real instructors in real classrooms. It is difficult for students to find meaning for assignments out of context, so results may be more 
impactful in an actual learning environment where students and teachers have built relationships. Also, student-teacher relationships, specifically trust, could impact reactions to strategic ambiguity. Additionally, there is a need to determine how to best operationalize strategic ambiguity and clarity. As is, there is acknowledgement that both constructs are valid and can lead to positive learning outcomes; however, the relationship between them and the conceptualization of each construct varies across research studies and across disciplines. Studies should also explore teacher perspectives regarding the use of strategic ambiguity in assessments. For example, it would be beneficial to know whether or not teachers perceive students as responding favorably to strategic ambiguity. Importantly, the impact of covariates such as TFA and learning orientation should be examined. Research is needed to determine exactly how these variables impact student responses to instructor messaging regarding assignments. This study provided a basic introduction to the student characteristics that impact response to instructor messaging, but the extent to which student characteristics impact learning outcomes needs studied.

It is also possible that the type of assignment impacts responses to strategic ambiguity, and future research should explore this idea. For example, the current study used a summative persuasive writing assignment. Researchers should examine different types of assignments such as speaking assignments, formative assignments, in class and out of class assignments, or any other assessment type. This also needs explored in different disciplines and with a greater variety of learner levels. For example, it stands to reason that first time college students who came out of a standardized K-12 schooling system would respond differently to strategic ambiguity than upper classman or graduate students, and future research should explore these populations. Additionally, it is possible that certain disciplines lend themselves more favorably to ambiguity 
than others. Also, given the increase in online learning, the use of strategic ambiguity in face-toface verses online classes should be explored.

Additionally, the affective learning scale needs further developed. Specifically, the commonly used semantic differential scale that is used provides limited understanding of affective learning. The present study created an affective learning scale that measures the construct using a Likert response scale and this could prove more accurate and future research should build on the scale developed for this study in order to refine a more holistic affective learning scale. Both clarity and strategic ambiguity could lead to increased affective learning, and future research should seek to determine if there are differences in how they might do this. With a stronger measure of affective learning, scholars can better understand how assessment and instructor messages impact affective learning. Further, future research should seek to focus on cognitive learning in regard to instructor messaging as opposed to just affective learning. It is important to not only understand students' feelings toward learning, but also their actual gained knowledge. If future research could better explain conditions under which assignment outcomes can be enhanced, practitioners could more confidently promote learning among students.

\section{Conclusion}

The current study explored the role of instructor messaging about assignments on student learning outcomes. Teacher clarity is considered a norm in American education. Although clarity has many benefits to students, other ways in which student learning can be enhanced are underexplored. Through examining how instructor messaging impacts student learning, this study found that the message surrounding an assignment does have implications for student learning; specifically, students reported the most learning with an ambiguous assignment. Furthermore, the covariates of TFA and learning orientation were related to the set of dependent 
variables, which warrants the consideration of these student characteristics when making decisions regarding classroom assessment. Teachers make a variety of decisions regarding messages every day and communication related to assignments must be considered too.

There is a lack of research to fully understand the role of instructor messaging for classroom assessments; however, we know there are implications for how and when these messages are delivered. As such, researchers, teachers, and students need to be aware of how clarity and strategic ambiguity impact student learning. By expanding this line of research and teaching practice, educators can better serve a variety of students in a manner that promotes learning and critical thinking.

Thus, the critical takeaways from the data presented in this study are that instructor messaging regarding an assignment and the student characteristics of TFA and learning orientation impact student learning. Specifically, ambiguous instructor messages lead to the most student learning, which means instructors need to be deliberate in the messages they send regarding an assignment when initially presenting it to students. It is possible to give students so much information it adversely impacts learning. Likewise, students come to classrooms with specific characteristics and instructors should understand these characteristics in an attempt to best serve all students. In doing so, instructors and students can have a more positive, productive learning experience. 


\section{REFERENCES}

Aronson, J., Fried, C. B., \& Good, C. (2001). Reducing the effects of stereotype threat on African American college students by shaping theories of intelligence. Journal of Experimental Social Psychology, 38, 113-135. doi:10.1006/jsep.2001.1491

Avtgis, T. A. (2001). Affective learning, teacher clarity, and student motivation as a function of attributional confidence. Communication Research Reports, 18(4), 345-352. doi:10.1080/08824090109384815

Banning, K. C. (2003). The effect of the case method on tolerance for ambiguity. Journal of Management Education, 27(5), 556-567. doi:10.1177/1052562903252652

Barkley, E. F. (2010). Student engagement techniques: A handbook for college faculty. San Francisco, CA: Jossey-Bass.

Beghetto, R. A. (2005). Does assessment kill student creativity? The Educational Forum, 69, 255-263. doi:10.1080/00131720508984694

Blackwell, L. S., Trzesniewski, K. H., \& Dweck, C. S. (2007). Implicit theories of intelligence predict achievement across an adolescent transition: A longitudinal study and an intervention. Child Development, 78(1), 246-263. doi:10.1111/j.1467-8624.2007.00995.x

Bledsoe, T. S., \& Baskin, J. J. (2014). Recognizing student fear: The elephant in the classroom. College Teaching, 62(1), 32-41. doi:10.1080/87567555.2013.831022

Bloom, B. S., Engelhart, M. D., Furst, E. J., Hill, W. H., \& Krathwohl, D. R. (1956). Taxonomy of educational objectives: Cognitive domain. New York, NY: Longman. 
Bolkan, S., Goodboy, A. K., Kelsey, D. M. (2016). Instructor clarity and student motivation: Academic performance as a product of students' ability and motivation to process instructional material. Communication Education, 65(2), 129-148. doi:10.1080/03634523.2015.1079329

Bolkan, S., \& Griffin, D. J. (2018). Catch and hold: Instructional interventions and their differential impact on student interest, attention, and autonomous motivation. Communication Education, 67(3), 269-286. doi:10.1080/03634523.2018.1465193

Brooks, C. F., \& Young, S. L. (2011). Are choice-making opportunities needed in the classroom? Using self-determination theory to consider student motivation and learner empowerment. International Journal of Teaching and Learning in Higher Education, 25(1), 48-59. Retrieved from http://www.isetl.org/ijtlhe/

Brunson, D. A., \& Vogt, J. F. (1996). Empowering our students and ourselves: A liberal democratic approach to the communication classroom. Communication Education, 45, 73-83. doi:10.1080/03634529609379033

Budner, S. (1962). Intolerance of ambiguity as a personality variable. Journal of Personality, 30(1), 29-50. doi:10.1111/j.1467-6494.1962.tb02303.x

Carver, R. H. (2006, August). Ambiguity intolerance: An impediment to inferential reasoning? Paper presented at the annual meeting of the American Statistical Association, Seattle, WA.

Claro, S., Paunesku, D., \& Dweck, C. S. (2016). Growth mindset tempers the effects of poverty on academic achievement. Proceedings of the National Academy of Sciences, 113(31), 8664-8668. doi:10.1073/pnas.1608207113 
Chesebro, J. L. (2003) Effects of teacher clarity and nonverbal immediacy on student learning, receiver apprehension, and affect. Communication Education, 52(2), 135-147. doi:10.1080/03634520302471

Chesebro, J. L., \& McCroskey, J. C. (1999). The relationship of teacher clarity and immediacy with student state receiver apprehension, affect, and cognitive learning. Communication Education, 50(1), 59-68. doi:10.1080/03634520109379232

Chesebro, J. L. \& McCroskey, J. C. (2001). The relationship of teacher clarity and immediacy with student state receiver apprehension, affect, and cognitive learning. Communication Education, 50(1), 59-68, doi:10.1080/03634520109379232

Chesebro, J. L., \& Wanzer, M. B. (2006). Instructional message variables. In T. P. Mottet, V. P. Richmond, \& J. C. McCroskey (Eds.), Handbook of instructional communication: Rhetorical and relational perspectives (pp. 89-116). Boston, MA: Pearson.

Chory, R. M., \& McCroskey, J. C. (1999). The relationship between teacher management communication style and affective learning. Communication Quarterly, 47(1), 1-11. doi:10.1080/01463379909370120

Chory-Assad, R. M. (2002). Classroom justice: Perceptions of fairness as a predictor of student motivation, learning, and aggression, Communication Quarterly, 50(1), 58-77. doi: $10.1080 / 01463370209385646$

Christophel, D. M., (1990). The relationships among teacher immediacy behaviors, student motivation, and learning. Communication Education, 39, 323-340. doi:10.1080/03634529009378813 
Collie, R. J., Holliman, A. J., Martin, A. J. (2017). Adaptability, engagement and academic achievement at university. Educational Psychology, 37(5), 632-647. doi:10.1080/01443410.2016.1231296

Comadena, M. E., Hunt, S. K., \& Simonds, C. J. (2007). The effects of teacher clarity, nonverbal immediacy, and caring on student motivation, affective and cognitive learning. Communication Research Reports, 24(3), 241-248. doi:10.1080/0882409070144617

Dannels, D. P. (2015). Eight essential questions teachers ask. New York, NY: Oxford.

DeRoma, V. M., Martin, K. M., \& Kessler, M. L. (2003). The relationship between tolerance for ambiguity and need for course structure. Journal of Instructional Psychology, 30, 104109. Retrieved from http://www.projectinnovation.biz/index.html

DeVellis, R. F. (2003). Scale development: Theory and applications (2 ${ }^{\text {nd }}$ ed.): Vol 26. Applied social research methods series. Thousand Oaks, CA: Sage.

Dweck, C. S. (2000). Self-theories: Their role in motivation, personality, and development. New York, NY: Taylor \& Francis.

Dweck, C. S., Chiu, C., \& Hong, Y. (1995). Implicit theories and their role in judgments and reactions: A world from two perspectives. Psychological Inquiry, 6(4), 267-285. doi:10.1207/s15327965pli0604_1

Dweck, C. S., Hong, Y., \& Chiu, C. (1993). Implicit theories: Individual differences in the likelihood and meaning of dispositional inference. Personality and Social Psychology Bulletin, 19(5), 644-656. doi:10.1177/0146167293195015

Eaton, J. S. (2010). Accreditation and the federal future of higher education. Academe, 96(5), 2124. Retrieved from http://www.jstor.org/stable/25799818 
Eisenberg, E. (1984). Ambiguity as a strategy in organizational communication. Communication Monographs, 51, 149-242. doi:10.1080/03637758409390197

Frey, T. K., Simonds, C. J., Hooker, J., Meyer, K., \& Hunt, S. (2018). Assessing evaluation fidelity between students and instructors in the basic communication course: The impact of criterion-based speech evaluation training. Basic Communication Course Annual, 30, 2-31. Retrieved from: https://ecommons.udayton.edu/bcca

Finn, A. N., \& Schrodt, P. (2012). Students' perceived understanding mediates the effects of teacher clarity and nonverbal immediacy on learner empowerment. Communication Education, 61(2), 111-130. doi:10.1080/03634523.2012.656669

Fried, R. L. (2005). The game of school: Why we play it, how it hurts kids, and what it will take to change it. San Francisco, CA: Josey-Bass.

Frymier, A. B. (2016). Students' motivation to learn. In P. Witt (Ed.), Communication and learning (pp. 377-396). Boston, MA: DeGruyter Moulton.

Frymier, A. B., Shulman, G. M., \& Houser, M. (1996). The development of a learner empowerment measure. Communication Education, 45(3), 181-199. doi: $10.1080 / 03634529609379048$

Frymier, A. B., \& Weser, B. (2001). The role of student predispositions on student expectations for instructor communication behavior. Communication Education, 50(4), 314-326. doi:10.1080/03634520109379258

Furnham, A., \& Marks, J. (2013). Tolerance for ambiguity: A review of the recent literature. Psychology, 4(9), 717-728. doi:10.4236/psych.2013.49102

Gabella, M. S. (1995). Unlearning certainty: Toward a culture of student inquiry. Theory into Practice, 34(4), 236-242. doi:10.1080/00405849509543686 
Gibbs, G., \& Simpson, C. (2005). Conditions under which assessment supports students learning. Learning and Teaching in Higher Education, 1, 3-31. Retrieved from http://eprints.glos.ac.uk/id/eprint/3609

Good, C., Aronson, J., \& Inzlicht, M. (2003). Improving adolescents's standardized test performance: An intervention to reduce the efforts of stereotype threat. Applied Developmental Psychology, 24, 645-662. doi:10.1016/j.appdev.2003.09.002

Guskey, T. R., \& Jung, L. A. (2013). Answers to essential questions about standards, assessment, grading and reporting. Thousand Oaks, CA: Corwin.

Herman, J. L., Stevens, M. J., Bird, A., Mendenhall, M., \& Oddou, G. (2010). The tolerance for ambiguity scale: Toward a more refined measure for international management research. International Journal of Intercultural Relations, 34, 58-65. doi:10.1016/j.ijintrel.2009.09.004

Holliman, A. J., Martin, A. J., \& Collie, R. J. (2018). Adaptability, engagement, and degree completion: A longitudinal investigation of university students. Educational Psychology, 37(5), 1-15. doi:10.1080/01443410.2018.1426835

Houser, M. L., \& Frymier, A. B. (2009). The role of student characteristics and teacher behaviors in students' leaner empowerment. Communication Education, 58(1), 35-53. doi:10.1080/03634520802237383

Huber, N. (2003). An experiential leadership approach for teaching tolerance for ambiguity. Journal of Education for Business, 79(1), 52-55. doi:10.1080/08832320309599088

Ingman, B. C., \& Moroye, C. M. (2019). Experience-based objectives. Educational Studies, O(0), 1-22. doi:10.1080/00131946.1544900 
Kajs, L. T., \& McCollum, D. L. (2009). Examining tolerance for ambiguity in the domain of educational leadership. Academy of Educational Leadership Journal, 13(2), 1-16. Retrieved from https://www.abacademies.org/journals/academy-of-educationalleadership-journal-home.html

Kearney, P. (1994). Affective learning. In R. B. Rubin, P. Palmgreen, \& H. E. Sypher (Eds.), Communication research measures (pp. 81-85). New York, NY: Guilford.

Klyukovski, A. A., \& Medlock-Klyukovski, A. L. (2016). Instructor strategic ambiguity: delineation of the construct and development of a measure. Communication Education, 65(3), 253-271. doi:10.1080/03634523.2016.1142097

Kohn, A. (1993). Punished by rewards: The trouble with gold stars, incentive plans, A's, praise, and other bribes. New York, NY: Houghton Mifflin.

Kohn, A. (2011, November). The case against grades. Educational Leadership, Retrieved from http:/www.alfiekohn.org/article/case-grades/

Krathwohl, D. R., Bloom, B. S., \& Masia, B. B. (1964). Taxonomy of educational objectives: Affective domain. New York, NY: Longman.

Lalley, J. P., \& Gentile, J. R. (2009). Classroom assessment and grading to assure mastery. Theory into Practice, 48(1), 28-35. doi:10.1080/00405840802577577

Land, M. L. (1979). Low-inference variables of teacher clarity: Effects on student concept learning. Journal of Experimental Psychology, 71, 795-799. doi:10.1037/00220663.71.6.795

Land, M. L., \& Smith, L. R. (1979a). Effect of a teacher clarity variable on student achievement. The Journal of Educational Research, 72, 196-197. doi:10.1080/00220671.1979.10885152 
Land, M. L., \& Smith, L. R. (1979b). The effect of low inference teacher clarity inhibitors on student achievement. Journal of Teacher Education, 30(3), 55-57. doi: $10.1177 / 002248717903000322$

LePine, J. A., Colquitt, J. A., \& Erez, A. (2000). Adaptability to changing contexts: Effects of general cognitive ability, conscientiousness, and openness to experience. Personnel Psychology, 53(3), 563-593. doi:10.1111/j.1744-6570.2000.tb00214.x

Martin, A. J., Nejad, H. G., Colmar, S., \& Liem, G. A. D. (2013). Adaptability: How students' responses to uncertainty and novelty predict their academic and non-academic outcomes. Journal of Educational Psychology, 105(3), 728-746. doi:10.1037/a0032794

Marzano, R. J. (2010). Formative assessment \& standards-based grading. Bloomington, IN: Marzano Research Laboratory.

Mazer, J. P. \& Graham, E. E. (2015). Measurement in instructional communication research: A decade in review. Communication Education, 46(2), 208-240. doi:10.1080/03634523.2014.1002509

McBride, C., Kirby, E., Bergen, K. M., Wahl, S. T., Norander, S., \& Robinson, T. (2016). Social identities in the classroom. In P. Witt (Ed.), Communication and learning (pp. 337-375). Boston, MA: DeGruyter Moulton.

McCroskey, J. C., Richmond, V. P., \& McCroskey, L. L. (2006). An introduction to communication in the classroom: The role of communication in teaching and training. Boston, MA: Pearson.

McLain, D. L. (2009). Evidence of the properties of an ambiguity tolerance measure: The Multiple Stimulus Types Ambiguity Tolerance Scale II (MSTAT-II). Psychological Reports, 105, 975-988. doi:10.2466/PR0.105.3.975-988 
McMorran, C., Ragupathi, K., \& Luo, S. (2015). Assessment and learning without grades? Motivations and concerns with implementing graceless learning in higher education. Assessment \& Evaluation in Higher Education, 43(3), 361-377. doi:10.1080/02602938.2015.1114584

Mehta, J. (2013). The allure of order: High hopes, dashed expectations, and the troubled quest to remake American schooling. New York, NY: Oxford.

Mertler, C. A., \& Vannatta, R. A. (2005). Advanced and multivariate statistical methods: Practical application and interpretation (3rd ed.). Glendale, CA: Pyrczak.

Mottet, T. P., \& Beebe, S. A. (2006). Foundations of instructional communication. In T. P. Mottet, V. P. Richmond, \& J. C. McCroskey (Eds.), Handbook of instructional communication: Rhetorical and relational perspectives (pp. 3-32). Boston, MA: Pearson.

Mottet, T. P., Garza, R., Beebe, S. A., Houser, M. L., Jurrells, S., \& Furler, L. (2008). Instructional communication predictors of ninth-grade students' affective learning in math and science. Communication Education, 57(3), 333-355. doi:10.1080/03634520801989950

Myers, S. A., Goodboy, A. K., \& Members of, COMM 600. (2014). College student learning, motivation, and satisfaction as a function of effective instructor communication behaviors. Southern Communication Journal, 79(1), 14-26. doi:10.1080/1041794X.2013.815266

Nordin, K., \& Broeckelman-Post, M. A. (2019). Can I get better? Exploring mindset theory in the introductory communication course. Communication Education, 68(1), 44-60. doi:10.1080/03634523.2018.1538522 
Percell, J. C. (2014). The value of a pointless education. Educational Leadership, 71(3).

Retrieved from http://www.ascd.org/publications/educational-leadership.aspx

Pituch, K. A., \& Stevens, J. P. (2016). Applied multivariate statisitcs for the social sciences: Analysis with SAS and IBM's SPSS (6 ${ }^{\text {th }}$ ed.). New York: NY: Routledge.

Ployhart, R. E., \& Bliese, P. D. (2006). Individual adaptability (I-ADAPT) theory: Conceptualizing the antecedents, consequences, and measurement of individual differences in adaptability. In C. S. Burke, L. G. Pierce, \& E. Salas (Eds.), Understanding adaptability: A prerequisite for effective performance within complex environments (pp. 3-39). San Diego, CA: Elsevier.

Pogue, L. L., \& Ahyun, K. (2006). The effect of teacher nonverbal immediacy and credibility on student motivation and affective learning. Communication Education, 55(3), 331-344. doi:10.1080/03634520600748623

Pollio, H. R., \& Beck, H. P. (2000). When the tail wags the dog: Perceptions of learning and grade orientation in, and by, contemporary college students and faculty. The Journal of Higher Education, 71(1), 84-102. doi:10.2307/2649283

Reddy, Y. M., \& Andrade, H. (2010). A review of rubric use in higher education. Assessment \& Evaluation in Higher Education, 35(4), 435-448. doi:10.10801/02602930902862859

Rippin, A., Booth, C., Bowie, S., \& Jordan, J. (2002). A complex case: Using the case study method to explore uncertainty and ambiguity in undergraduate business education. Teaching in Higher Education, 7(4), 429-441. doi:10.1080/1356251

Rubin, R. B. (2011). Learner empowerment. In R. B. Rubin, A. M. Rubin, E. E. Graham, E. M. Perse, \& D. R. Seibold (Eds.), Communication Research Measures II (pp. 187-195). New York, NY: Routledge. 
Sisk, V. F., Burgoyne, A. P., Sun, J., Butler, J. L., \& Macnamara, B. N. (2018). To what extent and under which circumstances are growth mind-sets important to academic achievement? Two meta-analyses. Psychological Science, 29(4), 549-571. doi:10.1177/0956797617739704

Sorrentino, R. M., Short, J. C., \& Raynor, J. O. (1984). Uncertainty orientation: Implications for affective and cognitive views of achievement behavior. Journal of Personality and Social Psychology, 46(1), 180-206. doi:10.1037/0022-3514.46.1.189

Stewart, C. O., McConnell, J. R., Stallings, L. A., \& Roscoe, R. D. (2017). An initial exploration of students' mindsets, attitudes, and beliefs about public speaking. Communication Research Reports, 34(2), 180-185. doi:10.1080/08824096.2016.1270821

Stitt, J. K., Simonds, C. J., \& Hunt, S. K. (2003). Evaluation fidelity: An examination of criterion-based assessment and rater training in the speech communication classroom. Communication Studies, 54(3), 341-353. doi:10.1080/1051097030963290

Sweeney, R. B., \& Owen, W. N. (2002). Categorizing ambiguity in assignments: A pilot study. Proceedings of ISECON 2002, USA, 19, 1542-7382. Retrieved from http://citeseerx.ist.psu.edu/viewdoc/download?doi=10.1.1.595.2807\&rep=rep1\&type=pdf

Titsworth, S., \& Mazer, J. P. (2010). Clarity in teaching and learning: Conundrums, consequences, and opportunities. In D. L. Fasset \& J. T. Warren (Eds.), The Sage handbook of instructional communication and instruction (pp. 241-262). Thousand Oaks, CA: Sage.

Titsworth, S., \& Mazer, J. P. (2016). Teacher clarity: An analysis of current research and future directions. In P. Witt (Ed.), Communication and learning (pp. 105-128). Boston, MA: DeGruyter Moulton. 
Titsworth, S., Mazer, J. P., Goodboy, A. K., Bolkan, S., \& Myers, S. A. (2015). Two metaanalyses exploring the relationship between teacher clarity and student learning. Communication Education, 64(4), 385-418. doi:10.1081/03634523.2015.1041998

Thomas, K., \& Valthouse, B. (1990). Cognitive elements of empowerment: An "interpretive" model of intrinsic task motivation. Academy of Management Review, 15, 661-681. doi: $10.2307 / 258687$

Torrance, E. P. (1970). Encouraging creativity in the classroom. Dubuque, IA: William C. Brown.

Visser, J., \& Visser, Y. L. (2004). Ambiguity, cognition, learning, teaching, and design. TechTrends, 48(1), 40-43. doi:10.1007/BF02784863

Vygotsky, L. S. (1978). Mind in society: The development of higher psychological processes. Cambridge, MA: Harvard University Press.

Weber, K. (2003). The relationship of interest to internal and external motivation. Communication Research Reports, 20(4), 376-383. doi:10.1080/08824090309388837

Weber, K., Martin, M. M, \& Cayanus, J. L. (2005). Student interest: A two-study reexamination of the concept. Communication Quarterly, 53, 71-86. doi:10.1080/01463370500055996

Wootton, S. (2002). Encouraging learning or measuring failure. Teaching in Higher Education, 7(3), 353-357. doi:10.1080/13562510220144833

Wrench, J. S., Thomas-Maddox, C., Richmond, V. P., \& McCroskey, J. C. (2008). Quantitative research methods for communication ( $1^{\text {st }}$ ed.). New York, NY: Oxford University Press.

Wright, A. M. (2019, April). Instructor use of strategic ambiguity in graded classroom assessments. Paper presented at the meeting of the Central States Communication Association annual convention, Omaha, NE. 
Wright, G. B. (2011). Student-centered learning in higher education. International Journal of Teaching and Learning in Higher Education, 23(3), 92-97. Retrieved from http://www.isetl.org/ijtlhe/

Yeager, D. S., \& Dweck, C. S. (2012). Mindsets that promote resilience: When students believe that personal characteristics can be developed. Educational Psychologist, 47(4), 302-314. doi:10.1080/00461520.2012.722805 


\section{APPENDIX A: SURVEY CONDITIONS}

\section{Clear Assignment/Clear Message}

\section{Using Persuasion to Sell}

You are responsible for writing a persuasive paper that convinces the reader to buy a product. You can use any of the persuasive principles learned throughout this class. Choose a product, but it must be an actual product that we could purchase. Your audience is members of this class. You will be assessed on how well you effectively use persuasive principles (60\% of the grade) and how well you conform to standard writing conventions ( $40 \%$ of grade).

Follow the following steps:

1. Analyze your audience. Consider what type of product they would want or need.

2. Craft an argument using the elements of the argumentation model that we learned about.

3. Include research to support your claims. You should have at least 5 sources.

4. Re-read your paper to ensure you have avoided making logical fallacies.

5. Ensure you have included persuasive appeals.

6. Proofread your paper. Did you follow the APA citation style guide? Do you have any typos?

7. Ensure your paper is a full 3 pages.

\section{Board Message}

Using Persuasion to Sell

- Analyze your audience

- Craft an argument

- 5 sources

- Avoid fallacies

- Use persuasive appeals

- Proofread and follow APA format

- 3 Pages

Grading:

$-60 \%$ - Effective use of persuasive principles

$-40 \%$ - Writing

\section{Instructor Message:}

"Our next assignment gives you the opportunity to write a paper selling a product. Your audience is our class. You will use this assignment to show me that you can employ the persuasive principles taught in this class. Know that the product must be something that already exists and that we could actually buy. I am grading you based on two overarching criteria (Point to the board) $-60 \%$ of your grade is based on your ability to effectively use persuasive principles. $40 \%$ of your grade is how you conform to standard conventions of writing. 
So, when completing the paper, there are some steps you should follow. (Point to the board) First, analyze your audience. Think about the type of product the members of this class would want to buy. For example, since we are college students, it is unlikely we are going to be on the market for a new Tesla. Second, write an argument. Use the elements of the argumentation model we learned about in this class. Third, use research to support the claims you make. You should have at least 5 sources. Fourth, ensure you avoid logical fallacies or errors in reasoning. Review these fallacies in your book when you are determining whether or not you used them. Fifth, check your paper to ensure you have included persuasive appeals learned in class such as logos, ethos, and pathos. Sixth, proofread your paper. Your citations should follow the APA citation style guide. You should proofread your paper to ensure you are using complete sentences, you don't have any typos, etc. Finally, your paper should be 3 full pages. Make sure you feel confident that you persuaded the audience to buy this product. If you have questions about the assignment, come talk to me, I'm happy to answer questions. I have examples from past students that I am willing to share. So, go ahead and get started."

\section{$\underline{\text { Strategically Ambiguous Assignment/No Rationale }}$}

\section{Using Persuasion to Sell}

You are responsible for writing a persuasive paper that convinces the reader to buy a product. You can use any of the persuasive principles learned throughout this class. Choose a product, but it must be an actual product that we could purchase. Your audience is members of this class. You will be assessed on how well you effectively use persuasive principles ( $60 \%$ of the grade) and how well you conform to standard writing conventions ( $40 \%$ of grade).

\section{Board Message}

Using Persuasion to Sell

- Sell a product

- Use persuasive principles

Grading:

$-60 \%$ - Effective persuasion

$-40 \%$ - Writing

\section{Instructor Message}

"Our next assignment gives you the opportunity to write a paper selling a product. (Point to board) Your audience is our class. You will use this assignment to show me that you can employ the persuasive principles taught in this class. Know that the product must be something that already exists and that we could actually buy. I am grading you based on two overarching criteria (Point to board) $-60 \%$ of your grade is based on your ability to effectively use persuasive principles. $40 \%$ of your grade is how you conform to standard conventions of writing. So, go ahead and get started." 


\section{Strategically Ambiguous Assignment/Clear Instructor Rationale}

You are responsible for writing a persuasive paper that convinces the reader to buy a product. You can use any of the persuasive principles learned throughout this class. Choose a product, but it must be an actual product that we could purchase. Your audience is members of this class. You will be assessed on how well you effectively use persuasive principles (60\% of the grade) and how well you conform to standard writing conventions ( $40 \%$ of grade).

\section{Board Message}

Using Persuasion to Sell

- Sell a product

- Use persuasive principles

- BE CREATIVE!

Grading:

$-60 \%$ - Effective use of persuasive principles

$-40 \%$ - Writing

\section{Instructor Message}

"Our next assignment gives you the opportunity to write a paper selling a product. (Point to the board) Your audience is our class. You will use this assignment to show me that you can employ the persuasive principles taught in this class. Know that the product must be something that already exists and that we could actually buy. I am grading you based on two overarching criteria - (Point to board) $60 \%$ of your grade is based on your ability to effectively use persuasive principles. $40 \%$ of your grade is how you conform to standard conventions of writing.

You may notice that this assignment is ambiguous. This is intentional. I want you to be able to have agency in your assignment. Ambiguity is a part of our everyday lives, so I want you to have the opportunity to mirror the process that working professionals go through when they face ambiguous situations and have to apply their knowledge to a challenging task. Rather than me telling you exactly what to do, this assignment gives you the freedom to be creative and use your critical thinking skills to decide which persuasive principles learned in this class apply best to this assignment, taking into consideration the product you chose and your audience. I don't have an example or specific details for you because I want you to be creative; however, I am happy to talk you through your thinking during this process to guide you through the assignment. So, go ahead and get started." 


\section{APPENDIX B: SURVEY INSTRUMENT}

Directions: When answering the following questions, please think of your role as a student in an educational or classroom environment generally.

\section{Learning and Grade Orientation}

Five-point Likert scale ranging from 1(strongly disagree) to 5 (strongly agree)

1. I dislike completing activities and assignments that are ungraded. (GO)

2. I enjoy learning new information. (LO)

3. When completing an assignment, I am most concerned with my grade. (GO)

4. I try to use assignment feedback to improve. (LO)

5. My end goal when taking a course is to get a good grade. (GO)

6 . When taking a class, I enjoy the process of learning. (LO)

7. Teachers should tell students exactly how they will be graded. (GO)

8. When instructors return papers I pay more attention to the feedback than I do the grade. (LO)

9. Grades are the most important thing in college. (GO)

10. Learning is the most important component of college. (LO)

11. If I learn something new from completing an assignment but do not get a good grade, I am still satisfied. (LO)

12. When turning in an assignment, I like to feel confident I will get a good grade. (GO)

13. I choose classes based on what grade I think I can get in the class. (GO)

14. I like to learn new information, even if I am never tested on that information. (LO)

15. I came to college to learn. (LO)

16. I am only satisfied with my learning if I receive a good grade. (GO)

\section{Mindset}

Six-point Likert scale ranging from 1 (strongly agree) to 6 (strongly disagree).

1. You have a certain amount of intelligence, and you can't really do much to change it.

2. Your intelligence is something about you that you can't change very much.

3. You can learn new things, but you can't really change your basic intelligence.

4. No matter who you are, you can change your intelligence a lot. (RC)

5. You can always change how intelligent you are. (RC)

6. No matter how much intelligence you have, you can always change it quite a bit. (RC)

\section{Tolerance for Ambiguity}

Five-point Likert scale ranging from 1(strongly disagree) to 5 (strongly agree)

These questions ask about ambiguity, which is vagueness or uncertainty.

1. I don't tolerate ambiguous situations well. (RC) 
2. I would rather avoid solving a problem that must be viewed from several different perspectives. (RC)

3. I try to avoid situations that are ambiguous. (RC)

4. I prefer familiar situations to new ones. $(\mathrm{RC})$

5. Problems that cannot be considered from just one point of view are a little threatening. $(\mathrm{RC})$

6. I avoid situations that are too complicated for me to easily understand. (RC)

7. I am tolerant of ambiguous situations.

8. I enjoy tackling problems that are complex enough to be ambiguous.

9. I try to avoid problems that seem to have more than a single "best" answer. (RC)

10. I generally prefer novelty over familiarity.

11. I dislike ambiguous situations. (RC)

12. I find it hard to make a choice when the outcome is uncertain. (RC)

13. I prefer a situation in which there is some ambiguity.

Directions: Please read the following assignment description and watch the corresponding video of an instructor explaining that assignment.

\section{[VIDEO CONDITION HERE]}

Directions: Now that you have read the assignment and watched the video of an instructor explaining that assignment, please think of that assignment while completing the following questions.

\section{Manipulation Check}

Five-point Likert scale ranging from 1(strongly disagree) to 5 (strongly agree)

1. This assignment has very clear guidelines.

2. I felt the instructor specifically communicated that they were being vague on purpose.

3. This instructor offers the appropriate amount of guidance.

4. This assignment is ambiguous.

\section{Learner Empowerment Scale}

Five-point Likert scale ranging from 1(strongly disagree) to 5 (strongly agree)

\section{Meaningful}

1. The work that I will do on this assignment is meaningful to me.

2. The work that I will do for this assignment is valuable to me.

3. The things I will learn from this assignment are useful.

4. This assignment will help me achieve my goals in life.

5. The work I will do on this assignment is a waste of time. (RC)

6. This assignment would not be important to me. (RC) 


\section{Competence}

7. I can do well on this assignment.

8. I don't think that I can do well on this assignment. (RC)

9. I believe in my ability to do well on this assignment.

10. I have what it takes to do well on this assignment.

11. I don't have the confidence in my ability to do well on this assignment. (RC)

12. I feel very competent on this assignment.

\section{Impact}

Five-point Likert scale ranging from 1(strongly disagree) to 5 (strongly agree)

13. I have a choice in the approaches I can use to complete this assignment.

14. I have freedom to choose among options for this assignment.

15. Alternative approaches to learning are encouraged through this assignment.

16. I have the opportunity to make important decisions on this assignment.

17. I cannot influence what I do on this assignment. (RC)

18. I can determine how to perform tasks for this assignment.

19. I have no freedom to choose on this assignment. (RC)

\section{Affective Learning}

Five-point Likert scale ranging from 1(strongly disagree) to 5 (strongly agree)

1. I like this type of assignment.

2. This assignment will improve my thinking ability.

3. This assignment will not be valuable to me in the future. (RC)

4. I would enjoy completing an assignment like this.

5. I would like to have more assignments like this.

6. I would not enjoy learning from an assignment structured like this. (RC)

7. I appreciate the type of thinking required of me through this assignment.

8. I feel good about completing this assignment.

9. My initial reaction to being asked to complete this assignment is negative. (RC)

10. This assignment is worthless to me. (RC)

11. Assignments like this are valuable learning experiences.

12. I think I could learn a lot from an assignment like this.

13. This assignment would allow me to learn.

14. I believe I could succeed on this assignment.

\section{Demographics}

1. Choose the race/ethnicity you consider yourself to be: (Caucasian/White; Black/African American; Native American, Hispanic/Latino(a); Asian/Pacific Islander; Multiracial; Other). 2. What is the gender that you identify as? (Male; Female; Transgender; Other; Prefer Not to Specify) 
3. What is your age? (Sliding scale from 18-100)

4. What is your GPA? (Sliding scale from 0-4.00)

5. What is your year in school? (Freshman; Sophomore; Junior; Senior; Master's Student;

Doctoral Student)

6. What is your major? (Open-ended)

7. Have you ever taught a course as the instructor of record? (Yes; No) 